\author{
UNIVERSIDADE DE SÃO PAULO \\ FACULDADE DE MEDICINA DE RIBEIRÃO PRETO
}

DENISE HOLLANDA IUNES

\title{
Análise da Confiabilidade Inter e Intra- Examinador na Avaliação Postural pela Fotogrametria Computadorizada
}

Ribeirão Preto- SP 2004 
DENISE HOLLANDA IUNES

\title{
Análise da Confiabilidade Inter e Intra- Examinador na Avaliação Postural pela Fotogrametria Computadorizada
}

\author{
Dissertação de Mestrado \\ apresentada a Faculdade de \\ Medicina de Ribeirão Preto da \\ Universidade de São Paulo para \\ obtenção do titulo de Mestre em \\ Ciências Médicas. \\ Área de concentração: \\ Ortopedia, Traumatologia e \\ Reabilitação
}

Orientadora: Profa. Dra. Débora Bevilaqua-Grossi

Ribeirão Preto- SP

2004 


\section{FOLHA DE APROVAÇÃO}

\section{Denise Hollanda lunes}

Análise da Confiabilidade Inter e Intra-Examinador na Avaliação Postural pela Fotogrametria Computadorizada

Dissertação de Mestrado apresentada à Faculdade de Medicina de Ribeirão Preto da Universidade de São Paulo para obtenção do titulo de Mestre em Ciências Médicas.

Área de concentração: Ortopedia, Traumatologia e Reabilitação.

Aprovado em:

Banca Examinadora

Prof. Dr Antonio Carlos Shimano -

Instituição: USP

Assinatura

Prof. Dra. Vanessa Monteiro Pedro

Instituição: UfsCar

Assinatura

Prof. Dra. Débora Bevilaqua- Grossi

Instituição: USP

Assinatura 


\section{DEDICATÓRIA}

Dedico este trabalho ao meu marido e aos meus pais, que sempre me apoiaram e incentivaram ao longo do período de elaboração deste trabalho. Também dedico este trabalho as minhas filhas, que sofreram comigo neste árduo caminho e aceitaram as minhas ausências. 


\section{AGRADECIMENTOS}

Á Profa. Dra. Débora Bevilaqua-Grossi, minha orientadora, pela atenção e apoio que tanto contribuiu para meu crescimento científico e pelo carinho e incentivo nos momentos difíceis.

Á Profa. Dra. Anamaria Sirianini pelos grandes momentos de colaboração na execução deste trabalho.

Aos colegas de pós-graduação que estiveram presentes e de alguma forma colaboraram durante este curso.

As acadêmicas Flavia de Almeida Castro, Helke Swerts Salgado e Igna C. Moura que estiveram presentes auxiliando a parte experimental com grande dedicação.

À Universidade de São Paulo, pela oportunidade de realização do curso de mestrado.

À Universidade José do Rosário Vellano (UNIFENAS) pela flexibilidade de horários o que tornou viável a realização deste mestrado.

Enfim, a todos aqueles que de alguma forma me auxiliaram. 
"O corpo humano é talvez uma simples aparência, escondendo a nossa realidade, e condensando-se sobre a nossa luz ou sobre a nossa sombra. A realidade é a alma. A bem dizer, o rosto é uma mascara. O verdadeiro homem é o que está debaixo do homem. Mais de uma surpresa haveria se pudesse vê-lo agachado e escondido debaixo da ilusão que se chama carne. O erro comum é ver no ente exterior um ente real. Tal criaturinha, por exemplo, se pudéssemos vê-la como realmente é, em vez de moça mostrar-se-ia pássaro."

Victor Hugo (trecho do livro "Os trabalhadores do mar") 


\section{RESUMO}

IUNES, D. H. Análise da Confiabilidade Inter e Intra-Examinador na Avaliação Postural pela Fotogrametria Computadorizada. 2004. 109 f. Dissertação (mestrado) - Faculdade de Medicina de Ribeirão Preto, Universidade de São Paulo, Ribeirão Preto, 2004.

O propósito deste trabalho foi verificar a reprodutibilidade bem como a repetibilidade do método de avaliação postural por meio da fotogrametria computadorizada. Para isto 21 indivíduos, com idade 24,2 \pm 1,3 anos de idade, foram fotografados em posição anterior, posterior, perfil e face. Para realização destas fotografias foram demarcados sobre a pele pontos anatômicos que são normalmente utilizados na avaliação postural tradicional. A partir destes pontos foram analisados diferentes ângulos através do aplicativo ALCimagem-2000. Para a análise interexaminador as fotos foram avaliadas por três examinadores diferentes e os resultados comparados. Para a análise intraexaminador as mesmas fotos foram avaliadas pelo mesmo examinador em duas ocasiões diferentes com um mês de intervalo. Para a análise da repetibilidade do método os voluntários foram fotografados duas vezes com intervalo de uma semana e as fotos avaliadas pelo mesmo examinador. Para comparação dos resultados intra e interexaminadores foram aplicados o coeficiente de correlação intraclasse. Os resultados revelaram que o método proposto apresenta significativa confiabilidade interexaminadores. Dos ângulos estatisticamente confiáveis, alguns tiveram menor coeficiente de confiabilidade, principalmente os ângulos do plano sagital referentes às curvaturas vertebrais, como lordose cervical, cifose torácica e lordose lombar. $\mathrm{Na}$ avaliação intra-examinador só não apresentou confiabilidade o ângulo da cifose torácica. Na repetibilidade do método somente o ângulo inferior da escápula não apresentou confiabilidade. Portanto, a fotogrametria computadorizada sugere ser um método confiável para avaliação postural no plano frontal anterior e posterior. Porém, para a análise no plano sagital necessita de mais estudos para definir parâmetros de normalidade das curvaturas vertebrais.

Palavras-chave: fotogrametria, postura, avaliação, reprodutibilidade, confiabilidade. 


\section{ABSTRACT}

IUNES, D. H. Intra and Inter Observers Reliability Analysis Through Photogrammetry. 2004. 109 p. Dissertation (mester degree) - Faculdade de Medicina de Ribeirão Preto, Universidade de São Paulo, Ribeirão Preto, 2004.

The purpose of this work was to verify the reproducibility, as well as the method repeatibility for postural evaluation through photogrammetry. For that, 21 individuals being 24,2 $\pm 1,3$ years old were photographed in anterior, posterior, profile and face positions. To perform these photos, several anatomic sites, which are often used in the traditional postural evaluation, were marked on the skin. Different angles from these sites were examined through the program ALCimagem-2000. For the inter-examiner analysis, the photos were evaluated by three different examiners whose results were compared. For the intra-examiner analysis, the same photos were evaluated by the same examiner in two different occasions. For the analysis of the repeatibility of the method, the volunteers were photographed twice with a period of a week interval, and the photos were evaluated by the same examiner. For comparing inter and intraexaminer results, the intra-class correlation coefficient was applied. The results revealed that the proposed method presented good inter-examiner reliability. From the statistically reliable angles, some had a lesser reliability coefficient, mainly the sagital plane angles referring to vertebral flexures such as the cervical lordosis, thoracic kyphosis, and lumbar lordosis. In the intra-examiner evaluation, just the thoracic kyphosis angle hasn't presented reliability. As for the repeatibility of the method just the inferior scapular angle haven't presented reliability. Thus, computerized photogrammetry seem be a reliable method for postural evaluation on the frontal, anterior and posterior planes. However, the sagital plane needs more studies to define normality parameters for the vertebral flexures.

Keywords: photogrammetry, posture, evaluation, reproducibility, reliability. 


\section{LISTA DE ILUSTRAÇÕES}

Figura 1 Plano frontal - indivíduo normal com linhas de simetrias .............. 23

Figura 2 Linhas de gravidade no plano sagital.......................................... 25

Figura $3 \quad$ Posicionamento da pelve...................................................... 26

Figura $4 \quad$ Técnica de Moiré .................................................................. 28

Figura 5 Plantografia espinhal ou inclinômetro............................................ 30

Figura 6 Medidas das curvaturas dorsal e lombar através do ângulo de 32 Cobb

Figura $7 \quad$ Haste cilíndrica plástica............................................................ 45

Figura 8 Colocação do marcador na protuberância occipital........................ 46

Figura 9 Posicionamento do voluntário e do equipamento fotográfico para realização da fotografia digital ................................................ 48

Figura 10 Dispositivos de madeira para elevar os voluntários ...................... 49

Figura 11 Pontos e ângulos avaliados no plano frontal anterior .................... 52

Figura 12 Pontos e ângulos avaliados no plano frontal posterior .................... 54

Figura 13 Pontos e ângulos avaliados na face ........................................... 55

Figura 14 Pontos e ângulos avaliados no plano sagital ............................... 57 


\section{LISTA DE TABELAS}

Tabela 1 Valores de ICC para as medidas obtidas interexaminadores ...... 62

Tabela 2 Valores de ICC para as medidas obtidas Intra-examinador.......... 64

Tabela 3 Valores de ICC para as medidas obtidas na repetibilidade do 66 Método de avaliação Postural ...................................................

Tabela 4 Valores do erro padrão para as medidas obtidas pela 68 repetibilidade do método de avaliação

Tabela 5 Valores das médias angulares das medidas dos ângulos da face na análise interexaminador

Tabela 6 Valores das médias angulares das medidas dos ângulos do plano frontal anterior na análise interexaminador

Tabela 7 Valores das médias angulares das medidas dos ângulos do plano frontal posterior na análise interexaminador

Tabela 8 Valores das médias angulares das medidas dos ângulos do plano sagital (PC, LC, CT, LL) na análise interexaminador

Tabela 9 Valores das médias angulares das medidas dos ângulos do plano sagital (BP, FJ, ATT) na análise interexaminador

Tabela 10 Valores das médias angulares das medidas dos ângulos da face na análise intra-examinador

Tabela 11 Valores das médias angulares das medidas dos ângulos do plano frontal anterior na análise intra-examinador

Tabela 12 Valores das médias angulares das medidas dos ângulos do plano frontal posterior na análise intra-examinador

Tabela 13 Valores das médias angulares das medidas dos ângulos do plano sagital na análise intra-examinador

Tabela 14 Valores das médias angulares das medidas dos ângulos da face na análise de repetibilidade do método de avaliação

Tabela 15 Valores das médias angulares das medidas dos ângulos do plano frontal anterior na análise de repetibilidade do método de avaliação

Tabela 16 Valores das médias angulares das medidas dos ângulos do plano frontal posterior na análise de repetibilidade do método de avaliação

Tabela 17 Valores das médias angulares das medidas dos ângulos do plano sagital (PC, LC, CT, LL) na análise de repetibilidade do método de avaliação

Tabela 18 Valores das médias angulares das medidas dos ângulos do plano sagital (BP, FJ, ATT) na análise de repetibilidade do método de avaliação 


\section{LISTA DE ABREVIATURAS E SIGLAS}

\begin{tabular}{cl} 
UNESP & Universidade Estadual Paulista \\
UNIFENAS & Universidade José do Rosário Vellano \\
USP & Universidadede São Paulo \\
EIAS & Espinhas ilíacas ântero-superiores \\
EIPI & Espinhas ilíacas pôstero-inferiores \\
EIPS & Espinhas ilíacas pôstero-superiores \\
E.V.A. & Etil vinil acetato \\
AS & Ângulo das Espinhas ilíacas ântero-superiores \\
$\Delta T d$ & Triângulo de Talles direito \\
$\Delta T e$ & Triângulo de Talles esquerdo \\
AJd & Angulação do joelho direito \\
AJe & Angulação do joelho esquerdo \\
IE & Ângulo inferior da escapula \\
PS & Ângulo das espinhas ilíacas postero-superiores \\
LP & Ângulo da linha poplitea \\
Ipd & Ângulo da inclinação do pé direito \\
Ipe & Ângulo da inclinação do pé esquerdo \\
OE & Ângulo do orbicular externo \\
CL & Ângulo da comissura labiail \\
AC & Ângulo da articulação acrômio clavicular \\
EC & Ângulo da articulação esternoclavicular \\
PC & Ângulo da protusão da cabeça \\
LC & Ângulo da lordose cervical \\
\hline The &
\end{tabular}




$\begin{array}{ll}\text { CT } & \text { Ângulo da cifose torácica } \\ \text { LL } & \text { Ângulo da lordose lombar } \\ \text { BP } & \text { Ângulo da báscula de pelve } \\ \text { FJ } & \text { Ângulo flexo de joelho } \\ \text { ATT } & \text { Ângulo tibio társico } \\ \text { ICC } & \text { Coeficiente de correlação intra-classe }\end{array}$




\section{SUMÁRIO}

\section{RESUMO \\ ABSTRACT \\ LISTA DE ILUSTRAÇÕES \\ LISTA DE TABELAS \\ LISTA DE ABREVIATURAS E SIGLAS}

1 INTRODUÇÃO

2 REVISÃO DA LITERATURA .............................................................. 18

2.1 Postura e as curvaturas fisiológicas da coluna vertebral ............................ 18

2.2 Principais alterações posturais ………................................................ 20

2.3 Avaliação postural qualitativa ……................................................... 22

2.4 Avaliação postural quantitativa ............................................................ 28

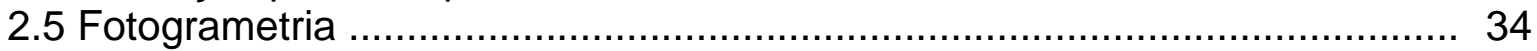

2.6 A Fotografia para avaliar a postura ……............................................... 36

2.7 Confiabilidade da avaliação postural ..................................................... 39

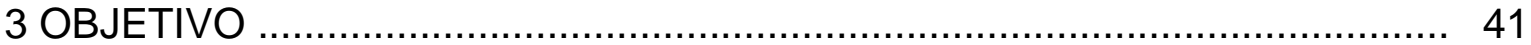

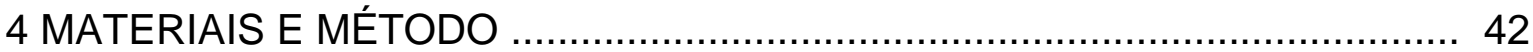

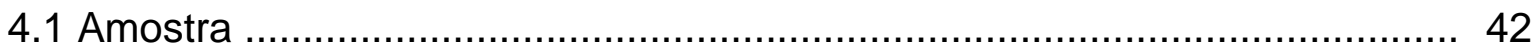

4.1.1 Critérios de inclusão ............................................................... 42

4.1.2 Critérios de exclusão ................................................................ 43

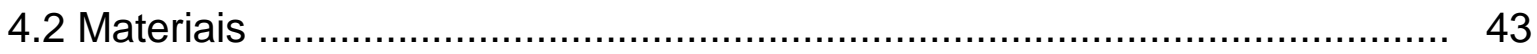

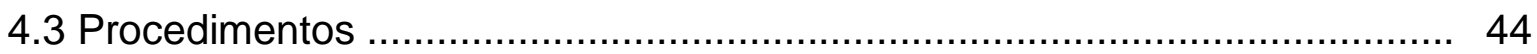

4.3.1 Pontos anatômicos demarcados ........................................................ 44

4.3.2 Posicionamento do voluntário ...................................................... 46

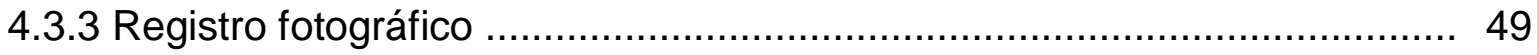

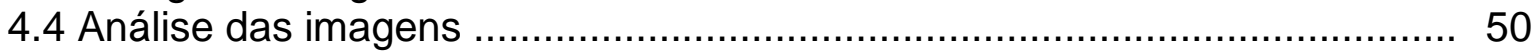

4.4.1 Software para análise dos dados ................................................. 50

4.4.2 Ângulos analisados ................................................................... 50

4.4.2.1 Ângulos do plano frontal anterior ................................................... 50

4.4.2.2 Ângulos do plano frontal posterior .................................................. 53

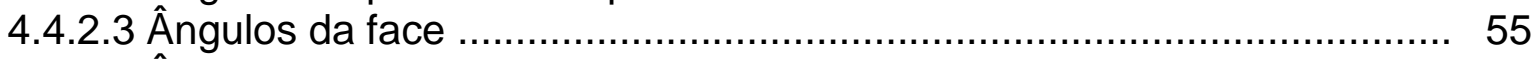

4.4.2.4 Ângulos do plano sagital ............................................................. 56

4.4.3 Análise de reprodutibilidade (interexaminador) ..................................... 58

4.4 Análise de repetibilidade ................................................................. 58

4.4.1 Análise de repetibilidade intra-examinador .......................................... 58

4.4.2 Análise da repetibilidade do método de avaliação postural ...................... 59

4.5 Análise dos ângulos no software ..................................................... 59

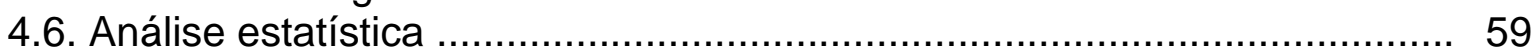

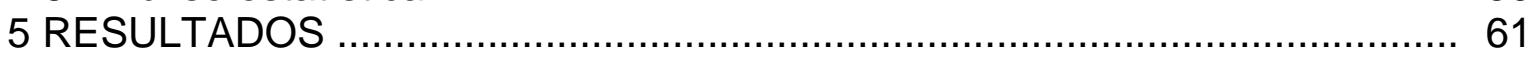

5.1 Resultados da análise de reprodutibilidade (interexaminador) .................... 61

5.2 Resultados da análise da repetibilidade ................................................. 63

5.2.1 Resultados da análise da repetibilidade intra-examinador ...................... 63

5.2.2 Resultados da análise de repetibilidade do método de avaliação postural 65

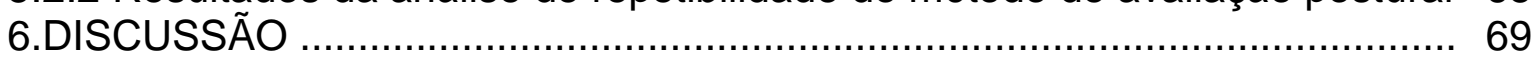

6.1 Análise de reprodutibilidade (interexaminador) ………........................... 70

6.2 Análise da repetibilidade ................................................................. 74 
6.2.1 Análise da repetibilidade intra-examinador ...................................... 74

6.2.2 Análise da repetibilidade do método de avaliação ................................. 76

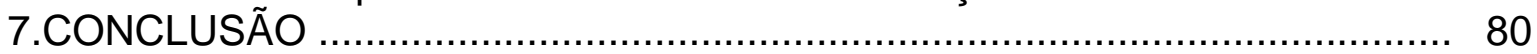

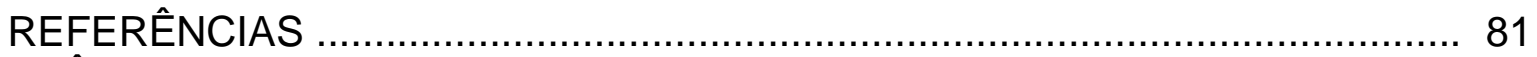

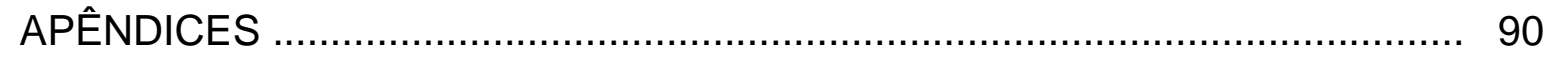

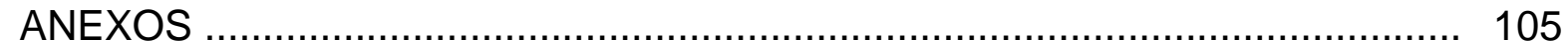




\section{INTRODUÇÃO}

A postura é um arranjo relativo das partes do corpo para a realização de uma atividade com menor gasto de energia (FERRARIO et al., 1995). Embora exista a concordância que uma boa postura é importante, trata-se de um fenômeno complexo e difícil de se quantificar. Isto pode explicar porque há poucos resultados de estudos associando desvios posturais à problemas específicos como dor lombar (WATSON, 1998). Para manter a postura é necessário um complexo sistema neuromuscular integrado com vários proprioceptores em músculos, tendões, articulações, receptores vestibulares e visuais (FERRARIO et al., 1995).

A avaliação postural é de fundamental importância para o planejamento de um tratamento fisioterapêutico, para o acompanhamento da evolução e dos resultados do tratamento. Normalmente a avaliação postural é feita através do método clássico, que consiste na análise visual nos aspectos anterior, lateral e posterior com o sujeito em trajes sumários, analisando as assimetrias de ombros, clavículas, mamilos, cintura, espinhas ilíacas, joelhos e pés (KENDALL; McCREARY e PROVANCE, 1995; WATSON E MACDONNCHA, 2000).

Vários métodos para quantificar a postura corporal e da cabeça têm sido utilizados e descritos na literatura, tais como: inclinômetro (FERRARIO et al., 1995; YOUDAS et al., 1996; LUNDON, LI, BIBERSHTEIN, 1998; ZEPPA et al., 2000), radiografias (FERRARIO et al., 1995; SANDOVAL et al., 1999; BISTER et al., 2002), 
câmeras de vídeo (FERRARIO et al., 1995; ZONNENBERG et al 1996 b; BUENDIA et al., 1999; NORMAND et al., 2002), topografia de Moiré (BUENDIA et al., 1999; RODRIGUES et al., 2003). Nem sempre esses métodos são empregados na prática clínica, seja pelo custo do equipamento, seja pela falta de disponibilidade do equipamento ou porque os planos de saúde não aceitam solicitações dos fisioterapeutas, como no caso da radiografia. Além de que, a radiografia tem a desvantagem de ser um recurso que expõe o indivíduo a radiação.

Muitos fisioterapeutas já utilizam a fotografia para avaliação postural. Este recurso pode ser um valioso registro das transformações posturais ao longo do tempo e são capazes de inter-relacionar diferentes partes do corpo que são difíceis de mensurar (WATSON, 1998). Porém, a maioria dos profissionais utiliza desse recurso apenas como uma avaliação qualitativa e nem sempre adotam parâmetros metodológicos que permitam quantificar a postura e garantir a repetibilidade do procedimento. Sendo que a quantificação das alterações posturais é essencial para verificar a evolução, a eficácia do tratamento utilizado, permitindo futuras comparações. Portanto, a fotografia pode ser considerada um meio de documentação cientifica e clínica.

Outro recurso que vem sendo divulgado no meio acadêmico é a fotogrametria computadorizada, que permite realizar a avaliação postural e quantificar as alterações encontradas. Além disso, é um recurso acessível à maioria dos fisioterapeutas que já utilizam a fotografia e possuem equipamentos básicos como uma câmera digital e um computador.

A fotogrametria computadorizada, que significa aplicação da fotografia à métrica, consiste em um método de medida angular das assimetrias corporais utilizando os princípios fotogramétricos a partir de imagens fotográficas corporais (O 
COFFITO, 2002). Tommaselli et al. (1999) descrevem que os estudos sobre a utilização da fotogrametria na área da fisioterapia tiveram início no Brasil em 1992 na Universidade Estadual Paulista (UNESP) - Presidente Prudente. Outros pesquisadores têm utilizado essa ferramenta de avaliação e divulgado no meio acadêmico e na imprensa como um recurso eficaz e preciso para avaliação fisioterapêutica (BARAÜNA et al., 2004). Porém, ainda há poucas publicações científicas relacionando a fotogrametria e avaliação postural. Dessas publicações, Pereira et al. (2003) utilizaram esse método de avaliação de forma qualitativa para detectar assimetrias corporais e Zonnenberg et al. (1996 b) utilizaram o método de forma quantitativa, porém fizeram uma análise postural muito diferente do que é empregado normalmente pelos fisioterapeutas. Estes autores analisam a distância das estruturas anatômicas ao solo e fazem uma relação com a distância entre os pontos anatômicos do dímeros direito e esquerdo do corpo.

No entanto, ainda não há comprovação suficiente se este é um método realmente eficaz e confiável. Para que a fotogrametria possa ser adotada como método de avaliação é preciso primeiro estabelecer sua reprodutibilidade e repetibilidade. Depois é necessária a validação do método, para que a partir disso, esse recurso possa futuramente ser empregado na prática clínica e corretamente divulgado no meio científico. 


\section{REVISÃO BIBLIOGRÁFICA}

\subsection{Postura e as curvaturas fisiológicas da coluna vertebral}

Segundo Busquet (2000), o corpo humano é uma máquina sofisticada que deve assumir várias funções: deve permitir o manter-se ereto, o equilíbrio e o deslocamento. Para exercer essas funções é importante adotar uma postura. Este termo "postura" vem há anos sendo definido por vários autores sem grandes variações. Oliver e Middleditch (1998) definem postura como a posição assumida pelo corpo, quer seja por meio da ação integrada dos músculos operando para contra-atuar com a força da gravidade ou para manter-se mesmo durante a inatividade muscular. Segundo Lehmkul e Smith (1989), postura é um arranjo relativo das partes corporais para uma atividade especifica, ou uma maneira característica de uma pessoa sustentar seu corpo. Uma boa postura tem sido definida como uma situação em que o centro de gravidade de cada segmento é colocado verticalmente sobre o segmento seguinte. Se

o centro de gravidade de um segmento desvia, inúmeras anormalidades posturais podem ocorrer (WATSON e MAcDONNCHA, 2000).

Maannheinen e Rosenthal (1991), descrevem que a postura ideal é o estado de equilíbrio esquelético e muscular que protege a estrutura corporal contra lesões e deformidades progressivas, independentes da atitude em que estas estruturas trabalham e guardam repouso. A postura padrão, de acordo com Farias, Alves, Gandelman (2001) permite um alinhamento postural esquelético ideal que envolve 
uma quantidade mínima de esforço e sobrecarga e de uma máxima eficiência do corpo.

Para Zonnenberg et al. (1996b) a postura corporal é considerada normal quando pode ser mantida sem dificuldade, na mesma posição por um período razoável sem desconforto e quando a postura produz uma aparência estética aceitável.

As posturas são usadas para realizar atividades com o menor gasto de energia. A postura prepara o indivíduo para a realização de um movimento, bem como promove a sustentação durante o movimento (TANAKA e FARAH, 1997). Para que isso ocorra e para haver maior capacidade de suportar uma pressão axial, a coluna vertebral apresenta quatro curvaturas no plano sagital: lordose cervical, cifose torácica, lordose lombar e curvatura sacral. Sendo as lordoses uma curvatura com concavidade posterior; a cifose e a curvatura sacral uma curvatura com concavidade anterior (KNOPLICH, 2002).

No plano frontal anterior e posterior a coluna vertebral normal é retilínea (TANAKA e FARAH, 1997 e KAPANDJI, 2000).

Esta postura ereta (em movimento e/ou parada) é obtida pelo equilíbrio entre as forças que agem puxando o corpo anteriormente para o chão e a força dos músculos posteriores da coluna vertebral e membros inferiores que fazem esforço em sentido contrário. A ação integrada desses músculos posteriores que agem em grupo (cadeias musculares) é de extrema importância, eles são responsáveis para manter a postura e o alinhamento corporal (TANAKA e FARAH, 1997).

As posturas são mantidas ou adaptadas como resultado de estímulos aferentes de várias fontes ao longo do corpo (articulação, ligamentos, músculos) que coordenam entre si através do sistema nervoso central. A resposta efetora é o tipo motor e os 
músculos posteriores da coluna vertebral e membros inferiores são os principais órgãos efetores (OLIVER e MIDDLEDITCH, 1998).

Portanto, as alterações nos ossos da coluna vertebral, membros superiores, inferiores e crânio ou mesmo encurtamentos musculares dessas regiões podem gerar alterações posturais (KNOPLICH, 2002).

Segundo Oliver e Middleditch (1998) durante a permanência das posturas em pé, quando as curvaturas da coluna apresentam em correto alinhamento, a atividade muscular é moderada ao nível de paravertebrais. Já em situações de anormalidades dessas curvaturas a atividade muscular requerida é bem maior. A ação integrada dos músculos que constituem as cadeias musculares é responsável pela manutenção do alinhamento postural. As cadeias posturais são sistemas que interligam todo o corpo do indivíduo por músculos, fáscias e ligamentos que não possuem solução de

continuidade e são interdependentes entre si. Essa união muscular, aponeurótica e osteoarticular abrangem toda a estrutura humana, desde a cabeça até os pés.

\subsection{Principais alterações posturais:}

A postura corporal e da cabeça estão correlacionadas com diferentes condições fisiológicas e patológicas (FERRARIO, et al. 1995). Portanto, as alterações posturais muitas vezes surgem por compensações. Ou seja, o corpo faz adaptações para compensar um quadro álgico ou devido a tensões musculares. Essas adaptações geram mais tensões musculares e mais deformidades (BUSQUET, 2000).

A má postura predispõe o indivíduo a uma série de lesões (WATSON e MAcDONNCHA, 2000). 
Os fatores que podem contribuir para uma alteração postural e desequilíbrio muscular são: fatores genéticos, alterações congênitas, crescimento, atividades de vida diária, enfermidades, confinamento prolongado no leito, atividades ocupacionais, alterações psicológicas, aspectos culturais, estresse, dor ou traumatismos (MAANNHEINEN e ROSENTHAL, 1991; NORMAND et al. 2002).

Em situações anormais as curvaturas fisiológicas da coluna vertebral podem estar alteradas. Quando essas curvaturas aumentam são denominadas hiperlordose cervical, hipercifose dorsal e hiperlordose lombar. Quando há diminuição dessas curvaturas vertebrais são assim denominadas: retificação cervical, retificação dorsal e retificação lombar. Tanto a hiperlordose cervical quanto à retificação cervical podem ser acompanhadas de um posicionamento mais anterior da cabeça, chamado de protrusão de cabeça. Como conseqüência pode ocorrer uma alteração da articulação temporo - mandibular (KISNER e COLBY, 1998).

Quando ocorre um aumento anormal de uma curvatura da coluna vertebral, as outras curvas acima e/ou abaixo também se alteram em direção oposta para permitir um equilíbrio (TÜZÜN et al , 1999).

Segundo Kendall, Mccreary e Provance (1995), a hiperlordose lombar normalmente vem acompanhada de uma inclinação anterior da pelve, a retificação lombar por uma inclinação posterior da pelve.

No plano frontal podem ser observadas assimetrias anteriores e posteriores do ombro e da pelve que podem indicar a presença de escoliose, ou assimetrias de membros inferiores (BRICOT, 2001; PEREIRA, 2003). 


\subsection{Avaliação postural qualitativa}

A avaliação postural é usualmente incluída no exame clínico do paciente que procura um serviço de ortopedia, de reumatologia ou de fisioterapia (TÜZÜN et al, 1999).

Um exame clínico de coluna tipicamente começa com a avaliação postural, incluindo uma inspeção visual, que é uma avaliação qualitativa (FEDORAK et al., 2003).

Para iniciar-se uma avaliação postural toma-se por base a postura-padrão. Esta postura envolve uma quantidade mínima de esforço muscular e sobrecarga que conduz a eficiência máxima dos músculos (KISNER e COLBY, 1998).

A avaliação postural deve constar da avaliação da cabeça, pescoço, coluna torácica, cintura escapular, coluna lombar, pelve e membros inferiores. Pede-se ao sujeito a ser avaliado para manter a postura natural com os membros superiores ao longo do corpo (FEDORAK et al., 2003).

Na postura padrão, a posição dos pés é descrita como sendo uma postura na qual os calcâneos estão separados cerca de $7,5 \mathrm{~cm}$, e a parte anterior de cada pé está abduzida cerca de $8^{\circ}$ a $10^{\circ}$ da linha mediana (KENDALL, McCREARY e PROVANCE, 1995).

A avaliação qualitativa no plano frontal anterior, segundo Bricot (2001), deve-se observar a simetria dos olhos e da comissura labial. Na região do tronco anteriormente observa-se a simetria dos ombros (articulação acromioclavicular), clavículas, mamilos,

o triângulo tóraco-braquial (triângulo de Talles), o nível dos membros superiores, a linha Alba, o tórax, as espinhas ilíacas ântero-superiores, as cristas ilíacas (Figura 1). Nos membros inferiores observa-se a posição dos joelhos, se este é valgo ou varo; a 
posição das patelas; os arcos plantares; os hálux e a descarga de peso (GRIEVE, 1994; KENDALL, McCREARY e PROVANCE, 1995; BRICOT, 2001).

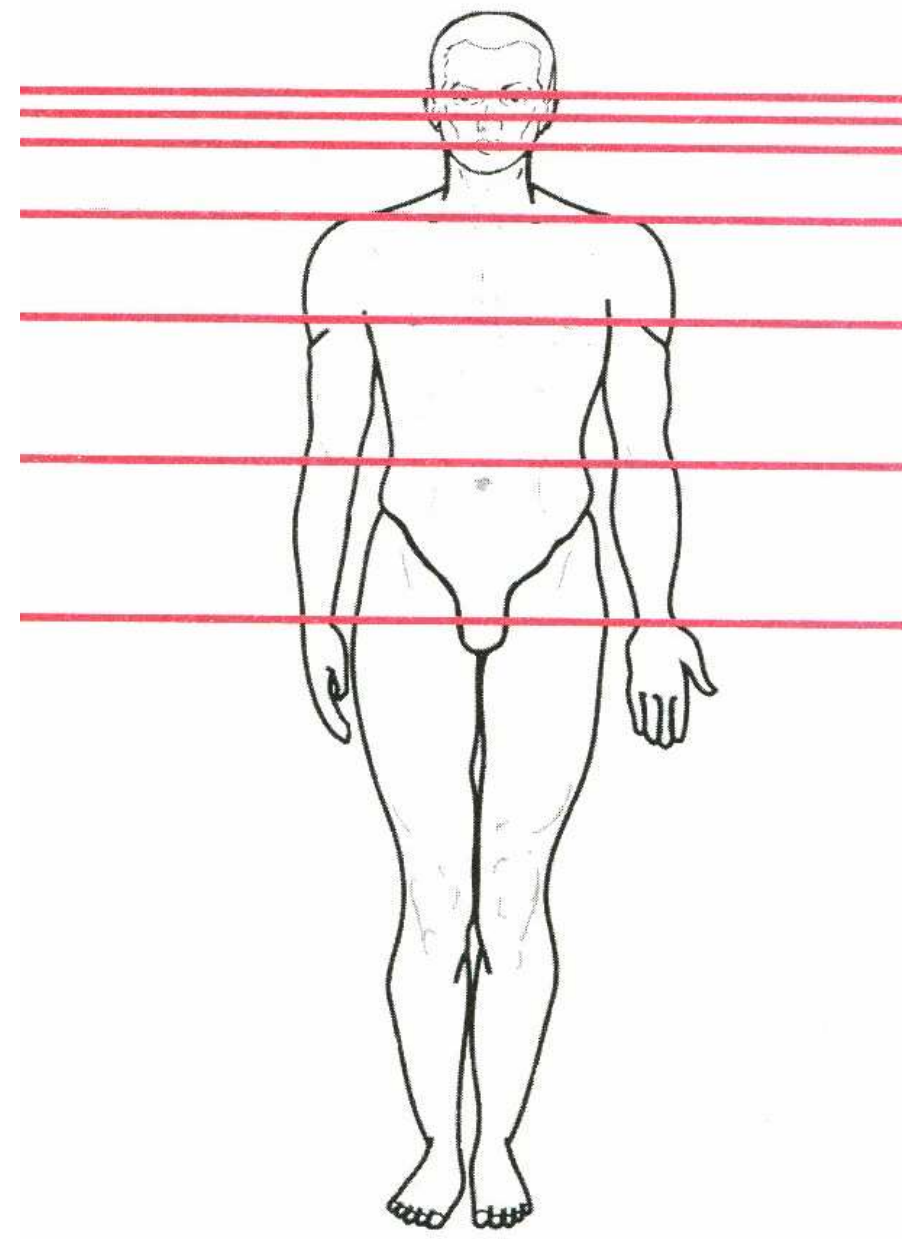

Figura 1- Plano frontal - indivíduo normal com linhas de simetrias (BRICOT, 2001)

No plano frontal posterior analisa-se: 1) o posicionamento da cabeça; 2) o grau de simetria dos ombros; 3) o posicionamento das escápulas; 4) o triângulo de Talles; 5) as espinhas ilíacas postero-superiores; 6) os forames sacrais; 7) o posicionamento do tronco e da pelve; 8) as pregas glúteas; 9) as linhas poplíteas; 10) os joelhos; 11) os tendões calcâneos; 12) o posicionamento dos calcâneos.

No plano sagital observa-se: 1) o posicionamento da cabeça; 2) o posicionamento dos ombros; 3) a curvatura cervical; 4) a curvatura torácica; 5) a 
curvatura lombar; 6) a presença de lordose diafragmática; 7) o posicionamento da pelve; 8) o posicionamento dos joelhos (ZONNENBERG et al., 1996 a).

No plano sagital um método para detectar desvios posturais é a utilização do fio de prumo que serve para representar uma linha de referência, o qual é suspenso a partir de um ponto fixo padronizado. O teste de fio de prumo é usado para determinar se os pontos de referência da pessoa observada estão no mesmo alinhamento que os pontos correspondentes na postura padrão. Os desvios dos pontos de referência, a partir do fio de prumo revelam a extensão na qual o alinhamento da pessoa está alterado (CARADONA e ALVES, 1997).

$\mathrm{Na}$ postura normal ereta em plano sagital (Figura 2), o eixo do centro de gravidade passa pela apófise odontóide de $C_{2}$, corpo vertebral de $L_{3}$ e projeta-se no solo eqüidistante dos dois pés (BRICOT, 2001).

No alinhamento ideal da articulação do ombro (Figura 2), a linha de referência da vista lateral passa no centro da articulação. A posição do braço e articulação do ombro depende da posição da escápula. Para um bom alinhamento, a parte costal das escápulas, que são côncavas, ficam posicionadas contra o gradil costal, aproximadamente entre a segunda e a sétima vértebra torácica, e cerca de $10 \mathrm{~cm}$ separadas (KAPANDJI, 2000). Segundo Bricot (2001), o alinhamento escapular deve coincidir no mesmo plano que os glúteos.

A coluna torácica ideal se curva com uma convexidade levemente em direção posterior. A coluna cervical e lombar ideal se curva com uma convexidade anterior. Se uma dessas três curvaturas se altera conseqüentemente as outras são modificadas (BRICOT, 2001).

A linha de referência da vista lateral através dos membros inferiores passa levemente posterior ao centro da articulação do quadril e levemente anterior ao eixo 
da articulação do joelho, representando uma posição estável desta articulação (figura 2). No tornozelo a linha de referência passa levemente anterior ao maléolo externo, e aproximadamente através do ápice do arco, designado lateralmente pela articulação calcaneocuboídea (Figura 2) (KENDALL, McCREARY e PROVANCE, 1995).

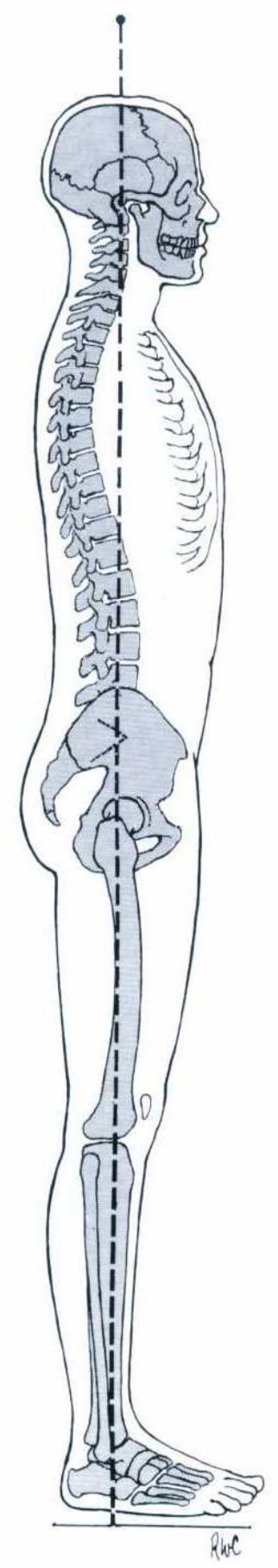

Figura 2- Linha de gravidade no plano sagital (KENDALL, McCREARY e PROVANCE, 1995). 
A posição neutra da pelve usada como padrão é aquela onde a espinha ilíaca ântero-superior (EIAS) fica no mesmo plano horizontal que a espinha ilíaca posteroinferior (EIPS), e as espinhas ilíacas ântero-superiores e a sínfise púbica ficam no mesmo plano vertical (Figura 3A). Nesta posição existe uma curvatura anterior normal na coluna lombar. Se a EIAS fica mais alta que a EIPS é considerado anteversão pélvica (Figura 3B). Se a EIPS fica mais alta que a EIAS é considerado retroversão pélvica (Figura 3C) (KENDALL, McCREARY e PROVANCE, 1995).

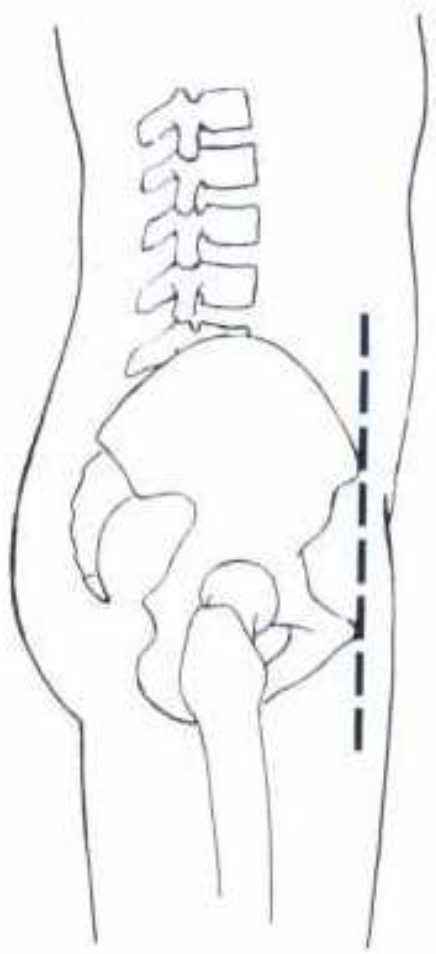

A

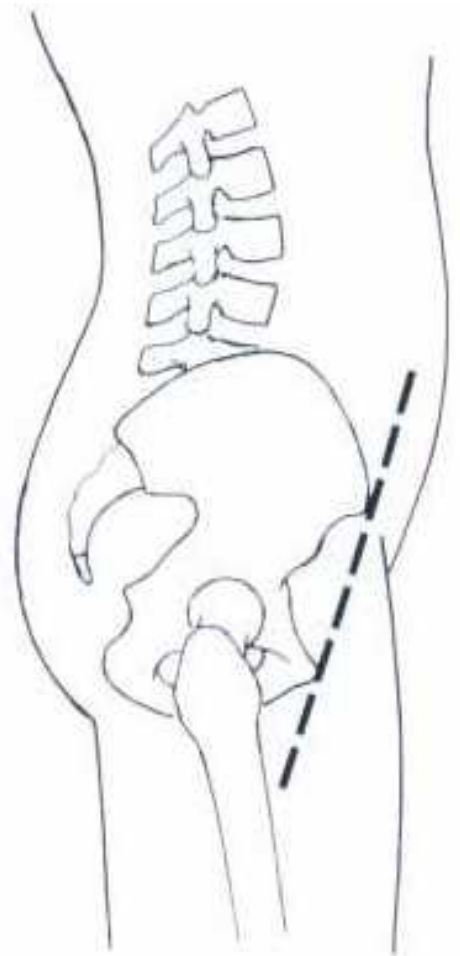

B

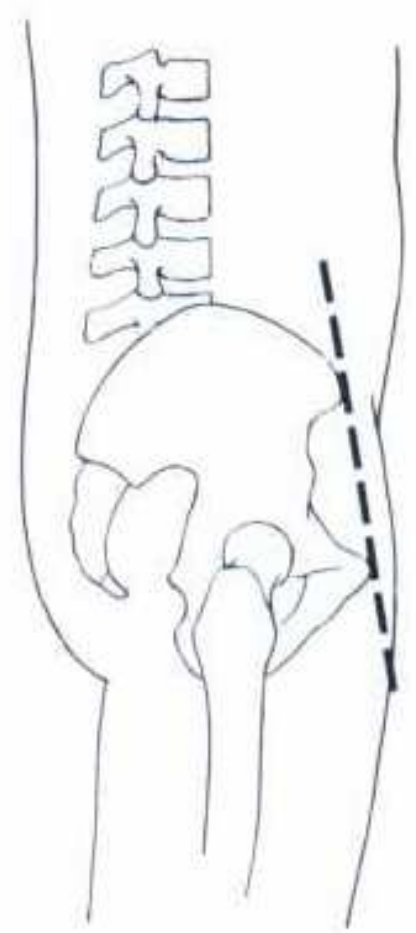

C

Figura 3- Posicionamento da pelve - A (indivíduo normal - posição neutra), B (com inclinação anterior anteversão pélvica), C (com inclinação posterior - retroversão pélvica) (KENDALL, McCREARY e PROVANCE, 1995).

Normand et al. (2002) descreveram que as pesquisas são freqüentemente baseadas nessa avaliação qualitativa da postura, que permite detectar, na maioria das vezes, apenas desvios clinicamente significativos, o que dificulta a comparação dos resultados obtidos com os tratamentos. 
Na literatura são descritos alguns recursos para realizar a avaliação qualitativa. Dentre esses recursos podemos citar a fotografia que foi utilizada por Fedorak et al. (2003). Estes autores fotografaram 36 indivíduos, apresentaram as fotos para 28 profissionais (fisioterapeuta, fisiatra, ortopedista, quiropata, reumatologista) para que fosse analisada, a lordose cervical e lombar e classificada a alteração dessas curvaturas. Como resultado obtiveram uma pobre confiabilidade interexaminador pois, apresentou um coeficiente de Kappa $<0,40$ e uma regular confiabilidade intraexaminador pois, apresentou um coeficiente de Kappa $<0,50$.

Outro recurso utilizado para avaliação qualitativa e descrito na literatura é o acromiopelviômetro, descrito por Fuentes, Freesmeyer e Henríquez (1999), este recurso marca a posição da pelve e ombro para verificar a presença de assimetrias. Mas é um recurso que não é encontrado nas clínicas e escolas de fisioterapia. Neste trabalho foi desenvolvido para detectar assimetrias em pacientes com disfunção craniomandibular.

Na literatura, outro instrumento descrito para avaliação qualitativa é a técnica de Moiré, que consiste na projeção de luz sobre uma tela, formando uma sombra com franjas no tronco examinado ou em outra área do corpo (Figura 4). Rodrigues et al. (2003) analisaram crianças de uma escola pública através da técnica de Moiré. Neste trabalho os autores verificaram a ausência ou presença de assimetrias de tronco (gibosidade), assimetria de ombro e triângulo de Talles, mas não quantificaram essas alterações. Concluíram que a técnica é confiável para análise postural, não excluíram a necessidade da radiografia para realizar uma avaliação postural e não fizeram considerações sobre as limitações da técnica. 


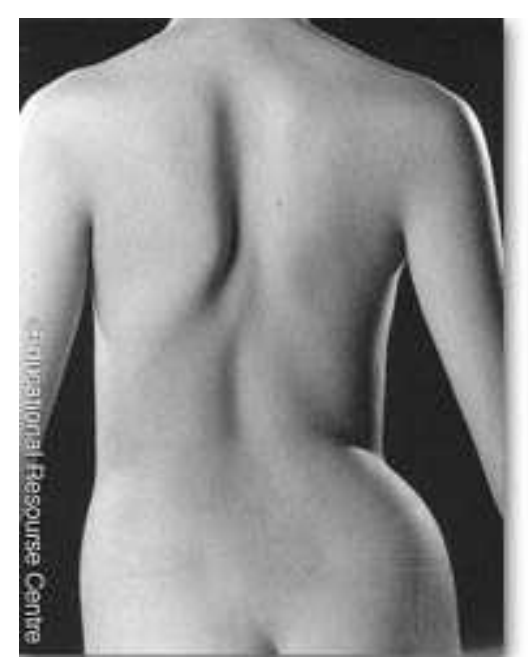

A

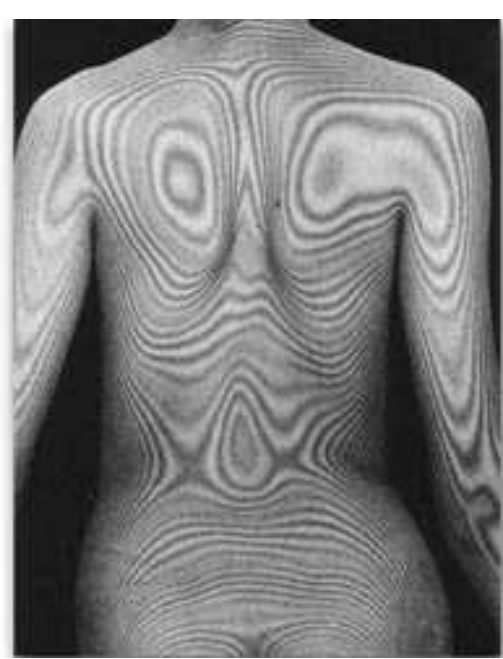

B

Figura 4- Técnica de Moiré, A (tronco com assimetria), B (tronco com a sombra da projeção na tela de Moiré)(disponível em:<http://www.rch.unimelb.edu.an>.Acesso em: 29 jul. 04.)

Pereira (2003) descreve o uso da fotogrametria como uma forma de avaliação postural das assimetrias corporais e compara com a avaliação visual de 50 indivíduos, relatando boa coerência nos resultados. Porém este mesmo autor não quantificou essas assimetrias.

Como descrito por Claman, Patton e Rashid, (1990); Buendia et al. (1999) Normand et al. (2002); Hockman, Castilho, Ferreira (2002); Fedorak et al. (2003); Pereira (2003), a avaliação qualitativa da postura não permite detectar pequenas alterações posturais, dá margem a erros e variações entre examinadores diferentes.

\subsection{Avaliação postural quantitativa}

A quantificação das alterações posturais não é comumente utilizada nas clínicas e escolas de fisioterapia. Pouca atenção tem sido dada para a mensuração dos desvios posturais na avaliação clínica e em trabalhos científicos, apesar de sua importância para documentação pré e pós-tratamento, por permitirem comparações de 
pequenas alterações na postura que possam surgir com os tratamentos aplicados (FEDORAK et al., 2003).

Diversos métodos têm sido testados, no entanto, como nem sempre são facilmente disponíveis acabam por não serem empregados na prática clínica (FERRARIO et al., 1995; YOUDAS et al.,1996; LUNDON, LI e BIBERSHTEIN, 1998; JOHNSON, 1998; BUENDIA et al.,1999; ZEPA et al.,2000; RODACKI et al., 2001; BENSON e RICHMOND, 1997; RODRIGUES et al., 2003).

Um dos métodos utilizados é o inclinômetro, também conhecido como plantografia espinhal ou flexicurva (Figura 5). Este recurso consiste em uma régua flexível que é colocada sobre a coluna vertebral moldando sua curvatura. Depois essa régua moldada é retirada, e quantificado o grau da curvatura. Este método é descrito por Zepa et al. (2000), que quantificaram a cifose dorsal e lordose lombar em pacientes com disfunção craniomadibular, comparando-os com indivíduos normais. Este mesmo recurso é descrito por Lundon, Li e Bibershtein (1998) que objetivaram determinar o meio mais efetivo, com menor custo, não invasivo, e mais viável para determinar cifose dorsal em mulheres pós-menopausa com osteoporose. Para isso, utilizaram além da flexicurva, o cifômetro De Brunner's e a radiografia em perfil (onde foi usada a técnica de Cobb para medir a cifose). Seus resultados demonstraram que as medidas foram confiáveis intra e interexaminador, porém o raio-x foi a técnica de maior confiabilidade.

O inclinômetro também foi utilizado no trabalho de Youdas et al. (1996) que através deste recurso avaliaram e quantificaram o ângulo de inclinação pélvica e a lordose lombar. As medidas foram realizadas em indivíduos com dor lombar. Os pesquisadores tentaram relacionar a posição da pelve e alteração da lordose com os valores dos comprimentos dos músculos abdominais e iliopsoas. 


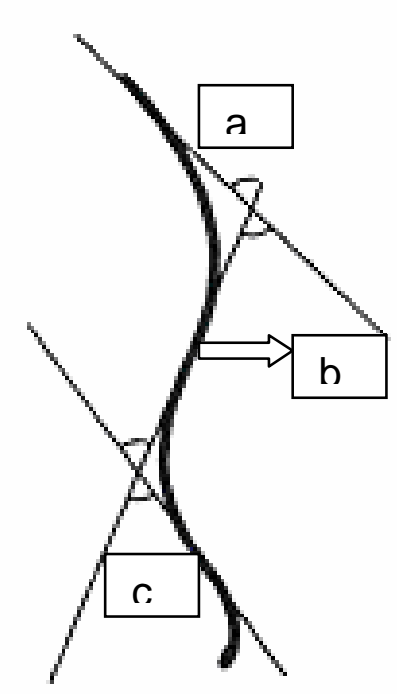

Figura 5- Plantografia espinhal ou inclinômetro para determinar os ângulos da cifose dorsal ou lordose lombar , onde a (ângulo da cifose torácica), b (inclinômetro), c (ângulo da lordose lombar) (ZEPA et al., 2000)

Outro método quantitativo de avaliação é a técnica de Moiré. Esta técnica para ser usada para quantificar as assimetrias deve ser associada com fotografias (RODRIGUES et al., 2003). Buendia et al. (1999), utilizaram essa técnica para analisar e quantificar assimetrias em pacientes escolióticos. Segundo esses autores, esse método tem a vantagem de quantificar assimetrias e não é invasivo, porém relatam a necessidade de mais estudos para sua utilização, pois as pequenas assimetrias que geram uma diferença de projeção de luz sobre a tela menor que 3.0 pixels não são detectadas por essa técnica.

RODACKI et al. (2001) descrevem outro recurso quantitativo para avaliação da coluna vertebral, que é o estadiômetro. Este instrumento permite quantificar o comprimento crânio-caudal da coluna vertebral. Segundo estes autores, esta medição é importante devido às reduções do disco intervertebral que ocorrem durante o dia, o que provoca variações no comprimento do corpo humano. Estes autores testaram a repetibilidade e a reprodutibilidade do método. Porém, a verificação do comprimento 
da coluna vertebral é um dado que não traz informações posturais nas avaliações dos fisioterapeutas, portanto este recurso de avaliação não é utilizado nas escolas e clínicas de fisioterapia.

Ferrario et al. (1995) descrevem o uso da câmera de vídeo para avaliação da oclusão, da posição natural da cabeça e da postura corporal. Segundo estes autores esta técnica permite uma rápida avaliação, não é invasiva e permite análise em três dimensões. No entanto, Benson e Richmond (1997) compararam a fotografia, a radiografia e o vídeo para avaliação de crianças. Verificaram que dos três recursos uilizados, o vídeo teve resultados menos reprodutíveis e a radiografia teve resultados mais reprodutíveis.

A radiografia também pode ser usada para quantificar a posição da cabeça e as curvaturas vertebrais. Normalmente, a posição da cabeça e a lordose cervical têm sido estudadas por dentistas e fisioterapeutas comparando indivíduos com disfunções craniomandibulares e indivíduos normais. Um exemplo é o trabalho de Visscher et al. (2002) que quantificaram a posição da cabeça tanto com raio-x (cefalometria) e com fotografias usando um ângulo formado pela intersecção de uma reta que une o tragus da orelha ao processo espinhoso de $\mathrm{C}_{7}$ com uma reta paralela ao solo. Este mesmo ângulo para avaliar posição de cabeça foi realizado por Johnson (1998) também através de fotografias e radiografias. Nestes trabalhos foram observados uma pobre correlação entre as medidas obtidas pelas duas técnicas utilizadas.

A quantificação de outras curvaturas vertebrais através da radiografia normalmente é vista em trabalhos associando curvaturas vertebrais e presença de dores na coluna, como no trabalho de Tüzün et al. (1999), que compararam a análise das curvaturas através da avaliação postural e através de radiografias. Estes autores utilizaram a técnica de Cobb (Figura 6) para quantificar a cifose torácica, a lordose 
lombar e a inclinação sacral. A medida da cifose (figura 6 a) foi realizada em radiografia, através do ângulo formado pela intersecção de duas linhas traçadas superior a primeira vértebra dorsal $\left(T_{1}\right)$ com uma linha inferior a última vértebra dorsal $\left(\mathrm{T}_{12}\right)$. A medida da lordose lombar (Figura $6 \mathrm{~b}$ ) nesse trabalho foi realizada através do ângulo formado pela intersecção de duas linhas traçadas superior a primeira vértebra lombar $\left(L_{1}\right)$ com uma linha inferior a primeira vértebra sacral $\left(S_{1}\right)$. Segundo estes mesmos autores o valor normal deste ângulo é entre 20 a 45ํㅜ um valor menor que $20^{\circ}$ é considerado retificação lombar e um valor superior à 45e é considerado hiperlordose. O ângulo de inclinação sacral (figura 6 c) é o ângulo formado por uma linha traçada no platô sacral que intercede a uma linha horizontal. Estes autores não acharam uma correlação entre avaliação postural no plano sagital e a avaliação radiológica e atribuíram este fato à presença de tecidos moles que dificultam o diagnóstico das curvaturas vertebrais na ausência do exame radiológico.

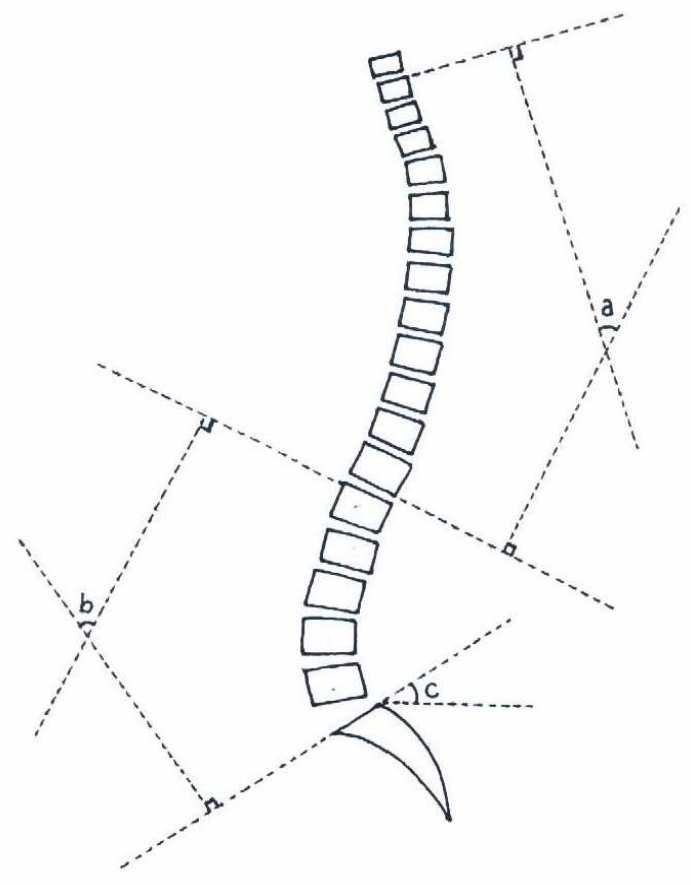

Figura 6 - Medida das curvaturas dorsal e lombar através do ângulo de Cobb, onde a (medida da cifose torácica), b (medida da lordose lombar), c (medida do ângulo de inclinação sacral)(TÜZÜN et al.,1999). 
Outro estudo que utiliza a radiografia para quantificação das curvaturas lombares é o trabalho de Jackson et al. (2000) que analisaram em 50 voluntários através de radiografias de perfil a morfologia pélvica, a lordose lombar e o ângulo lombossacro. Concluíram que a morfologia pélvica e lordose lombossacra são fortemente relacionadas. Esta relação determina a lordose lombar.

Amonoo-Kuofi (1992) também utilizou o raio-x para avaliar a curvatura lombar e a posição do sacro, concluiu que a alteração da lordose lombar predispõe a alteração da inclinação sacral.

Gardocki, Waltkins, Willians (2002) concluiram que a radiografia é um importante recurso para determinar alterações da coluna lombar ao analisar 28 radiografias da coluna inteira em perfil para determinar a lordose lombopélvica e rotação pélvica através do ângulo de Cobb.

Apesar do raio-x ser considerado um método eficaz para detectar alterações das curvaturas vertebrais, é um recurso que apresenta vários obstáculos a sua utilização. Por ser um recurso dispendioso, nem sempre o paciente pode pagar para sua realização e para ser feito pelo Sistema único de Saúde depende de um encaminhamento médico e de agendamento do exame, portanto este recurso nem sempre está disponível ao fisioterapeuta durante uma avaliação ou durante um tratamento. Outro empecilho é que por se tratar de uma radiação apresenta critérios em sua utilização, não devendo ser repetido freqüentemente e apresenta contraindicações como, por exemplo, em gestantes (BENSON e RICHMOND, 1997).

A fotogrametria, que será descrita nesse trabalho, é outro método que pode quantificar as alterações posturais. Este é um método não invasivo, tem a vantagem de não necessitar de um encaminhamento para sua realização, é um recurso que está à mão do fisioterapeuta, não requer equipamentos sofisticados e não apresenta 
contra-indicações para sua utilização. Porém, como descreve Normand et al. (2002), antes de um método de avaliação ser empregado em pacientes, devem ser testadas a confiabilidade e a validade deste método, o que não foi ainda realizado com a fotogrametria.

\subsection{Fotogrametria}

A fotogrametria é uma palavra de origem grega onde photos significa luz; gramma, algum desenho ou escrito e metron significa medir. De acordo com a origem da palavra, fotogrametria significa medir graficamente usando a luz. Em 1979, a American Society of Photogrammetry definiu de forma mais abrangente a fotogrametria como sendo "A arte, ciência e tecnologia de obtenção de informação confiável sobre objetos físicos e o meio ambiente através de processos de gravação, medição e interpretação de imagens fotográficas, padrões de energia eletromagnética radiante e outras fontes" (TOMMASELLI et. al.,1999).

A fotogrametria é dividida em fotogrametria aérea (aerofotogrametria), onde as fotografias do terreno são tomadas em uma aeronave; fotogrametria terrestre, onde as fotografias são tomadas em posição fixa no terreno; fotogrametria espacial, que compreende fotografias onde a câmera é fixada em um satélite e a fotogrametria à curta distância, utilizada na arquitetura, engenharia, medicina e também na fisioterapia.

A fotogrametria médica também denominada bioestereometria tem sido utilizada com a finalidade de obter medidas da forma, das dimensões dos corpos e/ ou de parte deles (TOMMASELLI et. al.,1999). 
Na odontologia, desde 1980, há relatos de sua utilização por Farkas et al. (1980), que compararam as análises de medidas da face através da fotogrametria com as realizadas através de uma régua diretamente na face do paciente. Outros trabalhos na odontologia empregam a fotogrametria para a análise de dismorfismo facial, assimetrias faciais, crescimento facial em pacientes ortodônticos e/ou que serão submetidos a cirurgias maxilofaciais (FERRARIO et al. 1999).

No Brasil, a fotogrametria a curta distância começou a ser desenvolvida na UNESP de Presidente Prudente, a partir de 1982, na área de arquitetura. Em 1986, foi empregada em aplicações cartográficas para cadastro urbano e rural. A partir de 1992, com aplicação da metodologia utilizando câmeras fotográficas, que são de um custo baixo em relação às câmeras fotogramétricas é que passou a ser estimulada novos estudos. Neste período, iniciou-se a aplicação no curso de fisioterapia para o diagnóstico de várias patologias (TOMMASELLI et. al.,1999).

Outro relato de sua utilização pela fisioterapia é descrito por Baraúna et al. (2004) que utilizaram a fotogrametria para quantificar as oscilações corporais no plano sagital e frontal em indivíduos idosos, porém colheram as imagens através de uma câmera de vídeo.

Atualmente, outra área que vem utilizando a fotogrametria é a cirurgia plástica, para avaliar o pré e o pós-operatório de rinoplastia. Porém, é utilizada a fotografia convencional, com a digitalização da imagem através de um scanner óptico e analisada esta imagem no Corel Draw. (HOCKMAN, CASTILHO e FERREIRA, 2002). Estes autores afirmam que o uso da fotografia digital simplificaria a técnica, pois dispensaria o uso do scanner, mas eles julgam ser mais dispendiosa devido ao preço da câmera. Atualmente, isso já não é realidade, pois as câmeras digitais estão tornando-se cada vez mais acessíveis. 


\subsection{A fotografia para avaliar a postura}

A fotografia pode ser uma ajuda útil para avaliar a postura corporal e pode registrar as transformações posturais ocorridas ao longo do tempo e inter-relacionar diferentes partes do corpo que são difíceis de mensurar (WATSON, 1998).

Vários autores descrevem a utilização da fotografia como um recurso de avaliação. Zonnenberg et al. (1996) descrevem o uso da fotografia para quantificar as alterações posturais comparando indivíduos saudáveis e indivíduos com disfunção craniomandibular. Porém, essa quantificação foi realizada na própria fotografia revelada.

Para Bister et al. (2002), em seus estudos analisaram a posição da cabeça comparando cefalometria com fotografia, concluíram que técnicas fotográficas são úteis para reproduzir a cefalometria em posição natural da cabeça. Já Johnson (1998), avaliou a correlação entre a mensuração externa da cabeça e pescoço com a posição anatômica das quatro primeiras vértebras cervicais através de cefalometria, verificou que não há correlação entre protusão de cabeça utilizando fotografia e cefalometria.

Benson e Richmond (1997) compararam a avaliação da face através da fotografia, vídeo e radiografia e como resultados verificaram que a radiografia é o mais confiável dos métodos, e o vídeo não se mostrou reprodutível. A fotografia pode ser clinicamente aceitável para avaliar o contorno da face, mas segundo os autores são sujeitas a erros.

Alguns autores que controlam a postura através da fotografia, normalmente posicionam o indivíduo diante de uma parede com um fio de prumo colocado atrás da pessoa para ter uma referência dos desvios (WATSON e MAcDONNCHA, 2000). 
No entanto, a utilização da técnica não é tão simples como aparenta e requer vários cuidados metodológicos para padronizar as fotos e evitar efeitos de distorção (VEGTER E HAGE, 2000). As distorções implicam em alterações na imagem fotográfica que podem causar uma impressão enganosa da postura do indivíduo (WATSON e MAcDONNCHA, 2000). De acordo com Claman, Patton e Rashid (1990); Bishara et al. (1995); Watson e Macdonncha (2000), alguns cuidados que podem ser utilizados para evitá-las são:

- Evitar usar zoom ou lentes de aumento que podem reproduzir imagens com curvas convexas ou côncavas.

- Algumas partes do corpo podem ampliar-se em relação a outras. Este tipo de distorção pode ser eliminado se a máquina estiver paralela ao sujeito e completamente alinhada na vertical, daí a importância do tripé.

- Posicionar bem os pés do sujeito de modo que nenhum lado do corpo fique mais anterior para evitar distorções, pois se o corpo é fotografado com o lado esquerdo mais à frente, o pé esquerdo é reproduzido na fotografia maior que o direito (WATSON, 1998).

- A distorção devido ao erro paralaxe pode ser minimizada se a distância sujeitomáquina for aumentada, com isso aumentando o comprimento focal da máquina. $A$ câmera deve ser sempre posicionada horizontal e direcionada em frente do centro do corpo do sujeito (WATSON, 1998).

Outros cuidados metodológicos envolvem ainda o treinamento do pesquisador que realizará as fotografias, trabalhar com apenas um pesquisador fotografando para aumentar a probabilidade de se obter fotografias comparativas, utilizar sempre a mesma câmera, posicioná-la sempre na mesma distância do paciente, usando marcas 
no chão (FARKAS et al., 1980; CLAMAN, PATTON e RASHID, 1990; WATSON, 1998; HOCKMAN, CASTILHO e FERREIRA, 2002).

Outros cuidados que devem ser tomados são: o uso de um equipamento fotográfico e lentes de boa qualidade para produzir boas imagens; a câmera deve estar fixada em um tripé posicionado no nível; o sujeito a ser fotografado deve ser iluminado pelo flash (WATSON, 1998).

O ambiente para fotografar a postura deve ser livre de interferências, aquecido, confortável e privado para quem vai ser fotografado. Deve ser adequadamente iluminado para permitir que a câmera seja precisamente focada além de usar um fundo não reflexivo (WATSON e MAcDONNCHA, 2000).

A roupa para fotografar postura deve ser um traje de banho para que a maior parte do corpo fique exposta permitindo uma boa visualização das áreas marcadas. 0 posicionamento para fotografar postura deve ser com o sujeito em pé ereto, com os braços ao longo do corpo, olhando para frente. Se a altura do paciente não permitir que a câmera seja focalizada no centro do seu corpo pode-se posicionar o sujeito sobre uma caixa para elevar sua altura (WATSON, 1998).

Para fotografar a face, a distância ideal é aquela que permite enquadrar o topo da cabeça e a base das clavículas. Deve-se posicionar o centro da lente entre os olhos do paciente para evitar distorções (CLAMAN, PATTON e RASHID, 1990).

Além disso, a fotografia postural para ser de alta qualidade, deve ter alta nitidez, ter uma dimensão suficiente para permitir observações, de modo que pequenos detalhes do corpo do sujeito sejam visíveis na fotografia não levando o observador a cometer equívocos na análise (WATSON, 1998).

Apesar de todos estes cuidados metodológicos, a utilização da Fotogrametria Computadorizada ainda necessita ser melhor fundamentada uma vez que não foram 
encontrados trabalhos que testaram a confiabilidade intra e inter examinadores, também não estão padronizados os ângulos a se medir. Portanto, não é possível afirmar se as análises que o método oferece são reprodutíveis e confiáveis, ou não.

\subsection{Confiabilidade da avaliação postural}

Segundo a ISO (1994), citado por Bister et al., (2002)., repetibilidade refere-se às condições testadas tão constantes quanto possíveis, usando a mesma metodologia, o mesmo laboratório, o mesmo operador, o mesmo equipamento com intervalos curtos de tempo. É a análise intra-examinador.

Reprodutibilidade refere-se a condições de testes obtidos com o mesmo método, mas em diferentes laboratórios, com diferentes operadores, usando diferentes equipamentos. Refere-se à análise interexaminador (BISTER et al., 2002).

Para analisar o nível de confiança de uma técnica de avaliação devem-se ter três propostas primárias: 1) estabelecer a confiança de um mesmo examinador; 2) determinar a repetibilidade da postura assumida pelo voluntário; 3) estabelecer a confiança entre os examinadores (WATSON e MAcDONNCHA, 2000).

Watson e Macdonncha (2000) objetivaram estabelecer o nível de confiança na avaliação postural através do uso de fotografias em vista anterior, posterior e de perfil. Para isso fotografaram 114 adolescentes, com idade de 15 a 17 anos. As analises das fotografias foram realizadas utilizando um papel quadriculado.

Para avaliar o nível de confiança de um mesmo examinador foram selecionados ao acaso as fotografias de 30 participantes que foram avaliadas em duas ocasiões diferentes, sendo a segunda avaliação realizada duas semanas após a primeira, para 
que o examinador não memorizasse os resultados. A análise estatística demonstrou uma maior confiabilidade na segunda avaliação. Os dados foram considerados de alto índice de confiança, pois tiveram um intervalo de confiança maior que $75 \%$, exceto a posição do tornozelo que teve um intervalo de confiança de 66,6\% na primeira avaliação. A simetria de ombros e cifose tiveram um intervalo de confiança de $73,3 \%$ também na primeira avaliação. No reteste todos os itens avaliados tiveram um intervalo de confiança maior que $85 \%$.

Para estabelecer o grau de confiança entre diferentes examinadores, 30 participantes ao acaso foram selecionados e avaliados por um dos autores e por um assessor experiente. A análise estatística de todos os itens avaliados demonstrou um alto índice de confiança, superior a 90\%.

A reprodutibilidade da postura assumida pelo participante durante a avaliação foi estabelecida por uma seleção de 20 adolescentes jovens que foram fotografados em duas ocasiões, em um intervalo de sete dias, para que o participante não memorizasse a postura assumida. Os resultados demonstram uma boa reprodutibilidade da postura apresentando um intervalo de confiança superior a $80 \%$ (WATSON e MAcDONNCHA, 2000). 


\section{OBJETIVOS}

O objetivo desse estudo foi propor um método de quantificação das assimetrias e desvios posturais a partir da avaliação postural pela fotogrametria bem como: a) analisar a reprodutibilidade das mensurações angulares das assimetrias e desvios posturais entre examinadores diferentes; b) verificar a repetibilidade das medidas intraobservador em duas avaliações diferentes com intervalo de um mês entre eles; c) verificar a repetibilidade das medidas angulares das assimetrias e desvios posturais em fotografias do mesmo voluntário obtidas em duas ocasiões com um intervalo de uma semana entre elas; d) verificar a reprodutibilidade e repetibilidade de ângulos que possam ser adotados para utilização da fotogrametria na avaliação postural. 


\section{MATERIAIS E MÉTODOS}

\subsection{Amostra}

Foram analisados 21 voluntários, com idade média de 24,2 $\pm 1,3$ anos, sendo 4 do sexo masculino e 17 do sexo feminino, peso médio de 59,1 $\pm 12,3 \mathrm{Kg}$ e altura média de 1,66 $\pm 0,05 \mathrm{~m}$. Todos os voluntários receberam informações para a participação no projeto e assinaram um termo de consentimento formal concordando em participar da pesquisa (APÊNDICE A), de acordo com a resolução 196/96 do Conselho Nacional de Saúde. Este estudo foi aprovado pelo comitê de ética e pesquisa da UNIFENAS (ANEXO A), onde a pesquisa foi realizada.

\subsubsection{Critérios de inclusão}

Esta amostra foi constituída por estudantes universitários voluntários escolhidos aleatoriamente desde que tivessem bom estado de saúde e concordassem em participar da pesquisa. 


\subsubsection{Critérios de exclusão}

Foram excluídos desta pesquisa os estudantes com história dor crônica, problemas neurológicos ou doenças reumáticas, deficiência física e seqüela físicas de cirurgias.

\subsection{Materiais}

Foram utilizados os seguintes equipamentos e recursos para a realização da pesquisa:

- Máquina digital -Sony ${ }^{\circledR}$ - Mavica FD 200,

- $\quad$ Tripé - First Moonlight ${ }^{\circledR} 6156$,

- Software ALCimagem-2000 Manipulando Imagens, versão 1,5,

- Computador Pentium ${ }^{\circledR}$ III,

- Disquetes.

- Demarcador de borracha,

- Dispositivos de madeira (figura 10),

- Etiquetas auto-adesivas brancas de 0,9 mm de diâmetro - Pimaco ${ }^{\circledR}$,

- Marcador de haste cilíndrica plástica (figura 7),

- Fita dupla face - $3 \mathrm{M}^{\circledR}$,

- Faixa de cabelo,

- Prendedor de cabelo,

- Fio de prumo,

- Trena, 


\subsection{Procedimentos}

Após os esclarecimentos iniciais foi solicitada aos voluntários a colocação do traje de banho para coleta de dados.

\subsubsection{Pontos anatômicos demarcados}

Foram demarcados alguns pontos anatômicos, bilateralmente, para serem utilizados na análise de imagem. Esses pontos são:

- Ponto A - articulação esternoclavicular (figura 13);

- Ponto B - articulação acrômio clavicular (figura 13);

- Ponto C - espinha ilíaca antero- superior (EIAS) (figura 11);

- Ponto D - tuberosidade da tíbia (figura 11);

- Ponto E - protuberância occipital (figura 14);

- Ponto $\mathrm{F}$ - processo espinhoso de $\mathrm{C}_{4 \text {; }}$ (figura 14);

- Ponto $\mathrm{G}$ - processo espinhoso de $\mathrm{C}_{7}$ (figura 14);

- Ponto H - processo espinhoso de $\mathrm{T}_{7}$; (figura 14);

- Ponto I - processo espinhoso de $\mathrm{T}_{12}$; (figura 14);

- Ponto $\mathrm{J}$ - processo espinhoso de $\mathrm{L}_{3}$; (figura 14);

- Ponto K - processo espinhoso de $L_{5}$; (figura 14);

- Ponto L - ângulos inferiores da escápula (figura 12);

- Ponto M - espinha ilíaca postero- superior (EIPS) (figura 12);

- Ponto N - espinha ilíaca postero- inferior (EIPI) (figura 14);

- Ponto O - Linha Poplítea (figura 12); 
- Ponto P - trocânter maior (figura 14);

- Ponto Q - cabeça da fíbula (figura 14);

- Ponto R - maléolo lateral (figura 14);

- Ponto $S$ - tuberosidade da diáfise do $5^{\circ}$ metatarsiano (figura 14);

Outros cinco pontos que foram analisados mas não precisaram de demarcação devido a sua total visualização são:

- Ponto T - ângulo orbicular externo (figura;13);

- Ponto U-comissura labial (figura;13);

- Ponto V - centro do tragus da orelha (figura;14);

- Ponto X - maléolo medial (figura;12);

- Ponto Z - bordo interno do pé (figura;12).

Esta demarcação foi realizada pela mesma pessoa com etiquetas auto-adesivas brancas da marca $P I M A C O^{\circledR}$ de 0,9 mm de diâmetro.

Para a demarcação dos pontos da protuberância occipital, da coluna vertebral e da pelve foram utilizadas hastes cilíndrica plástica de 6,0 cm (Figura 7) presas através de fita dupla face.

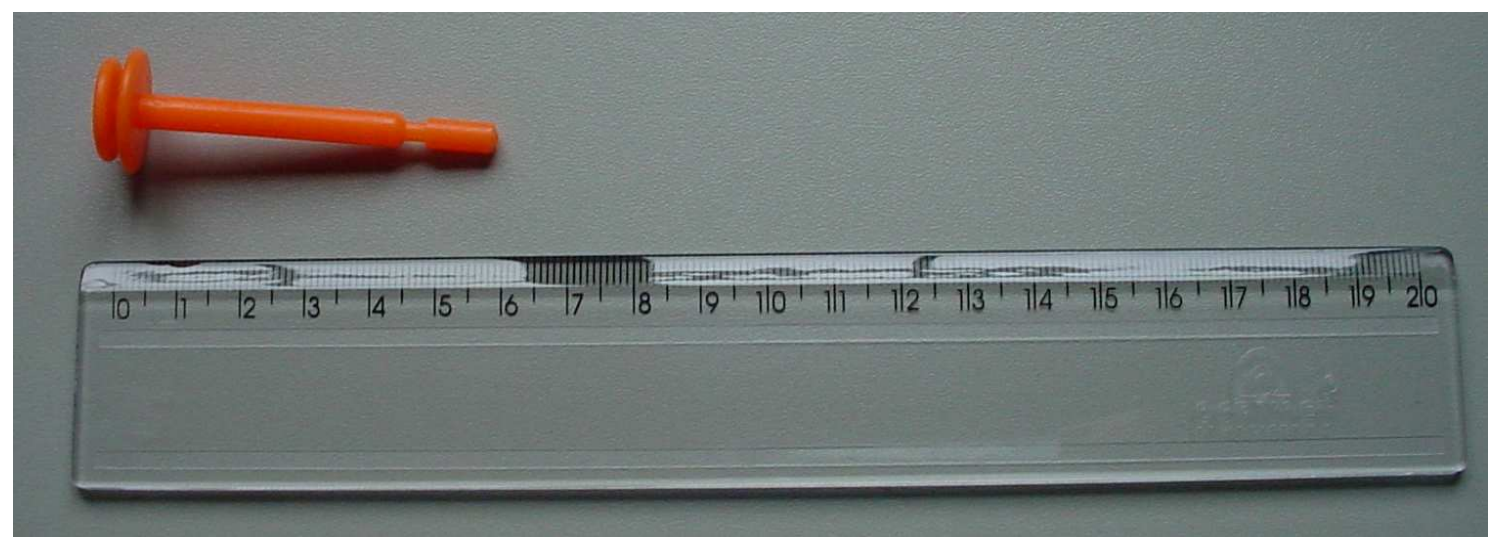

Figura 7- Haste cilíndrica plástica de $6,0 \mathrm{~cm}$ para demarcar os pontos a serem analisados no plano sagital (protuberância occipital, da coluna vertebral e da pelve) 
Na região da protuberância occipital como há cabelo a demarcação do ponto teve que ser adaptada, colocando uma faixa com velcro na cabeça do voluntário para adequada fixação do marcador (Figura 8). Quando o voluntário tinha o cabelo longo, este era mantido preso.

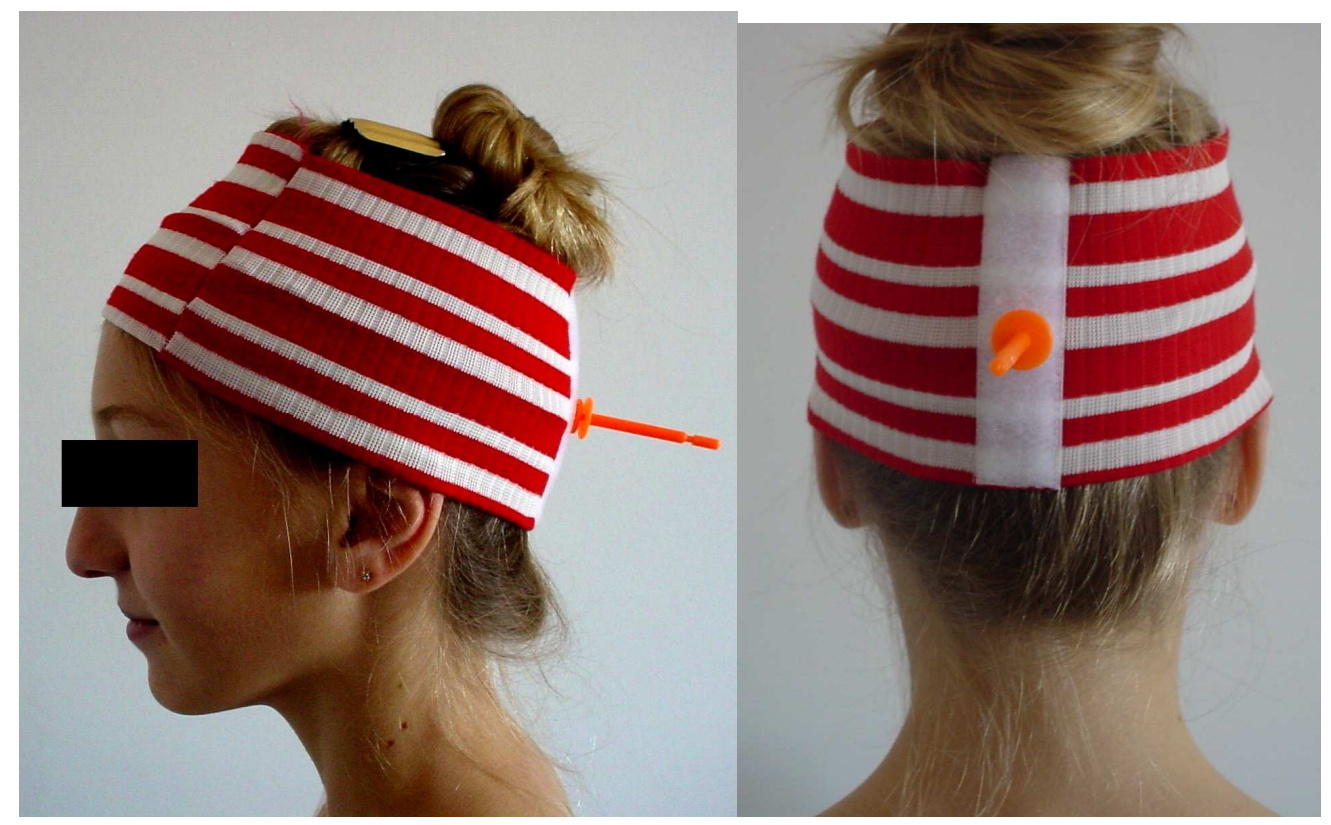

Figura 8- Colocação do marcador na região da protuberância occipital

\subsubsection{Posicionamento do voluntário}

Para o registro fotográfico os participantes permaneceram em postura ortostática, em local previamente demarcado, com uma distância padronizada de 2,40m do centro da lente da máquina fotográfica também previamente demarcada, conforme figura 9.

Neste posicionamento a porção mais posterior do calcanhar do voluntário estava $0,15 \mathrm{~m}$ afastado da parede. Para manter esta distância fixa, foi utilizado um demarcador retangular em etil vinil acetato (E.V.A.) (1B) de 0,15m de largura, 0,60m de comprimento e $0,05 \mathrm{~m}$ de espessura, colocado entre a parede e o voluntário. Outro 
dispositivo deste mesmo material de $0,075 \mathrm{~m}$ de largura foi colocado entre os pés do voluntário (1A), para manter os pés afastados de acordo com o padrão descrito por Kendall, McCreary e Provance (1995).

Para as imagens da face foi adotada uma distância de $0,94 \mathrm{~m}$, sendo que esta distância permitiu enquadrar o topo da cabeça e a base das clavículas do voluntário conforme descrito por Claman, Patton e Rashid (1990). A distância do voluntário e da máquina em relação à parede lateral direita foi de $1,75 \mathrm{~m}$ para que a câmera estivesse bem centralizada ao voluntário.

A câmera fotográfica foi posicionada paralela ao chão, sobre um tripé. Sendo este tripé posicionado de forma que sua base onde foi fixada a câmera estava a uma altura de 1,0 $\mathrm{m}$ do chão para fotografar o corpo inteiro e para fotografar a face estava a 1,53m do chão de acordo com Lovato (2001).

A sala era bem iluminada. A parede era azul, não reflexivo. Foi mantida a privacidade do sujeito a ser fotografado durante a coleta de dados. 


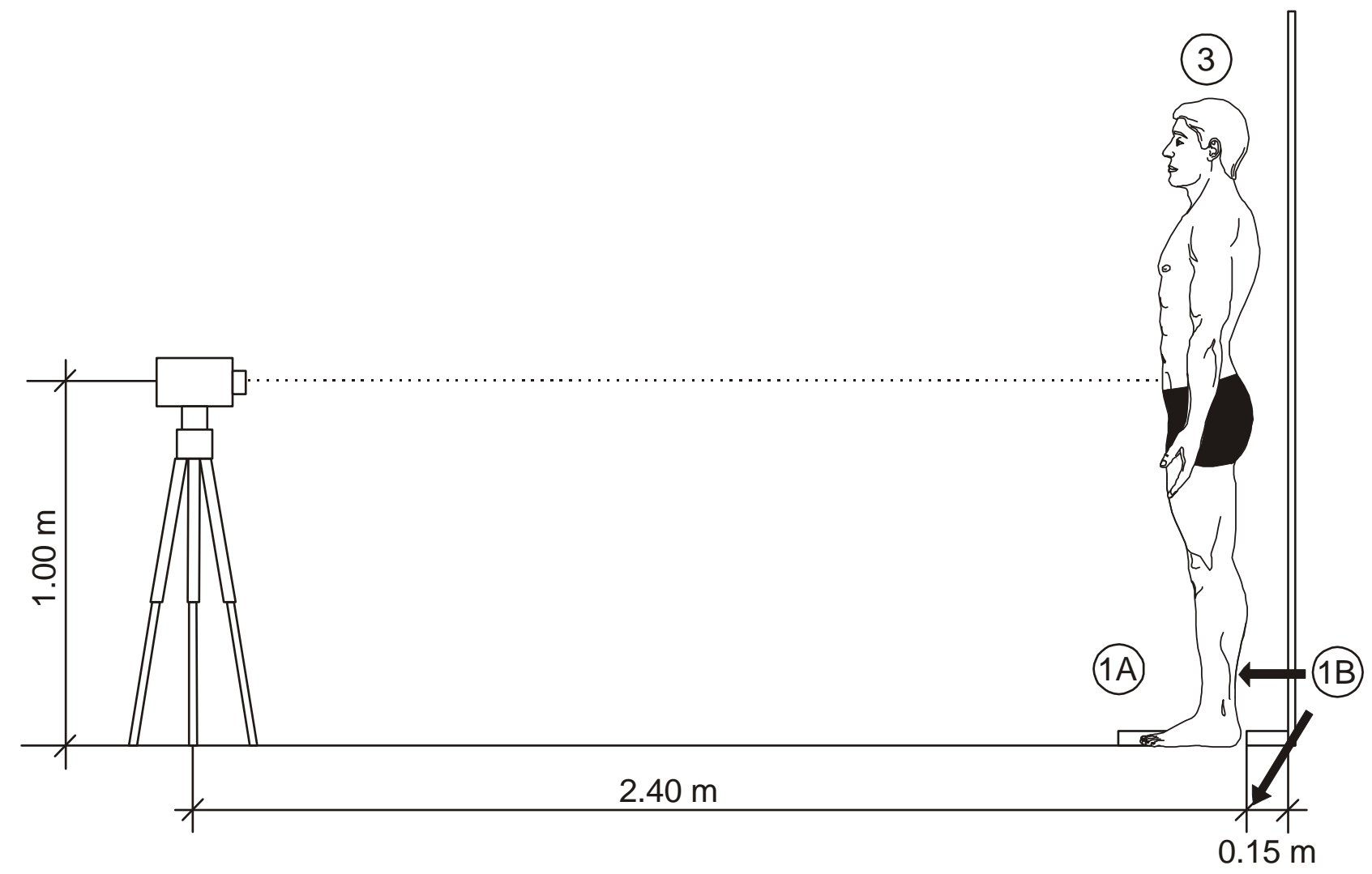

Figura 9- Posicionamento do voluntário e do equipamento para realização da fotografia digital, onde : $1 \mathrm{~A}$ é o dispositivo de E.V.A. para posicionamento dos pés; 1B é o dispositivo de E.V.A. para localização do voluntário em relação à parede; 3 o voluntário..

Os voluntários de baixa estatura foram posicionados sobre um dispositivo de madeira (Figura 10) para melhor registro das imagens. Dessa forma a máquina ficava sempre focalizada na região central do corpo voluntário, evitando assim qualquer distorção. 


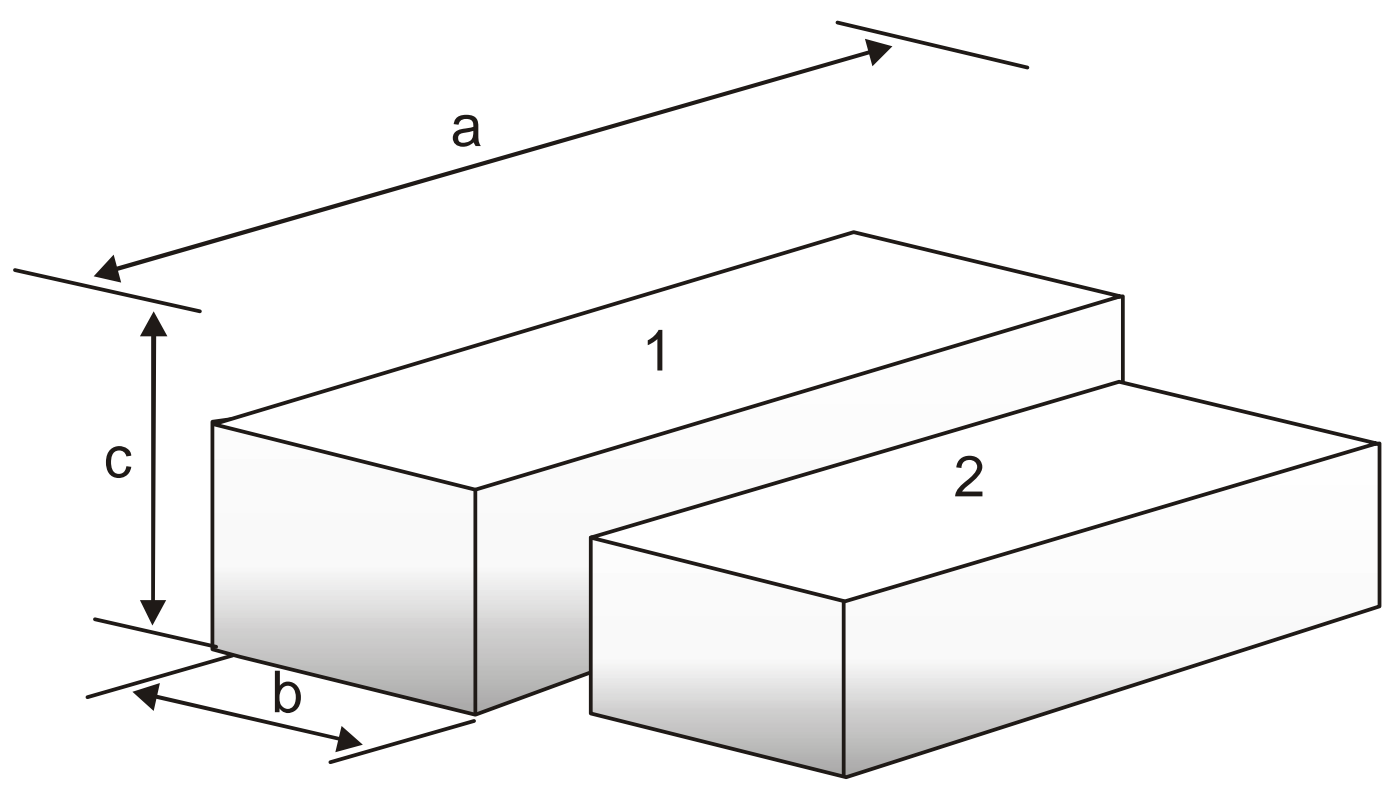

Figura 10 - Dispositivos de madeira utilizados para elevar os voluntários, onde as medidas referentes a; $1 \mathrm{a}, 56,0 \mathrm{~cm}$ (comprimento); 1b, 22,5 cm (largura); 1c, 19,5 cm (altura); 2a, 46,5 cm (comprimento); 2b, $22,5 \mathrm{~cm}$ (largura); 2c, 15,0 cm (altura).

\subsubsection{Registro Fotográfico}

O registro fotográfico foi realizado com uma máquina digital $\left(S O N Y^{\circledast}-\right.$ MAVICA FD 200) de 2.0 megapixels, posicionada paralela ao chão, sobre um tripé (FIRST MOONLIGHT ${ }^{\circledast}$ 6156). Esta câmera tem um zoom óptico de 3x e um zoom digital de $6 \mathrm{x}$, porém para o registro das fotos não foi utilizado zoom.

Foram realizados os registros fotográficos em posição anterior, posterior, perfil e de face. Em cada posição foram realizados três registros fotográficos com intervalo de 1 minuto entre cada um. Sete dias após o primeiro registro fotográfico foram repetidas todas as fotos nas mesmas posições pré-estabelecidas (posição do voluntário e da máquina) e no mesmo intervalo de tempo ( $2^{\mathrm{a}}$ série). Todas as fotografias foram realizadas por um único experimentador. As fotografias foram realizadas no mesmo horário do dia. 
As imagens fotográficas foram digitalmente armazenadas em disquetes com resolução de 1600x1200 pixel.

Para a realização da fotografia o único comando verbal utilizado foi: "mantenha seu olhar para frente", com isso evitando que a interferência verbal pudesse modificar a postura do voluntário.

\subsection{Análise das Imagens}

\subsubsection{Software para análise dos dados}

Os dados fotográficos foram analisados em um computador Pentium IV que contém o programa Aplicativo ALCimagem-2000 Manipulando Imagens, versão 1,5.

Este programa utilizado é um algoritmo matemático, que transforma pontos de imagens em eixos de coordenadas cartesianas. O programa permite quantificar ângulos a partir da imagem capturada.

\subsection{2 Ângulos analisados}

\subsubsection{1 Ângulos do plano frontal anterior}

No plano frontal anterior, os ângulos mensurados e analisados foram assim denominados:

- AS (ângulo das espinhas ilíacas ântero-superiores -EIAS): formado entre as linhas traçadas, unindo o ponto anatômico demarcado à direita com o da esquerda e a linha traçada na horizontal, paralelamente ao solo. (Figura 11). 
- $\Delta \mathrm{T}$ (triângulo de Talles): formado pela intersecção da reta que passa pelo bordo medial do membro superior com a reta que passa adjacente a cintura (Figura 11). 0 $\Delta T d$ refere-se ao triângulo de Talles do lado direito e o $\Delta T$ Te Talles ao lado esquerdo.

- AJ (angulação do joelho): formado pela intersecção da reta que unia os pontos C (EIAS) e ponto D (tuberosidade da tíbia) com a reta perpendicular ao solo (Figura 11). 


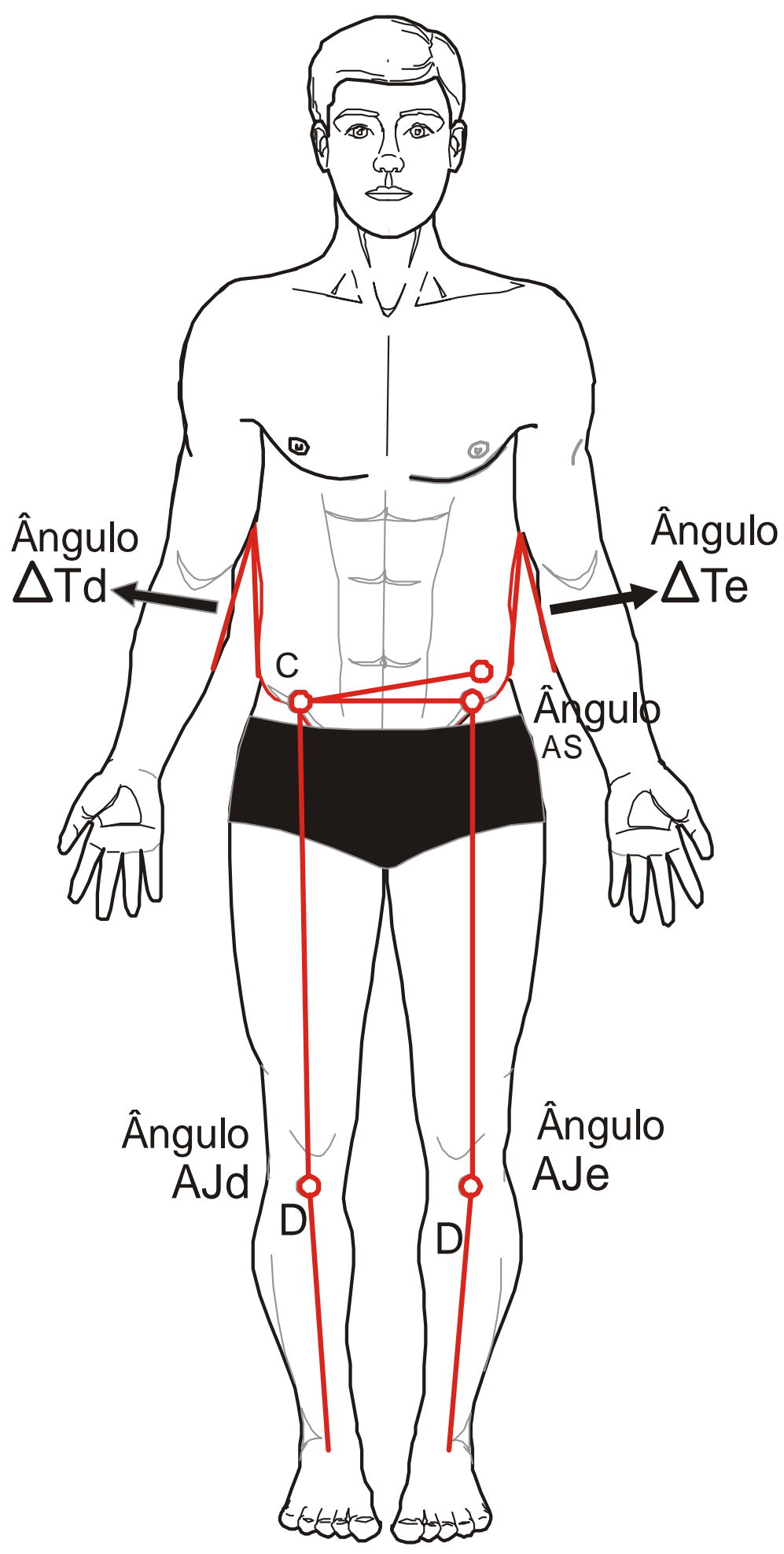

Figura 11- Pontos e ângulos avaliados na vista anterior, onde $C$ (EIAS), D (tuberosidade tibial), $\Delta T$ d (triângulo de Talles direito); $\Delta \mathrm{Te}$ (triângulo de Talles esquerdo); AS (ângulo das espinhas ilíacas ântero-superiores); AJd (angulação do joelho direito), AJe (angulação do joelho esqueredo). 


\subsubsection{2 Ângulos do plano frontal posterior}

No plano frontal posterior os ângulos foram assim denominados:

- IE: ângulo inferior da escapula (Figura 12)

- PS: ângulo das espinhas ilíacas póstero-superiores (EIPS) (Figura 12)

- LP: ângulo das linhas poplíteas (Figura 12)

- IP (ângulo de inclinação do pé): formado pela intersecção da reta que unia os pontos $\mathrm{X}$ (maléolo medial) e ponto $\mathrm{Y}$ (bordo interno do pé) com a reta paralela ao solo. IPd refere-se a inclinação do pé direito e IPe, a inclinação do pé esquerdo (Figura 12).

Os ângulos IE, PS e LP foram formados entre as linhas traçadas unindo o ponto anatômico demarcado à direita com o da esquerda e a linha traçada na horizontal, paralelamente ao solo. Este procedimento foi adotado para padronizar a análise dos dados. 


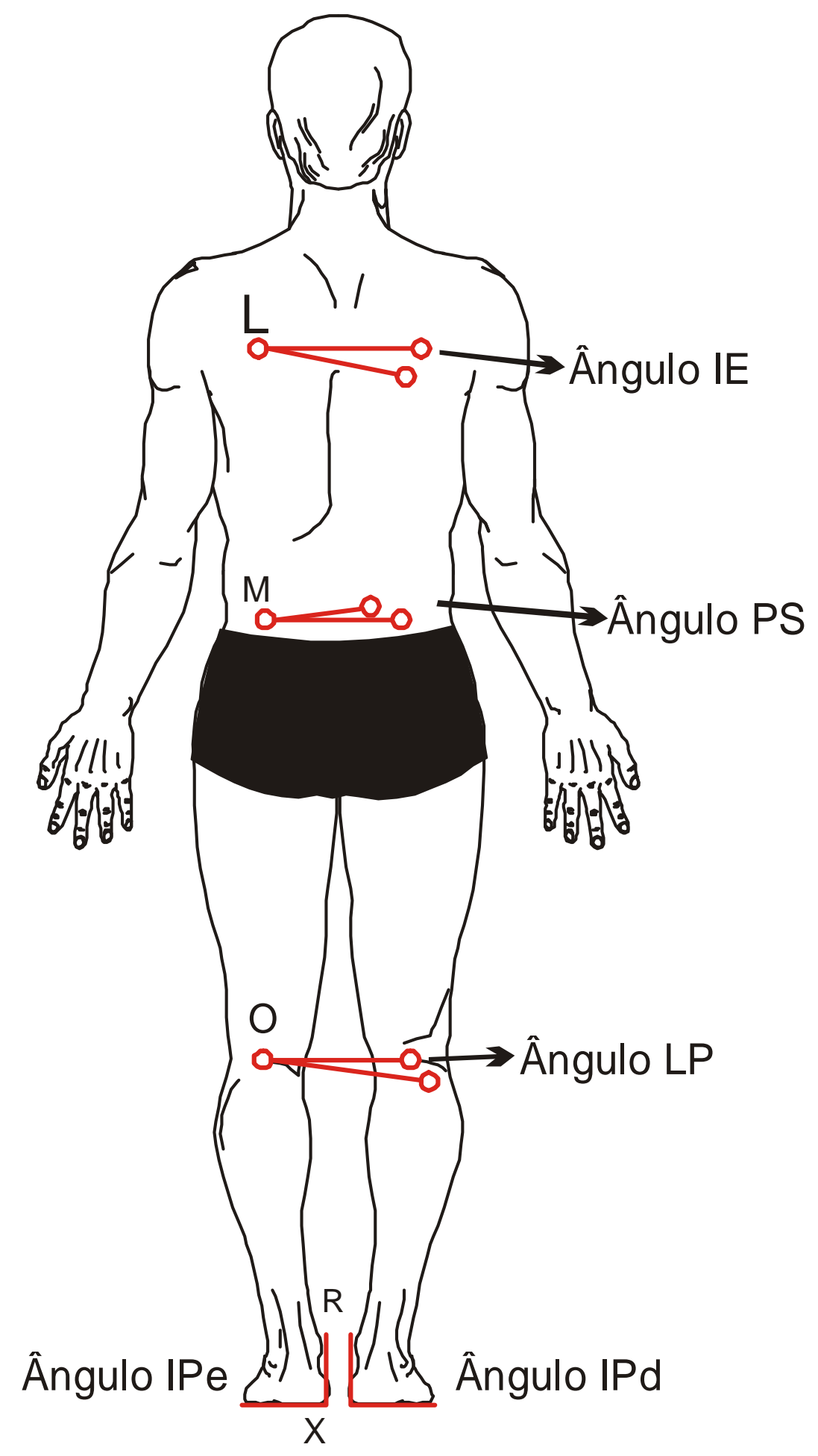

Figura 12- Pontos marcados e ângulos avaliados no plano frontal posterior, onde $L$ (ponto do ângulo inferior da escapula), M (EIPS), O (Linha poplítea), R (maléolo medial), X (bordo interno do pé) IE (ângulo inferior da escapula), PS (ângulo das espinhas ilíacas póstero-superiores), LP (ângulo das linhas poplíteas), IPd (ângulo de inclinação do pé direito) e IPe (ângulo de inclinação do pé esquerdo). 


\subsubsection{3 Ângulos da face}

Para melhor definição da imagem, os seguintes ângulos foram mensurados nas imagens obtidas somente da face, em vista anterior e foram formados entre as linhas traçadas unindo o ponto anatômico demarcado à direita com o da esquerda e a linha traçada na horizontal, paralelamente ao solo.

- OE: ângulo do orbicular externo (Figura 13)

- CL: ângulo da comissura labial (Figura 13)

- AO: ângulo da articulação acrômio clavicular (Figura 13)

- EC: ângulo da articulação esternoclavicular (Figura 13)

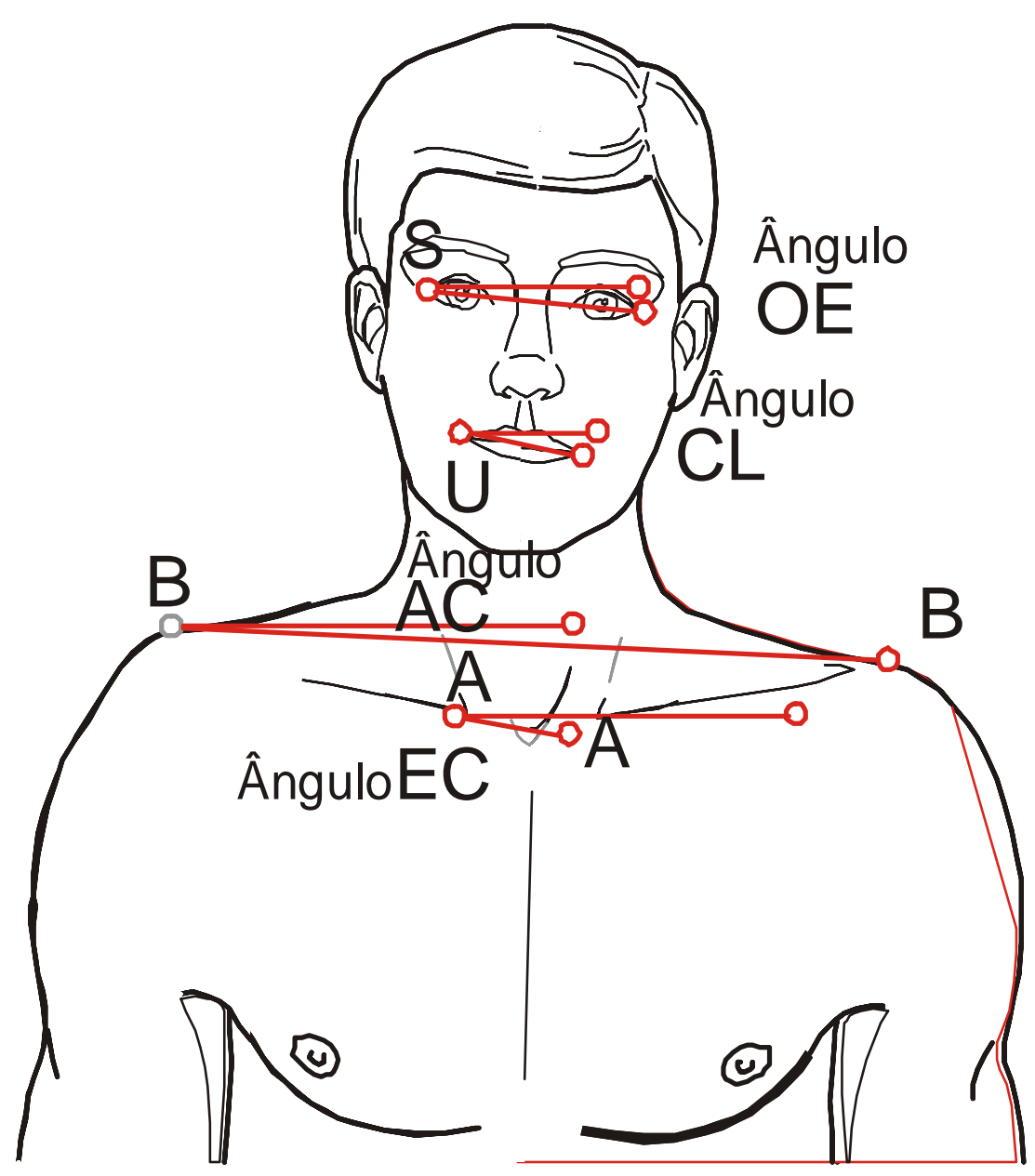

Figura 13- Pontos e ângulos avaliados na foto da face onde, A (ponto da esternoclavicular), B (ponto da acrômio clavicular), U (ponto da comissura labial), S (ponto do orbicular externo), OE (ângulo do orbicular externo), CL (ângulo da comissura labial), AO (ângulo da articulação acrômio clavicular) e EC (ângulo da articulação esternoclavicular) 


\subsubsection{4 Ângulos do plano sagital}

No plano sagital os ângulos foram formados, unindo os pontos descritos anteriormente e assim denominados:

- PC (ângulo de protusão da cabeça): formado pela intersecção da reta que unia os pontos $\mathrm{V}$ (tragus da orelha) e $\mathrm{G}$ (processo espinhoso de $\mathrm{C}_{7}$ ) com a reta paralela ao solo (Figura 14)

- LC (ângulo da lordose cervical): formado pela intersecção da reta que unia os pontos $E$ (protuberância occipital) e prolongamento horizontal do ponto $F$ (processo espinhoso de $\mathrm{C}_{4}$ ) no fio de prumo com a reta que unia os pontos $G$ (processo espinhoso de $\mathrm{C}_{7}$ ) e prolongamento horizontal do ponto $\mathrm{F}$ (processo espinhoso de $\mathrm{C}_{4}$ ) no fio de prumo (Figura 14).

- CT (ângulo da cifose torácica): formado pela intersecção da reta que unia os pontos $G$ (processo espinhoso de $C_{7}$ ) e prolongamento horizontal do ponto $H$ (processo espinhoso de $T_{7}$ ) no fio de prumo com a reta que unia os pontos I (processo espinhoso de $T_{12}$ ) e prolongamento horizontal do ponto $H$ (processo espinhoso de $T_{7}$ ) no fio de prumo (Figura 14).

- LL (ângulo da lordose lombar): formado pela intersecção da reta que unia os pontos I (processo espinhoso de $\mathrm{T}_{12}$ ) e prolongamento horizontal do ponto $\mathrm{H}$ (processo espinhoso de $T_{7}$ ) no fio de prumo com a reta que unia os pontos $K$ (processo espinhoso de $L_{5}$ ) e prolongamento horizontal do ponto $H$ (processo espinhoso de $T_{7}$ ) no fio de prumo (Figura 14).

- BP (ângulo da báscula pélvica): formado pela intersecção da reta que unia os pontos $\mathrm{N}$ (EIPI) e C (EIAS) com a reta paralela ao solo (Figura 14). 
- FJ (ângulo flexo de joelho): formado pela intersecção da reta que unia os pontos $P$ (trôcanter maior) e ponto $Q$ (cabeça da fíbula) com a reta que unia os ponto $Q$ e ponto R (maléolo lateral) (Figura 14).

- ATT (ângulo tíbio társico): formado pela intersecção da reta que unia os pontos $Q$ (cabeça da fíbula) e ponto $R$ (maléolo lateral) com a reta que unia os ponto $R$ e ponto $S$ (tuberosidade da diáfise distal do $5^{\circ}$ metatarso) (Figura 14).
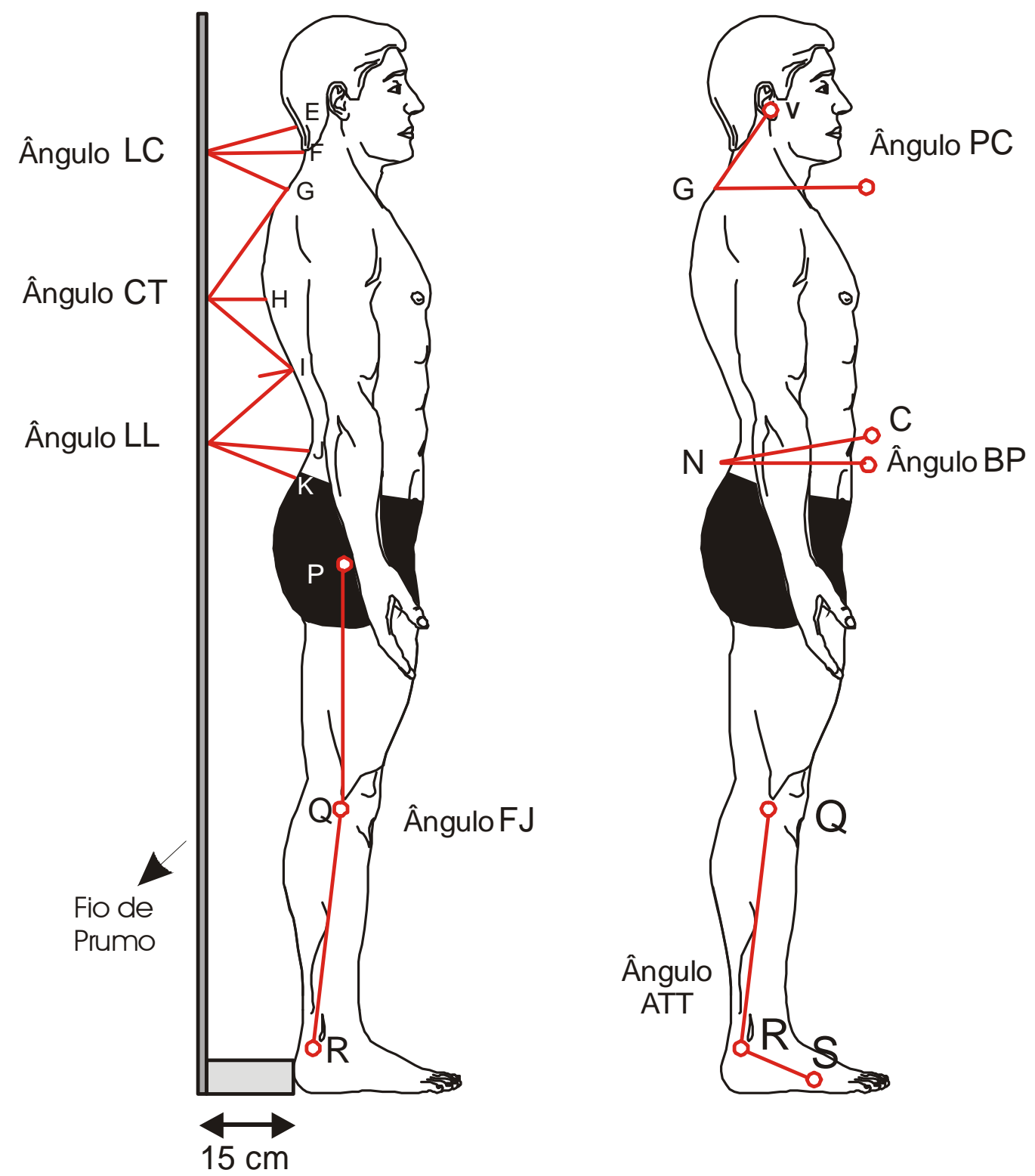

Figura 14- Pontos e ângulos avaliados na vista lateral direita, onde $E$ (ponto da protuberância occipital), $F$ (ponto de $\mathrm{C}_{4}$ ),, $\mathrm{G}$ (ponto de $\mathrm{C}_{7}$ ), $\mathrm{H}$ (ponto de $\mathrm{T}_{7}$ ), I (ponto de $\mathrm{T}_{12}$ ), $\mathrm{J}$ (ponto de $\mathrm{L}_{3}$ ), $\mathrm{K}$ (ponto de $\mathrm{L}_{5}$ ), $\mathrm{N}$ (ponto da EIPI), $P$ (ponto do trocânter maior), $Q$ (ponto da cabeça da fíbula), $R$ (maléolo lateral), $S$ (ponto tuberosidade da diáfise do $5^{\circ}$ dedo), V (ponto do tragus), PC (protusão da cabeça), LC (lordose cervical), CT (cifose torácica), LL (lordose lombar), BP (báscula pélvica), FJ (flexo de joelho), ATT (ângulo tíbio társico). 
Nem todos os ângulos propostos nesse trabalho foram descritos por outros autores. De todos eles, os seguintes foram definidos neste trabalho: EC, BP, FJ, ATT, IP, AJ. Os ângulos PS, LP e $\Delta T$ são descritos na literatura, mas foram utilizados de forma qualitativa por Pereira (2003) e Rodrigues et al. (2003).

\subsubsection{Análise de reprodutibilidade (interexaminador)}

Para avaliar o nível de confiança entre os diferentes examinadores (reprodutibilidade), as mesmas fotos foram analisadas por três examinadores diferentes e treinados, em laboratórios diferentes, com computadores diferentes, sem que houvesse conhecimento entre eles dos resultados obtidos.

Para garantir a confiabilidade das medidas angulares na fotogrametria todos os examinadores tiveram o mesmo procedimento. Após a realização das medidas dos ângulos estas eram apagadas e posteriormente repetidas o procedimento mais duas vezes.

\subsubsection{Análise de repetibilidade}

\subsubsection{Análise de repetibilidade intra-examinador}

Para avaliar o nível de confiança de um mesmo examinador (repetibilidade) as mesmas fotos foram examinadas em duas ocasiões diferentes com intervalo de no mínimo quatro semanas, para que este examinador não memorizasse os resultados, conforme Watson e Macdonncha (2000) 


\subsubsection{Análise da repetibilidade do método de avaliação postural}

A fim de verificar a reprodutibilidade do método utilizado, os mesmos voluntários foram novamente fotografados e todos os procedimentos repetidos sete dias depois pelo mesmo experimentador.

\subsection{Análise dos ângulos no software}

As fotografias armazenadas em disquetes foram analisadas através do programa ALCimagem-2000. Para as fotografias do plano frontal anterior, posterior e de face a análise foi realizada marcando com o mouse o ponto demarcado do dímero direito traçando uma reta até o ponto demarcado do dímero esquerdo e retornando para direita com uma reta horizontal paralela ao solo.

Para as fotografias no plano sagital, inicialmente era traçada o fio de prumo a partir do marcador de E.V.A. colocado no chão. Em seguida foram traçadas linhas dos pontos de $C_{4}, T_{7}, L_{3}$. Depois foram analisados os ângulos como já descritos anteriormente.

Ao terminar de traçar os ângulos o programa já apresenta a medida em graus.

\subsection{Análise Estatística}

A análise de confiabilidade interexaminador, intra-examinador e da repetibilidade do método foi testada pelo coeficiente de correlação intraclasse (Intraclass correlation coefficient - ICC). O ICC permite avaliar em que extensão as múltiplas medidas estão de acordo (são iguais). Para esses cálculos foi utilizado os quadrados 
médios dos valores angulares a partir da fotogrametria obtidos pela aplicação de análise de variância (ANOVA), utilizando o programa SPSS $\vee$ 11.5. O nível de significância adotado foi de $5 \%$, de forma que, $p$-valores $<0,05$ indicam que o ICC é diferente de zero, o que representa resultados concordantes entre as medidas; já para $p$ valores $>0,05$, o ICC é considerado igual a zero, indicando que não há concordância entre os observadores, ou seja, não são confiáveis.

O valor de $I C C=1$ indica que os valores angulares são idênticos nas comparações realizadas. Os valores de ICC foram classificados de acordo com Wahlund, List e Dworkin (1998) que consideraram: 1) excelente confiabilidade para o ICC maior que 0.90; 2) Boa confiabilidade para o ICC entre 0,80 e 0,89; 3) Aceitável para o ICC entre 0,70 e 0,$79 ; 4)$ não aceitável para o ICC menor que 0,70.

Para determinar a variação da fotogrametria ao obter as imagens fotográficas em duas ocasiões diferentes foi calculado o erro padrão da medida. 


\section{RESULTADOS}

\subsection{Resultados da análise de reprodutibilidade (interexaminador)}

A análise dos valores de ICC para confiabilidade interexaminador revelou que as medidas angulares apresentaram níveis aceitáveis (2 ângulos), muito bom (3 ângulos) e excelente (12 ângulos). Não apresentaram níveis aceitáveis os ângulos CT (ICC $=0,603 p=0,0000)$ e LL (ICC $=0,667 p=0,0000)$, obtidos no plano sagital, e IPd $(I C C=0,586 p=0,0000)$ e IPe $(I C C=0,594 p=0,0000)$, no plano frontal posterior. Para todas as medias $p<0,05$. (Tabela 1 )

Os valores angulares médios obtidos à partir de três medidas para cada ângulo e para cada examinador de 21 voluntários são apresentados nas tabelas 5, 6, 7, 8 e 9 (Apêndice). 
Tabela 1- Valores de ICC para as medidas obtidas interexaminadores nos três planos $\mathrm{A}$ (anterior), $\mathrm{P}$ (posterior), S (sagital) e $\mathrm{F}$ (face). A média representa os valores angulares obtidos a partir de três medidas $(n=21)$.

\begin{tabular}{|c|c|c|c|c|}
\hline PLANOS & ÂNGULOS & ICC & MÉDIA & NÍVEL \\
\hline A & AS (EIAS) & 0,905 & $0,23^{\circ}$ & Excelente \\
\hline A & AJd (angulação do joelho direito) & 0,984 & $174,94^{\circ}$ & Excelente \\
\hline$A$ & AJe (angulação do joelho esquerdo) & 0,943 & $177,29^{\circ}$ & Excelente \\
\hline A & $\Delta \mathrm{Td}$ (triângulo de Talles direito) & 0,854 & $14,03^{\circ}$ & Muito bom \\
\hline A & $\Delta \mathrm{Te}$ (triângulo de Talles esquerdo) & 0,904 & $15,25^{\circ}$ & Excelente \\
\hline$P$ & IE (ângulo. Inferior da escápula) & 0,992 & $-0,64^{\circ}$ & Excelente \\
\hline$P$ & PS (EIPS) & 0,954 & $-1,00^{\circ}$ & Excelente \\
\hline$P$ & LP (linha poplítea) & 0,909 & $-0,37^{\circ}$ & Excelente \\
\hline$P$ & IPd (inclinação do pé direito) & 0,586 & $91,95^{\circ}$ & Ñ-aceitável \\
\hline$P$ & IPe (inclinação do pé esquerdo) & 0,594 & $92,86^{\circ}$ & $\tilde{N}$-aceitável \\
\hline$S$ & PC (protusão de cabeça) & 0,897 & $54,35^{\circ}$ & Muito bom \\
\hline S & LC (lordose cervical) & 0,748 & $64,81^{\circ}$ & Aceitável \\
\hline S & CT (cifose torácica) & 0,603 & $126,91^{\circ}$ & $\tilde{N}$-aceitável \\
\hline$S$ & LL (lordose lombar) & 0,667 & $85,60^{\circ}$ & Ñ-aceitável \\
\hline$S$ & BP (bascule de pelve) & 0,996 & $3,45^{\circ}$ & Excelente \\
\hline S & FJ (flexo de joelho) & 0,996 & $182,78^{\circ}$ & Excelente \\
\hline S & ATT (ângulo tibio társico) & 0,840 & $113,12^{\circ}$ & Muito bom \\
\hline $\mathrm{F}$ & OE (orbicular externo) & 0,962 & $-2,24^{\circ}$ & Excelente \\
\hline $\mathrm{F}$ & CL (comissura labial) & 0,714 & $-2,51^{\circ}$ & Aceitável \\
\hline $\mathrm{F}$ & AC (acrômio clavicular) & 0,957 & $-1,89^{\circ}$ & Excelente \\
\hline $\mathrm{F}$ & EC (esternoclavicular) & 0,941 & $-2,75^{\circ}$ & Excelente \\
\hline
\end{tabular}




\subsection{Resultados da análise da repetibilidade}

\subsubsection{Resultados da análise da repetibilidade intra - examinador}

A análise dos valores de ICC para confiabilidade intra-examinadores ou testereteste evidenciou que as medidas angulares apresentaram níveis aceitáveis (2 ângulos) e excelente (16 ângulos). O ângulo CT (ICC =0,031 $p=0,4046)$, medido no plano sagital sendo considerado não aceitável. Da mesma forma, as medidas para o ângulo FJ, apesar de apresentar $p=0,0000$, o valor de ICC é não aceitável (ICC $=$ 0,385) (Tabela 2).

Os valores angulares médios obtidos à partir de três medidas para cada ângulo e do mesmo examinador de 21 voluntários realizadas com um mês de diferença são apresentados nas tabelas 10, 11, 12, 13 e 14 (Apêndice). 
Tabela 2- Valores de ICC para as medidas obtidas intra-examinadores nos três planos $A$ (anterior), $P$ (posterior), S (sagital) e $\mathrm{F}$ (face). A média representa os valores angulares obtidos a partir de três medidas $(n=21)$.

\begin{tabular}{|c|c|c|c|c|}
\hline PLANOS & ÂNGULOS & ICC & MÉDIA & NÍVEL \\
\hline A & AS (EIAS) & 0,903 & $0,21^{\circ}$ & Excelente \\
\hline A & AJd (angulação do joelho direito) & 0,923 & $174,97^{\circ}$ & Excelente \\
\hline A & AJe (angulação do joelho esquerdo) & 0,955 & $177,13^{\circ}$ & Excelente \\
\hline A & $\Delta \mathrm{Td}$ (triângulo de Talles direito) & 0,980 & $14,07^{\circ}$ & Excelente \\
\hline A & $\Delta \mathrm{Te}$ (triângulo de Talles esquerdo) & 0,981 & $15,41^{\circ}$ & Excelente \\
\hline$P$ & IE (ângulo. Inferior da escápula) & 0,990 & $-0,54^{\circ}$ & Excelente \\
\hline$P$ & PS (EIPS) & 0,636 & $-0,75^{\circ}$ & $\tilde{N}$-aceitável \\
\hline$P$ & LP (linha poplítea) & 0,972 & $-0,25^{\circ}$ & Excelente \\
\hline$P$ & IPd (inclinação do pé direito) & 0,700 & $90,74^{\circ}$ & Aceitável \\
\hline$P$ & IPe (inclinação do pé esquerdo) & 0,783 & $92,59^{\circ}$ & Aceitável \\
\hline$S$ & PC (protusão de cabeça) & 0,983 & $54,12^{\circ}$ & Excelente \\
\hline$S$ & LC (lordose cervical) & 0,966 & $54,78^{\circ}$ & Excelente \\
\hline$S$ & CT (cifose torácica) & $0,031^{*}$ & $124,25^{\circ}$ & $\tilde{N}$-aceitável \\
\hline$S$ & LL (lordose lombar) & 0,999 & $71,42^{\circ}$ & Excelente \\
\hline$S$ & BP (bascule de pelve) & 0,999 & $3,55^{\circ}$ & Excelente \\
\hline$S$ & FJ (flexo de joelho) & 0,385 & $182,71^{\circ}$ & $\tilde{N}$-aceitável \\
\hline$S$ & ATT (ângulo tibio társico) & 0,988 & $113,07^{\circ}$ & Excelente \\
\hline $\mathrm{F}$ & OE (orbicular externo) & 0,990 & $-2,44^{\circ}$ & Excelente \\
\hline $\mathrm{F}$ & $\mathrm{CL}$ (comissura labial) & 0,962 & $-2,68^{\circ}$ & Excelente \\
\hline $\mathrm{F}$ & AC (acrômio clavicular) & 0,992 & $-1,90^{\circ}$ & Excelente \\
\hline $\mathrm{F}$ & EC (esternoclavicular) & 0,957 & $-2,63^{\circ}$ & Excelente \\
\hline
\end{tabular}




\subsubsection{Resultados da análise da repetibilidade do método de avaliação postural}

A tabela 3 apresenta o ICC da repetibilidade do método, onde a medida dos valores angulares de quatorze ângulos não mostraram níveis aceitáveis de repetibilidade do método $(\mathrm{ICC}<0,700)$. Os demais valores foram considerados aceitáveis (4 ângulos), muito bom (2 ângulos), e excelente (1 ângulo).

Os valores angulares médios obtidos à partir de três medidas para cada ângulo e do mesmo examinador de 21 voluntários realizadas em duas ocasiões diferentes são apresentados nas tabelas 15, 16, 17, 18 e 19 (Apêndice). 
Tabela 3- - Valores de ICC para as medidas obtidas na repetibilidade do método de avaliação nos três planos A (anterior), P (posterior), S (sagital) e F(face). A média representa os valores angulares obtidos a partir de três medidas $(n=21)$.

\begin{tabular}{|c|c|c|c|c|}
\hline PLANOS & ÂNGULOS & ICC & MÉDIA & NÍVEL \\
\hline A & AS (EIAS) & 0,563 & $0,02^{\circ}$ & $\tilde{N}$-aceitável \\
\hline A & AJd (angulação do joelho direito) & 0,575 & $175,85^{\circ}$ & $\tilde{N}$-aceitável \\
\hline A & AJe (angulação do joelho esquerdo) & 0,765 & $175,57^{\circ}$ & Aceitável \\
\hline A & $\Delta \mathrm{Td}$ (triângulo de Talles direito) & 0,867 & $15,20^{\circ}$ & Muito bom \\
\hline A & $\Delta \mathrm{Te}$ (triângulo de Talles esquerdo) & 0,922 & $15,77^{\circ}$ & Excelente \\
\hline$P$ & IE (ângulo. Inferior da escápula) & $0,198^{*}$ & $1,49^{\circ}$ & $\tilde{N}$-confiável \\
\hline$P$ & PS (EIPS) & 0,454 & $-1,22^{\circ}$ & $\tilde{N}$-aceitável \\
\hline$P$ & LP (linha poplítea) & 0,489 & $0,02^{\circ}$ & $\tilde{N}$-aceitável \\
\hline$P$ & IPd (inclinação do pé direito) & 0,863 & $90,89^{\circ}$ & Muito bom \\
\hline$P$ & IPe (inclinação do pé esquerdo) & 0,729 & $90,34^{\circ}$ & Aceitável \\
\hline$S$ & PC (protusão de cabeça) & 0,737 & $52,02^{\circ}$ & Aceitável \\
\hline$S$ & LC (lordose cervical) & 0,451 & $35,09^{\circ}$ & $\tilde{N}$-aceitável \\
\hline S & CT (cifose torácica) & 0,329 & $83,29^{\circ}$ & $\tilde{N}$-aceitável \\
\hline S & LL (lordose lombar) & 0,482 & $56,30^{\circ}$ & $\tilde{N}$-aceitável \\
\hline$S$ & BP (bascule de pelve) & 0,501 & $2,84^{\circ}$ & $\tilde{N}$-aceitável \\
\hline$S$ & FJ (flexo de joelho) & 0,782 & $184,48^{\circ}$ & Aceitável \\
\hline$S$ & ATT (ângulo tibio társico) & 0,680 & $109,91^{\circ}$ & $\tilde{N}$-aceitável \\
\hline $\mathrm{F}$ & OE (orbicular externo) & 0,688 & $-0,75^{\circ}$ & $\tilde{N}$-aceitável \\
\hline $\mathrm{F}$ & CL (comissura labial) & 0,560 & $-1,01^{\circ}$ & $\tilde{N}$-aceitável \\
\hline $\mathrm{F}$ & AC (acrômio clavicular) & 0,535 & $-1,22^{\circ}$ & $\tilde{N}$-aceitável \\
\hline $\mathrm{F}$ & EC (esternoclavicular) & 0,300 & $-1,11^{\circ}$ & $\tilde{N}$-aceitável \\
\hline
\end{tabular}


Foi calculado o erro padrão de cada ângulo analisado, a partir das médias dos resultados da análise de repetibilidade do método. O erro padrão traduz a variação da postura do indivíduo e o erro experimental (GUARATINI, 1999). É essencial estabelecer o erro para que ao repetir a fotografia para ser analisada através da fotogrametria, o terapeuta ou pesquisador deve estar ciente que as variações de medida apresentadas na tabela 4 são esperadas de serem encontradas. Só poderá ser considerada uma melhora ou piora na postura do voluntário quando a variação da medida for superior ao ângulo apresentado como erro padrão. 
Tabela 4- Valores do erro padrão para as medidas obtidas pela repetibilidade do método de avaliação nos três planos, A (anterior), $\mathrm{P}$ (posterior), $\mathrm{S}$ (sagital) e $\mathrm{F}($ face),

\begin{tabular}{|c|c|c|}
\hline PLANOS & ÂNGULOS & $\begin{array}{c}\text { Erro Padrão } \\
\quad(E P)\end{array}$ \\
\hline A & AS (EIAS) & $0,396^{\circ}$ \\
\hline$A$ & AJd (angulação do joelho direito) & $0,211^{\circ}$ \\
\hline A & AJe (angulação do joelho esquerdo) & $0,312^{\circ}$ \\
\hline A & $\Delta \mathrm{Td}$ (triângulo de Talles direito) & $0,802^{\circ}$ \\
\hline$A$ & $\Delta T e$ (triângulo de Talles esquerdo) & $0,863^{\circ}$ \\
\hline$P$ & IE (ângulo. Inferior da escápula) & $0,543^{\circ}$ \\
\hline$P$ & PS (EIPS) & $0,426^{\circ}$ \\
\hline$P$ & LP (linha poplítea) & $0,288^{\circ}$ \\
\hline$P$ & IPd (inclinação do pé direito) & $0,708^{\circ}$ \\
\hline$P$ & IPe (inclinação do pé esquerdo) & 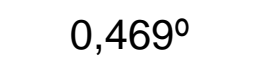 \\
\hline S & PC (protusão de cabeça) & $0,602^{\circ}$ \\
\hline S & LC (lordose cervical) & $1,345^{\circ}$ \\
\hline S & CT (cifose torácica) & $1,605^{\circ}$ \\
\hline S & LL (lordose lombar) & $1,486^{\circ}$ \\
\hline S & BP (bascule de pelve) & $0,682^{\circ}$ \\
\hline S & FJ (flexo de joelho) & $0,979^{\circ}$ \\
\hline$S$ & ATT (ângulo tibio társico) & $0,751^{\circ}$ \\
\hline $\mathrm{F}$ & OE (orbicular externo) & $0,482^{\circ}$ \\
\hline $\mathrm{F}$ & CL (comissura labial) & $0,430^{\circ}$ \\
\hline $\mathrm{F}$ & AC (acrômio clavicular) & $0,341^{\circ}$ \\
\hline $\mathrm{F}$ & EC (esternoclavicular) & $0,602^{\circ}$ \\
\hline
\end{tabular}




\section{DISCUSSÃO}

Há poucos trabalhos dentro da área da fisioterapia utilizando a fotogrametria de forma quantitativa para avaliar a postura. Muitos dos trabalhos encontrados são produzidos na área de odontologia e cirurgia plástica. Nesse estudo é sugerida uma proposta de avaliação para quantificar a postura, utilizando ângulos já descritos na literatura e outros ainda não estudados.

A fotogrametria é um instrumento de avaliação postural quantitativo que permite a partir de medidas angulares reproduzir uma avaliação postural. Houve uma preocupação neste trabalho de utilizar como referência as regiões do corpo que já são utilizados pelos profissionais de forma qualitativa e que os fisioterapeutas já estão habituados a localizar. O objetivo foi propor ângulos simples, de certa forma, já utilizados como referência na avaliação postural clássica, que podem ser adotados por outros profissionais. Alguns autores descrevem ângulos muito diferentes do que estamos acostumados a utilizar na prática clínica, analisando a distância das estruturas anatômicas ao solo, estabelecendo uma relação com a distância entre os pontos anatômicos do dímero direito e esquerdo do corpo, dificultando a leitura e interpretação dos dados (ZONNENNBERG et al.,1996)

Os dados serão discutidos segundo a apresentação dos resultados, inicialmente serão discutidos os dados referentes à análise interexaminador, posteriormente a análise intra-examinador e para finalizar os dados referentes a repetibilidade do método de avaliação. 


\subsection{Análise da reprodutibilidade (interexaminador)}

As medidas dos ângulos propostos na análise interexaminador são confiáveis e podem ser utilizadas com o software ALCimagem. A maioria dos ângulos analisados (12 ângulos) apresentou um ICC excelente, maior que 0,900 e três ângulos foram considerados muito bons, pois o ICC foi entre 0,800 e 0,890. Como apresentado a seguir: $\mathrm{OE}(\mathrm{ICC}=0,962), \mathrm{AC}(\mathrm{ICC}=0,957), \mathrm{EC}(\mathrm{ICC}=0,941)$; do plano frontal anterior AS $(0,905)$, AJd $(\mathrm{ICC}=0,984)$, AJe $(\mathrm{ICC}=0,943), \Delta \mathrm{Td}(\mathrm{ICC}=0,854), \Delta \mathrm{Te}(\mathrm{ICC}=$ $0,904)$; do plano frontal posterior IE $(\operatorname{ICC}=0,992)$, PS $(\operatorname{ICC}=0,954)$, LP $(\operatorname{ICC}=0,909)$ e do plano sagital PC $($ ICC $=0,897)$, BP $(0,996)$, FJ $(I C C=0,996)$ e ATT $($ ICC $=$ 0,840). (Tabela 1).

Poucos trabalhos analisaram a confiabilidade interexaminador utilizando esses ângulos. Apenas Bishara et al. (1995) avaliaram os ângulos OE e CL e relataram que seus resultados apresentaram boa confiabilidade.

Sem a preocupação de verificar a confiabilidade interexaminador, Ferrario et al. (1995) também utilizaram os ângulos OE e CL para avaliar a posição natural da cabeça de 303 crianças e adultos jovens saudáveis. Demonstrando que não houve diferenças significativas entre os dois grupos.

Estes pontos anatômicos foram referência para o trabalho de Farkas et al. (1980) que compararam as medidas através da fotogrametria com a medida antropométrica diretamente na face do voluntário e descrevem que a distância entre os olhos e entre as comissuras labiais por serem facilmente visualizadas na fotografia têm alta porcentagem de confiabilidade.

Outro trabalho que verificou a confiabilidade interexaminador foi o de Watson e Macdonncha (2000) que avaliaram os ângulos AC, AJ, IE. Estes autores concordam 
com os resultados desse trabalho, pois todos esses ângulos apresentaram excelente intervalo de confiança (superior a $80 \%$ ).

A avaliação qualitativa do alinhamento do joelho no plano frontal com fotografia descrita por estes autores atribuiu como genum varum quando as imagens mostraram que os voluntários uniam os pés, porém não encostavam os côndilos femurais; foi considerado genum valgo, quando as imagens mostravam que os voluntários aproximavam os joelhos, mas não uniam os calcanhares; joelho com alinhamento normal, quando os participantes encostavam joelhos e pés simultaneamente. No entanto, esta forma de medir não quantifica o alinhamento, por isso foi proposto nesse trabalho a medida do ângulo AJ com o objetivo de reproduzir a descrição de Kapandji (2001) para o alinhamento do joelho no plano frontal. Sendo o grau de normalidade desse ângulo entre $170^{\circ}$ a $175^{\circ}$, valores menores que $170^{\circ}$ indicam um genum valgo e maiores que $175^{\circ}$ um genum varo.

Como não foram encontrados outros trabalhos que analisaram a confiabilidade interexaminador para a medida dos outros ângulos analisados, discutiremos a seguir a utilização, por diferentes autores dos mesmos ângulos propostos em nossa avaliação postural.

Pereira (2003) descreveu em seu trabalho os ângulos AC, AS, IE, OS, LP, fazendo uma correlação entre avaliação postural visual tradicional e avaliação postural através da fotogrametria. Este autor descreve apenas que há uma coerência na percepção de assimetrias desses ângulos através das duas técnicas de avaliação, no entanto sem apresentar dados quantitativos.

A avaliação do $\Delta T$ é descrita por Rodrigues et al. (2003) que utilizaram a Técnica de Moiré para analisar a presença de simetrias ou assimetrias dessa região e 
do ombro.Esses autores demonstraram que essa técnica foi capaz de detectar essas assimetrias, mas da mesma forma sem quantificá-las.

O ângulo PC também foi analisado quantitativamente nos trabalhos de Lee, Okenson e Lindroth (1995) e Visscher et al. (2002) para avaliar a posição da cabeça em indivíduos com disfunção craniomandibular.

$\mathrm{Na}$ análise do ICC das curvaturas vertebrais no plano sagital revelaram que os ângulos CT e LL não são aceitáveis (ICC de 0,603 e 0,667 respectivamente) e apenas o ângulo LC apresentou ICC aceitável (ICC =0,748).

A análise das curvaturas por métodos diferentes dos de imagem seja, radiografia, tomografia computadorizada ou ressonância magnética, como a fotogrametria é sempre controverso e na maioria das vezes, realizada de forma qualitativa.

$\mathrm{Na}$ literatura, a análise de curvaturas como lordose cervical e lombar com fotografias é descrita no trabalho de Fedorak et al. (2003). Estes autores fazem uma análise qualitativa das fotografias interexaminador, apresentando pobre concordância, pois o Kappa encontrado foi de 0,16 e relataram que é difícil haver boa concordância utilizando a avaliação visual qualitativa. Por outro lado, Watson e Macdonncha (2000) ao avaliarem a lordose lombar qualitativamente através de fotografia, verificaram um excelente intervalo de confiança interexaminador, maior que $80 \%$.

A medida do ângulo CT tem sido utilizada por outros autores (GRANITO et al. 2004). No entanto, apenas Lundon, Li e Bibershtein (1998) testaram a confiabilidade dessa medida, discordando dos resultados desse trabalho, verificaram que a medida do ângulo CT apresentou ICC > 0,870 para os diferentes métodos testados: cifômetro, a flexicurva e a radiografia. 
Estes valores superam o obtido com a fotogrametria $(\mathrm{ICC}=0,603)$ que revelou que a medida do ângulo CT apresenta índices não aceitáveis de confiabilidade. Portanto, deve ser utilizado com critérios.

Os pontos do plano sagital apresentaram um índice de confiabilidade menor que os do plano frontal para análise interexaminador. Esses dados concordam com a descrição de Bishara et al. (1995) e Normand et al. (2002) que relataram que a análise no plano sagital, ou seja, das curvaturas da coluna através de fotografias é complexo porque é uma análise unidimensional e estas alterações são tridimensionais. Sendo assim, é importante neste plano definir os critérios para normalidade, pois no plano frontal o esperado é que o valor do ângulo seja próximo de zero, ou seja, uma menor assimetria. Mas no plano sagital isto modifica porque o normal é haver ângulos, que são as lordoses cervical e lombar e a cifose dorsal.

Os ângulos inclinação dos pés (IP) nessa pesquisa para análise interexaminador foram considerados não aceitáveis, pois o ICC foi menor que 0,700 $(\mathrm{IPd}=0,586 ; \mathrm{IPe}=0,590)$. A avaliação da inclinação dos pés $(\mathrm{IP})$ proposta neste trabalho, foi usada para permitir uma classificação do calcâneo como normal, valgo ou varo. Se o ângulo IP se aproximasse de 90ำ era considerado normal; maior que 90ํ, como valgo e menor que 90, como varo. A verificação dos ângulos IPd e IPe, não é fácil e simples, há a dificuldade de estabelecer o ponto no maléolo medial, pois não há marcador e a visibilidade do acidente ósseo é difícil.

Watson e Macdonncha (2000) também realizaram uma descrição do calcanhar onde usaram um ângulo formado por uma linha vertical traçada no tendão calcâneo com uma linha horizontal no centro do calcâneo e também encontraram um intervalo de confiança menor $(66,6 \%)$. 
A análise interexaminador revelou que os ângulos propostos apresentam boa confiabilidade em suas medidas através do software ALCimagem. No entanto os ângulos do plano sagital como CT e LL exigem atenção especial. Os ângulos propostos para avaliação do posicionamento dos pés não foram confiáveis e não deveriam ser utilizados.

\subsection{Análise da repetibilidade}

\subsubsection{Análise da repetibilidade intra-examinador}

$\mathrm{Na}$ análise intra-examinador a maioria dos ângulos apresentou excelente confiabilidade (ICC maior que 0,900). Os ângulos IPd $(I C C=0,700)$ e IPe $(I C C=$ $0,783)$ foram considerados aceitáveis. Os ângulos PS (ICC $=0,636)$ e o FJ (ICC $=$ $0,385)$ foram considerados não aceitáveis e a cifose torácica foi considerada sem confiabilidade, pois o $\mathrm{p}<0,05$.

Na literatura foram encontrados poucos trabalhos que fizeram uma análise intraexaminador, dificultando a comparação dos resultados.

Os resultados desse trabalho para os ângulos AC, IE, ATT, LL e FJ concordam com Watson e Macdonncha (2000) que encontraram um índice de confiança, maior que $80 \%$.

Apesar desses autores verificarem o mesmo índice para o ângulo FJ, nossos resultados não confirmaram estes dados, pois o ICC intra-examinador foi de 0,385. Essa discordância inicialmente pode ser atribuída ao fato de que os autores não utilizaram medidas precisas como as que foram utilizadas nesse trabalho. As 
alterações foram classificadas como leve, moderada ou grave, portanto menos susceptíveis a erro.

O ângulo PC também foi avaliado através do ICC intra-examinador por Johnson (1998) que concordando com os resultados deste trabalho, também verificaram excelente confiabilidade.

Na literatura, a análise intra-examinador de curvaturas como lordose cervical e lombar com fotografias é descrita no trabalho de Fedorak et al. (2003), que da mesma forma que na análise interexaminador, os valores de confiabilidade foram baixos. Discordando de nossos resultados, pois encontramos um ICC > 0,960. Esta diferença pode ser atribuída pelas diferenças metodológicas, pois Fedorak et al. (2003) analisaram qualitativamente. No que se refere às curvaturas vertebrais estão mais sujeitas a confundir sua classificação na análise qualitativa devido a influencia da posição do occipital em relação a cervical, das escápulas em relação a dorsal e da pelve em relação a lombar. Entretanto, em nosso trabalho usamos os marcadores diretamente na coluna vertebral.

Por outro lado, Youdas et al. (1996) avaliaram a curvatura lombar utilizando um inclinômetro e o ICC intra-examinador apresentou excelente confiabilidade (ICC = $0,82)$, coincidindo com os resultados dessa pesquisa.

Na literatura não há descrição de análise intra-examinador dos ângulos $A S, A J$, $\Delta T, P S, L P, I P, B P, O E, C L, E C$.

Assim como na análise interexaminador, esses ângulos apresentaram excelente repetibilidade entre um mesmo examinador. Portanto, os ângulos propostos e medidos através do software ALCimagem apresentam confiabilidade e podem ser utilizados para avaliação postural. 
Apesar da classificação de Wahlund et al. (1998) considerar como não aceitáveis o ICC $<0,700$, para Youdas et al. (1996) o ICC entre 0,400 e 0,750 pode ser considerado bom para regular. Portanto, o ICC para o ângulo PS que foi de 0,63 está muito próximo do aceitável por Wahlund et al. (1998) e de bom para Youdas et al. (1996). Porém este mesmo ângulo apresentou ICC de 0,954 na análise interexaminador, sugerindo que se trata de um ângulo cuja medida pode ser utilizada através do software ALCimagem.

$\mathrm{Na}$ análise intra-examinador, isto é, realizada as mesmas medidas, nas mesmas fotografias, em dias diferentes, espera-se maior concordância do que na análise interexeminador. No entanto, o ICC dos ângulos CT e FJ apresentaram valores surpreendentemente baixos (ICC $=0,031$ e 0,385 respectivamente).

A realização dessas medidas de forma cumulativa, ou seja, várias no mesmo dia e repetitivamente, pois cada medida foi repetida três vezes, favorecem a ocorrência de erros experimentais.

A análise dos diferentes ângulos no software ALCimagem é simples e fácil de realizar. No entanto, as mesmas devem ser realizadas pausadamente e com tranqüilidade do examinador, diminuindo então as chances de erro.

Mesmo com o cansaço e estresse do examinador, a análise intra-examinador revelou que as medidas dos ângulos propostos são na maioria confiáveis.

\subsubsection{Análise da repetibilidade do método}

Inicialmente é necessário distinguir que a repetibilidade do método de avaliação não se refere à repetibilidade das medidas dos ângulos no software ALCimagem e sim à todo o procedimento experimental para o uso da fotogrametria, que compreende 
desde a preparação e iluminação do ambiente com o posicionamento do tripé, da câmera, do voluntário, bem como a colocação dos marcadores, realização da fotografia e digitalização adequada da imagem e finalmente a medida dos ângulos.

Nenhum trabalho foi encontrado na literatura que realizou a análise quantitativa da postura e testou a repetibilidade do método.

Watson e Macdonncha (2000) realizaram uma primeira tentativa de testar a repetibilidade da avaliação postural e obtiveram excelente índice de confiança. No entanto, testou-se a avaliação qualitativa, isto é, foi analisado visualmente através da fotografia, o alinhamento dos ombros, das escápulas, da pelve, dos joelhos e a curvatura lombar. Esta análise qualitativa realizada por profissionais experiente apresenta menor chance de erro. No entanto, os resultados desse trabalho revelaram que dos 21 ângulos analisados 14 apresentaram $\mathrm{ICC}<0,700$, apenas 4 apresentaram ICC aceitáveis, 2 muito bom e 1 excelente

Estes resultados evidenciam que a repetibilidade do método está mais sujeita a erros do que a simples utilização do software.

Isto demonstra que quando a metodologia é repetida em duas ocasiões diferentes o número de variáveis é maior e maior a variabilidade das medidas realizadas. Ou seja, mesmo padronizando as condições para o registro fotográfico, como realizando a fotografia no mesmo horário do dia, com o mesmo examinador, usando o mesmo equipamento fotográfico, o mesmo tripé, o mesmo posicionamento do voluntário e da câmera, o mesmo local, ainda assim as condições do indivíduo podem sofrer modificações inerentes ao procedimento experimental.

Para a realização da segunda fotografia, o tripé, a máquina são reposicionados, mas a fonte de variabilidade pode ser a palpação com a colocação de novos marcadores. Mesmo contando com profissional experiente há 14 anos na área, o 
posicionamento de determinados marcadores, por exemplo, na escápula ou na espinha ilíaca pode ser de difícil reprodutibilidade.

No entanto, mesmos os pontos que não necessitam de marcadores como, por exemplo, o OE e CL apresentaram ICC não aceitáveis $(<0,700)$, sugerindo que outras variáveis não controladas na aplicação do método, ou seja, o controle postural.

A postura pode sofrer variações decorrentes, por exemplo, da dor que pode desencadear uma postura antálgica. A dor foi critério de exclusão para a seleção da amostra avaliada e, portanto não interferiu nos dados.

No entanto, as condições emocionais podem repercutir na postura corporal. O indivíduo que hoje se encontra preocupado e ansioso não apresentará a mesma postura em um dia que estiver tranqüilo e feliz. Estas variáveis não são possíveis de controlar facilmente e, portanto, podem ter influenciado nos resultados.

Da mesma forma, estar diante da câmera fotográfica para alguns pode não ser um gesto natural e como o comando verbal do tipo: "relaxa", "solte os ombros" não podia ser feito para não mascarar os resultados.

Os valores medidos são em graus e pequenas variações numéricas quantificadas pela fotogrametria, pela sensibilidade do método, tais variações são identificadas repercutindo na análise global dos dados.

Independente do valor de ICC para a repetibilidade do método o cálculo do erro padrão é essencial para caracterizar a variação esperada em cada ângulo. A partir daí, é possível estabelecer algum critério para utilização desse método proposto.

Apesar dos valores absolutos do erro padrão serem pequenos, eles representam um valor significativo na média dos ângulos encontrados.

Rodrigues et al. (2003) relatam ainda que os métodos não-invasivos, como a fotogrametria, para avaliação postural pode ser uma alternativa para o 
acompanhamento da postura, mas não excluem a necessidade de radiografia, apenas diminuem sua periodicidade. No entanto, os dados desse trabalho revelaram que a fotogrametria pode ser utilizada com maior confiabilidade para avaliação postural, porém no acompanhamento da postura, onde é necessária a repetição do método, os resultados devem ser interpretados com cautela.

Tüzün et al. (1999) ainda relata que os tecidos moles interferem na análise através das técnicas não invasivas, portanto segundo esse autor o raio-x ainda seria o exame mais confiável para a quantificação das curvaturas vertebrais. Portanto, a fotogrametria não pode ser utilizada para classificar as curvaturas vertebrais.

Esses resultados demonstram que por a fotogrametria ser uma medida de precisão, mínima alteração na realização da fotografia dará resultados diferentes. 


\section{CONCLUSÃO}

A análise interexaminador e intra-examinador revelou que 0 software ALCimagem é confiável e pode ser utilizado para a quantificação das alterações posturais.

Os ângulos propostos para avaliação postural quantificada apresentaram em sua maioria reprodutibilidade e repetibilidade.

O ângulo CT apresenta baixa reprodutibilidade e repetibilidade não sendo recomendável sua utilização.

O erro padrão deve ser considerado se eventuais comparações forem realizadas entre avaliações posturais.

A fotogrametria não é o melhor método para acompanhamento da evolução da postura no decorrer do tratamento, uma vez que a repetibilidade dos vários ângulos utilizados é baixa. 


\section{REFERÊNCIAS}

AMONOO-KUOFI, H. S. Changes in the Lumbosacral Angle Inclination and the curvature of the lumbar Spine during Aging. Acta Anat., v.145, n. 4, p.3733-7, 1992.

BARAÚNA, M.A.; BARBOSA, S. R. M.; CANTO, R. S. T.; SILVA, R. A. V.; SILVA, C. D. C.; BARAÚNA, K. M. P. Estudo do equilíbrio estático de idosos e sua correlação com quedas. Fisioterapia Brasil, v. 5, n.2, p. 136-141, 2004.

BENSON, P. E.; RICHMOND, S. A critical appraisal of measurement of the soft tissue outline using photographs and video. Eur. J. Orthod., Oxford, v.19, n 4, p. 397-409, 1997.

BISHARA, S. E.; CUMMINS, D. M.; JORGENSEN, G. J.; JAKOBSEN, J. R. A computer assissted photogrammetric analysis of soft tissue changes after orthodontic treatment. Part I: methodology and reliability. Am J. Orthod. Dentofacial Orthop.,St. Louis, v.107, n 6, p. 633-639, 1995.

BISTER, D.; EDLER, R. J.; TOM, B. D. M. e PREVOST, A. T. Natural head posture considerations of reproducibility. Eur. J. Orthood., Oxford, v.24, n 5, p. 457-70, 2002.

BRICOT, B. Posturologia. 2. ed. São Paulo: Ícone editora, 2001. 270 p. 
BUENDIA, M.; SALVADOR, R.; CIBRIÁN, R.; LAGUIA, M.; SOTOCA, J.M. Determination of the object surface function by structured light: application to the study of spinal deformities. Phs. Med. Biol. , v.44, n.1, p.75-86, 1999.

BUSQUET, L. As cadeias Musculares. Belo Horizonte: Edições Busquet, 2000. v. 1. $164 \mathrm{p}$.

CARAdONNA, D. e ALVES, F. A. Posturologia A.T.M. : oclusão e postura. J. Bras. Ortodontia Ortop. Maxilar, São Paulo, v.2, n. 12, p. 7-13, 1997.

CLAMAN, L.; PATTON, D. e RASHID, R. Standardized portraid photography for dental patients. Am.J.Orthod. Dentofac. Orthop., Weston, v.98, n. 3, p. 197-205, 1990.

FARIAS, A. C. R.; ALVES, V.C.R. e GANDELMAN, H. Estudo da relação entre disfunção da articulação temporomandibular e as alterações posturais. Rev. Odontol. UNICID, São Paulo, v.13, n.2, p. 125-33, 2001.

FARKAS, L. G.; BRYSON, W.; TECH, B.; KLOTZ, J. Is photogrammetry of the face reliable? Plast. Reconstr. Surg., Philadelphia, v.66, n 3, p. 346-355, 1980.

FEDORAK, C.; ASHWORTH, N.; MARSHALL, J.; PAULL, H. Reliability of the visual assessment of cervical and lumbar lordosis: how good are we? Spine, Philadelphia, v. 28, n. 16: p.1857-59, 2003. 
FERRARIO, V. F.; SFORZA, C.; MIANI JR, A. e BARBINI, E. New televisión techinique for natural head and body posture análisis. The J. of Craniomand.Practice, v.13, n. 4, p.: 247-55, 1995

FERRARIO, V. F,; SFORZA, C; POGGIO, C. E.; SCHMITZ, J. H. Soft- tissue facial morphometry from 6 years to adulthood : a three-dimensional growth study using a new modeling. Plast. Reconstr. Surg., Philadelphia, v.103, n 3, p. 768-778, 1999.

FUENTES, R.; FREESMEYER, W.; HENRÍQUEZ, J. Influencia de la postura corporal em la prevalência de lãs disfunciones craneomandibulares. Rev. Méd. Chile, v. 127, p. 1079-1085, 1999.

GARDOCKI, R. J.; WALTKINS, R. G.; WILLIANS, L. A. Measurements of lumbopelvic lordosis using the pelvic radius technique as it correlates with sagittal balance and sacral translation. Spine, Philadelphia, v.2, n 6, p.421-429, 2002.

GRANITO, R. N.; RENÓ, A. C. M.; AVEIRO,M. C.; NAVEGA, M. T.; DRIUSSO, P.; OISHI, J. Efeitos de um programa de atividade física na postura hipercifótica torácica, na dorsalgia e na qualidade de vida de mulheres com osteoporose. Rev. Bras. de Fisiot., São Carlos, v.8, n.3, p. 231-237, 2004.

GRIEVE, G. P. Moderna terapia manual da coluna vertebral. São Paulo: Panamericana. 897 p. 1994. 
GUARATINI, M. I. Confiabilidade e precisão da medida para teste-reteste no dinamômetro isocinético Biodex. 1999. 111f. Dissertação (Mestrado em Fisioterapia). Universidade Federal de São Carlos; São Carlos, 1999.

HOCKMAN, B.; CASTILHO, H.T.; FERREIRA, L.M.Padronização fotográfica e morfométrica na fotogrametria computadorizada do nariz. Acta Cir. Bras., São Paulo, v.12, n.4, p.258-66, 2002.

JACKSON, R. P.; KANEMURA, T.; KAWAKAMI, N.; HALES, C. Lumbopelvic Lordosis and Pelvic Balance on Repeated Standing Lateral Radiographs of Adult Volunteers and Untreated Patients with Constant Low Back Pain. Spine, Philadelphia, v. 25, n. 5, p. $575-86,2000$.

JOHNSON, G.M. The correlation between surface measurement of head and neck posture and the anatomic position of the upper cervical vertebrae. Spine. Philadelphia, v. 23, n.8, p. 921-27, 1998.

KAPANDJI, I. A. Fisiologia Articular. 5. ed., São Paulo: Editora Médica Panamericana. 2000. v. 3. 253 p.

KENDALL, F.P.; McCREARY, E. K. e PROVANCE, P. E. Músculos : provas e funções. 5. ed. São Paulo: Manole, 1995. 454 p.

KISNER, C. e COLBY, L. A. Exercícios Terapêuticos. São Paulo: Editora Manole, 1987. 699 p. 
KNOPLICH, J. Enfermidades da Coluna Vertebral. 3. ed. São Paulo: Panamed, 2002. 535 p.

LEE, W. Y.; OKENSON, J. P.; LINDROTH, J. The relationship between forward head posture and temporomandibular disorders. J. Orofacial Pain, Carol Stream, v.9, n.2, p. 161-167, 1995.

LEHMKUL, L.D. e SMITH, L.K. Cinesiologia Clínica de Brunnstrom. 4. ed. São Paulo: Editora Manole, 1989. 466 p.

LOVATO M. Relação entre mordida cruzada posterior unilateral e postura corporal. 2001. 120f. Dissertação (Mestrado em Fisioterapia). Centro Universitário do Triângulo; Uberlândia, 2001.

LUNDON, K. L.; LI, A. M. W. Y., BIBERSHTEIN, S. Interrater and intrarater reliability in the measurement of kyphosis in postmenopausal women with osteoporosis. Spine, Philadelphia, v.23, n 18, p. 1978-1985, 1998.

MAANNHEIMER, J. S. e ROSENTHAL, R. M. Acute and chronic postural abnormalities as related to craniofacial pain and temporomandibular disorders. Dental Clinics of North America, v. 35, n.185, p. ,1991 
NORMAND, M.C; HARRISON, E.; CALLIET, R.; BLACK, P.; HARRISON, D.D.; HOLLAND, B. Reliability and measurement error of the Biotonix Video Posture evaluation system- Part I : inanimate objects. J. Manipulative Physiol. Ther. v.25, n.4, p.246-50, 2002.

O COFFITO: Conselho Federal de Fisioterapia e terapia Ocupacional. Biofotogrametria: recurso diagnóstico do fisioterapeuta. São Paulo, n.17,p. 7-11, dez., 2002.

OLIVER, J. e MIDDLEDITCH, A. Anatomia funcional da coluna vertebral. Rio de Janeiro: Editora Revinter, 1998. 325 p.

PEREIRA, O. S. A utilização da análise computadorizada como método de avaliação das alterações posturais: um estudo preliminar. Fisioterapia em Movimento, Curitiba, v.16, n.2, p. 17-25, 2003.

RODACKI, N.C.L.; FOWLER, N.E.; RODACKI, A.L.F.; BIRCH, K. Repeatability of measurement in determining stature in sitting and standing postures. Ergonomics, Oxon, v.44, n. 12, p. 1076-1085, 2001.

RODRIGUES, L.F.; FERNANDES, M.; BARROS, J.W.; SHIMANO, A. C.; MOREIRA, F. B. R.; GONÇALVES, F. F.; AMORIM, G. S.; OTONI, N. T.; RODRIGUES, S. A. ; SANTOS, V. C. Utilização da técnica de moiré para detectar alterações posturais. Rev. Fisioter. Univ. São Paulo. São Paulo, v.10, n.1, p. 16-23, 2003. 
SANDOVAL, P.; HENRÍQUEZ, J.; FUENTES, R.; CABEZAS, G. e ROLDÁN, R. Curvatura cervical. Estudio cefalométrico en posición de reposo clínico postural. Rev. Med. de Chile, v. 127, n. 5, p. 547-555, 1999.

TANAKA, C. e FARAH, E. A. Anatomia Funcional das Cadeias Musculares. São Paulo: Ícone Editora, 1997. 104 p.

TÉCNICA DE MOIRÉ. Disponível em:<http://www.rch.unimelb.edu.an>. Acesso em: 29 jul. 2004.

TOMMASELLI, A. M. G.; SILVA, J.F.C.; HASEGAWA, J.K.; GALO, M.; DAL POZ, A. P. Fotogrametria: aplicações a curta distância. FCT 40 anos Perfil Cientifico Educacional. Presidente: Meneguetti Jr e Alves, p. 147-159, 1999.

TÜZÜN, C.; YORULMAZ, I.; CINDAS, A. ; VATAN, S. Low Back Pain and Posture. Clin. Reumatol. v. 18, n.4b, p.308-12, 1999.

VEGTER, F. e HAGE, J.J. Standardized facial photography of cleft patients: just fit the grid? The cleft palate-cranif. J. , Laurence, v.37, n. 5, p. 435-440, 2000.

VISSCHER, C. M.; BOER, W.; LOBBEZOO, F.; HABETS, L. L. M. H. ; NAEIJE, M. IS there a relationship between head posture and craniomandibular pain? J. Oral rehabilitation, Oxon, v. 29, p. 1030- 1036, 2002. 
WAHLUND, K.; LIST, T.; DWORKIN. Temporomandibular disorders in children and adolescents: reliability of a questionnaire, clinical examination, and diagnosis. J. of orofacial pain, Carol Stream, v.12, n.1, p. 42-51, 1998.

WATSON, A.W.S.. Procedure for the production of high quality photographs suitable for the recording and evaluation of posture. Rev. Fisioter. Univ. São Paulo, São Paulo, v.5, n. 1, p. 20-6, 1998.

WATSON, A.W.S. e MAcDONNCHA, C. A reliable technique for the assessment of posture: assessment criteria for aspects of posture. J. Sports Med Phys. Fitness, Turin, v.40, n. 3, p. 260-70, 2000.

YOUDAS, J.W.; GARRETT, T. R.; HARMSEN, S.; SUMAN, V.J.; CAREY, J. R. Lumbar lordosis and Pelvic Inclination os Asymptomatic Adults. Physical Therapy, Alexandria, v.76, n. 10, p. 1066-1081, 1996.

ZEPA, I; HERMERINTA, K.; KOVERO, O.; NISSINEM, M.; KÖNÖNEN, M.; HUGGARE, J. Association between thoracic kyposis, head posture and craniofacial morphology in Young adults. Acta Odontol Scand, Oslo, v.58, p. 237-242, 2000.

ZONNENBERG, A.J.J.; MAANEN, V.; OOSTENDORP, R.A.B.; ELVERS, J.W.H. Body posture photographs as a diagnostic aid for musculoskeletal disorders related to temporomandibular disorders (TMD). J. Cranomand. Pract. v.14, n. 3, p. 225-32, 1996. 
ZONNENBERG, A.J.J.; MAANEN, V.; ELVERS, J.W.H.; OOSTENDORP, R.A.B. Intra/interrater reliability of measurements on body posture photographs. J. Cranomand. Pract. v.14, n. 4, p. 326-31, 1996. 
APÊNDICES 
Tabela 5 - Valores das médias angulares das medidas dos ângulos da face na análise interexaminador. Onde OE (ângulo orbicular externo), CL (ângulo da comissura labial), AC (ângulo acrômio clavicular), EC (ângulo esternoclavicular), E1 ( $1^{\circ}$ examinador), E2 ( $2^{\circ}$ examinador) e E3 ( $3^{\circ}$ examinador).

\begin{tabular}{|c|c|c|c|c|c|c|c|c|c|c|c|c|}
\hline & $\mathrm{E}$ & & & $\mathrm{L}$ & & & & AC & & & EC & \\
\hline Voluntário & E1 & E2 & E3 & E1 & E2 & E3 & E1 & E2 & E3 & E1 & E2 & E3 \\
\hline 1 & -0.63 & -1.19 & -0.73 & -1.17 & -1.60 & -1.31 & 0.70 & 0.66 & 0.78 & -2.40 & -2.43 & 2.14 \\
\hline 2 & -0.83 & -5.62 & -4.77 & -1.14 & -4.36 & -2.68 & 0.86 & -4.14 & -2.80 & 6.69 & -3.43 & -1.73 \\
\hline 3 & 1.79 & 2.27 & 2.71 & -1.05 & -0.80 & 1.08 & -3.24 & -3.18 & -1.71 & -1.20 & -0.96 & -1.82 \\
\hline 4 & -1.61 & 1.96 & 0.17 & -1.09 & 1.31 & 0.11 & 1.05 & 1.73 & 1.39 & 0.96 & 5.68 & 3.32 \\
\hline 5 & -4.12 & -1.71 & -2.92 & -5.79 & -1.46 & -3.63 & -0.91 & 0.75 & -0.08 & -0.82 & 2.82 & 1.00 \\
\hline 6 & -2.47 & -6.09 & -4.28 & -0.82 & -5.17 & -3.00 & -1.19 & -0.54 & -0.86 & 1.24 & -2.71 & -0.74 \\
\hline 7 & -1.28 & -1.65 & -1.47 & -2.59 & -2.35 & -2.47 & -1.50 & -1.29 & -1.40 & -4.03 & -7.82 & -5.93 \\
\hline 8 & -2.14 & -3.37 & -2.76 & -3.26 & -3.51 & -3.39 & -4.46 & -4.22 & -4.34 & -4.98 & -3.65 & -4.32 \\
\hline 9 & -3.52 & 2.99 & -0.27 & -2.22 & 1.22 & -0.50 & -2.95 & 2.50 & -0.22 & -4.82 & 1.18 & -1.82 \\
\hline 10 & -3.33 & -3.12 & -3.23 & -2.33 & -2.01 & -2.17 & -4.21 & -3.57 & -3.89 & -6.99 & -3.72 & -5.35 \\
\hline 11 & -2.25 & -1.44 & -1.84 & -3.81 & -2.77 & -3.29 & -4.10 & -2.88 & -3.49 & -7.83 & -2.36 & -5.10 \\
\hline 12 & -3.34 & -2.25 & -2.80 & -3.52 & -2.59 & -3.06 & 0.49 & 1.96 & 1.22 & -1.45 & 1.61 & 0.08 \\
\hline 13 & -1.26 & 1.85 & 0.30 & -1.67 & 1.62 & -0.03 & -3.46 & -3.04 & -3.25 & 3.00 & -3.77 & -0.38 \\
\hline 14 & 1.84 & 1.84 & 0.85 & 0.96 & 0.96 & 0.25 & 1.83 & 1.83 & 1.61 & -3.91 & -3.91 & -3.73 \\
\hline 15 & -6.17 & -6.17 & -6.25 & -4.81 & -4.81 & -4.62 & -2.38 & -2.38 & -2.28 & -3.28 & -3.28 & -7.24 \\
\hline 16 & -3.25 & -0.19 & -1.72 & -3.42 & -0.16 & -1.79 & -2.47 & -1.15 & -1.81 & -4.69 & -0.25 & -2.47 \\
\hline 17 & -1.43 & 1.27 & -0.08 & -2.54 & 0.03 & -1.26 & -1.46 & 2.07 & 0.31 & -8.26 & -0.39 & -4.33 \\
\hline 18 & -5.76 & -5.30 & -5.53 & -5.33 & -5.83 & -5.58 & -0.89 & -0.76 & -0.83 & -6.18 & -1.06 & -3.62 \\
\hline 19 & -2.63 & -2.01 & -2.32 & -1.60 & -1.64 & -1.62 & -2.80 & -3.66 & -3.23 & -1.09 & -3.69 & -2.39 \\
\hline 20 & -3.04 & -3.07 & -3.06 & -3.75 & -3.88 & -3.82 & 0.31 & -2.14 & -0.92 & -0.46 & -1.13 & -0.80 \\
\hline 21 & -0.87 & 3.10 & 1.12 & -3.24 & 1.22 & -1.01 & -3.23 & -0.79 & -2.01 & 2.23 & -1.75 & 0.24 \\
\hline
\end{tabular}


Tabela 6 - Valores das médias angulares das medidas dos ângulos do plano frontal anterior na análise interexaminador. Onde V (voluntário), AS (ângulo da EIAS), AJd (ângulo do joelho direito), AJe (ângulo do joelho esquerdo), $\Delta \mathrm{Td}$ (triângulo de Talles direito) e $\Delta$ Te (triângulo de Talles esquerdo), E1 ( ${ }^{\circ}$ examinador), E2 ( $2^{\circ}$ examinador) e E3 ( $3^{\circ}$ examinador).

\begin{tabular}{|c|c|c|c|c|c|c|c|c|c|c|c|c|c|c|c|}
\hline & & AS & & & AJd & & & AJe & & & $\Delta \mathrm{Td}$ & & & $\Delta \mathrm{Te}$ & \\
\hline V & E1 & E2 & E3 & E1 & E2 & E3 & E1 & E2 & E3 & E1 & E2 & E3 & E1 & E2 & E3 \\
\hline 1 & 1.42 & -3.17 & -0.87 & 174.88 & 172.33 & 173.61 & 176.16 & 175.66 & 175.91 & 7.47 & 13.25 & 10.36 & 11.41 & 14.33 & 12.87 \\
\hline 2 & -3.17 & -4.26 & -1.87 & 172.33 & 175.62 & 176.51 & 175.66 & 179.75 & 178.57 & 13.25 & 14.50 & 14.60 & 14.33 & 14.81 & 15.07 \\
\hline 3 & -1.37 & -1.36 & -1.37 & 177.38 & 175.10 & 175.09 & 177.38 & 177.87 & 177.63 & 18.29 & 17.13 & 17.71 & 16.91 & 17.33 & 17.12 \\
\hline 4 & 0.56 & -0.59 & -0.01 & 175.95 & 176.23 & 176.09 & 176.53 & 176.00 & 176.27 & 12.22 & 13.79 & 13.00 & 9.61 & 12.24 & 10.92 \\
\hline 5 & 2.11 & 0.92 & 1.52 & 176.72 & 177.30 & 177.10 & 178.20 & 177.04 & 177.58 & 8.79 & 10.26 & 9.60 & 10.30 & 8.97 & 12.24 \\
\hline 6 & -2.21 & -1.45 & -1.83 & 174.52 & 175.93 & 175.33 & 175.52 & 175.63 & 175.83 & 15.75 & 15.11 & 15.01 & 16.90 & 20.19 & 18.14 \\
\hline 7 & -2.72 & -1.76 & -2.24 & 172.92 & 174.12 & 173.58 & 175.48 & 173.82 & 174.69 & 5.69 & 7.25 & 6.64 & 8.00 & 6.65 & 6.56 \\
\hline 8 & 2.74 & -1.40 & 0.67 & 176.50 & 178.91 & 177.41 & 175.67 & 177.26 & 176.88 & 24.75 & 25.90 & 24.01 & 20.32 & 23.54 & 21.54 \\
\hline 9 & -0.61 & 0.79 & 0.09 & 169.29 & 174.24 & 171.69 & 175.96 & 173.73 & 174.96 & 21.45 & 18.73 & 15.14 & 22.21 & 21.25 & 23.64 \\
\hline 10 & 0.26 & 2.18 & 1.22 & 172.65 & 175.58 & 174.16 & 177.31 & 175.86 & 176.61 & 13.34 & 13.21 & 12.88 & 16.08 & 14.45 & 15.91 \\
\hline 11 & -1.40 & -1.98 & -1.69 & 173.24 & 175.78 & 174.61 & 177.94 & 176.32 & 177.06 & 16.98 & 11.19 & 13.87 & 17.23 & 9.67 & 12.14 \\
\hline 12 & 3.46 & 0.05 & 2.40 & 175.83 & 175.23 & 175.65 & 175.65 & 177.50 & 176.63 & 17.29 & 17.18 & 19.08 & 17.83 & 15.75 & 18.08 \\
\hline 13 & 0.27 & 3.07 & 1.67 & 175.74 & 175.14 & 176.99 & 178.44 & 176.32 & 177.41 & 12.23 & 15.92 & 14.80 & 13.80 & 17.94 & 17.13 \\
\hline 14 & 3.33 & 2.03 & 3.08 & 174.41 & 174.52 & 174.55 & 175.44 & 175.05 & 175.18 & 16.84 & 19.64 & 19.17 & 12.50 & 12.40 & 13.72 \\
\hline 15 & -4.35 & -3.84 & -4.10 & 172.59 & 174.24 & 173.50 & 176.61 & 175.67 & 176.13 & 5.92 & 0.00 & 2.24 & 10.76 & 8.74 & 10.20 \\
\hline 16 & 1.00 & -1.35 & -0.18 & 187.58 & 176.17 & 172.21 & 177.67 & 178.41 & 176.96 & 14.70 & 16.18 & 20.29 & 11.27 & 12.43 & 16.65 \\
\hline 17 & -0.34 & 1.68 & 0.67 & 172.03 & 172.27 & 175.91 & 183.99 & 177.57 & 176.70 & 16.43 & 17.89 & 26.91 & 14.26 & 18.73 & 32.10 \\
\hline 18 & -2.63 & -1.21 & -1.92 & 174.68 & 177.03 & 177.90 & 177.14 & 176.20 & 176.95 & 21.09 & 22.98 & 10.46 & 31.09 & 31.46 & 15.26 \\
\hline 19 & 0.58 & -1.97 & -0.70 & 178.24 & 178.24 & 176.84 & 174.42 & 177.42 & 176.99 & 6.60 & 6.60 & 13.66 & 15.18 & 15.18 & 10.84 \\
\hline 20 & 3.00 & 1.14 & 2.07 & 177.53 & 175.97 & 174.27 & 176.34 & 177.48 & 178.21 & 12.05 & 12.05 & 14.07 & 9.75 & 9.75 & 18.44 \\
\hline 21 & 2.29 & 1.59 & 1.94 & 173.49 & 175.06 & 174.28 & 179.89 & 176.52 & 178.21 & 12.67 & 15.12 & 13.90 & 18.15 & 16.75 & 17.45 \\
\hline
\end{tabular}


Tabela 7 - Valores das médias angulares das medidas dos ângulos do plano frontal posterior na análise interexaminador. Onde V (voluntário), IE (ângulo inferior da escápula), PS (ângulo das EIPS), IPd (ângulo da inclinação do pé direito) e IPe (ângulo da inclinação do pé esquerdo), E1 ( $1^{\circ}$ examinador), E2 ( ${ }^{\circ}$ examinador) e E3 ( $3^{\circ}$ examinador).

\begin{tabular}{|c|c|c|c|c|c|c|c|c|c|c|c|c|c|c|c|}
\hline & \multicolumn{3}{|c|}{ IE } & \multicolumn{3}{|c|}{ PS } & \multicolumn{3}{|c|}{ LP } & \multicolumn{3}{|c|}{ IPd } & \multicolumn{3}{|c|}{ IPÊ } \\
\hline Voluntário & E1 & E2 & E3 & E1 & E2 & E3 & E1 & E2 & E3 & E1 & E2 & E3 & E1 & E2 & E3 \\
\hline 1 & -2.62 & -3.60 & -3.11 & 1.57 & -1.83 & -1.70 & -0.08 & -0.99 & -0.54 & 97.52 & 95.51 & 96.52 & 98.06 & 97.09 & 97.58 \\
\hline 2 & -3.60 & 1.95 & -0.29 & 1.34 & -0.17 & 0.59 & -0.99 & -1.79 & -0.31 & 95.51 & 91.64 & 89.99 & 97.09 & 88.46 & 90.88 \\
\hline 3 & 0.96 & 3.60 & 2.28 & -0.49 & -1.06 & -0.78 & 0.70 & -1.44 & 0.13 & 88.29 & 91.52 & 89.91 & 95.18 & 93.30 & 94.24 \\
\hline 4 & -3.35 & -1.76 & -2.55 & -0.30 & -2.36 & -1.33 & 1.42 & 1.64 & 1.53 & 92.72 & 91.72 & 92.22 & 97.76 & 88.30 & 93.03 \\
\hline 5 & 3.17 & 2.09 & 2.64 & 2.08 & -4.18 & -1.05 & -1.55 & -0.70 & -1.14 & 87.77 & 86.24 & 86.82 & 86.56 & 87.21 & 86.54 \\
\hline 6 & 5.46 & 3.69 & 4.66 & -1.27 & -1.15 & -1.83 & -3.58 & -0.75 & -2.01 & 99.99 & 98.79 & 97.99 & 94.66 & 97.10 & 94.85 \\
\hline 7 & 2.30 & 4.23 & 3.27 & -0.99 & 2.03 & 0.52 & 1.55 & -0.12 & 0.73 & 98.13 & 103.09 & 101.25 & 99.10 & 94.86 & 95.94 \\
\hline 8 & 2.14 & 3.29 & 2.78 & 2.22 & -1.42 & 0.40 & 1.37 & 2.79 & 2.09 & 94.49 & 93.05 & 93.45 & 99.84 & 94.40 & 95.60 \\
\hline 9 & -6.35 & 0.57 & -2.88 & -0.51 & 2.16 & 0.83 & -2.87 & 0.75 & -1.02 & 88.26 & 88.28 & 88.82 & 84.18 & 84.11 & 86.44 \\
\hline 10 & -0.58 & 1.84 & 1.28 & -0.86 & -5.54 & -3.20 & -2.80 & -2.69 & -2.66 & 90.43 & 89.06 & 89.25 & 89.81 & 89.18 & 88.56 \\
\hline 11 & -2.17 & 0.48 & -0.56 & 0.45 & -0.70 & -0.12 & -1.02 & -1.52 & -1.15 & 97.79 & 98.25 & 98.65 & 99.56 & 96.75 & 97.49 \\
\hline 12 & 3.41 & 1.78 & 2.70 & -2.60 & -5.78 & -4.19 & -0.66 & -1.20 & -0.44 & 81.80 & 84.20 & 81.86 & 84.44 & 83.24 & 82.79 \\
\hline 13 & -5.57 & -2.19 & -5.38 & -1.91 & -2.59 & -2.52 & -0.49 & 0.27 & -0.45 & 85.93 & 84.09 & 85.36 & 93.76 & 91.78 & 92.22 \\
\hline 14 & 0.86 & 0.14 & 0.50 & -0.75 & -1.63 & -1.19 & 1.47 & 0.12 & 0.84 & 92.73 & 95.84 & 93.89 & 93.97 & 89.95 & 90.70 \\
\hline 15 & 1.90 & 2.80 & 2.41 & -4.72 & -6.76 & -5.74 & -0.58 & 0.51 & 0.17 & 88.67 & 88.11 & 87.80 & 95.33 & 93.39 & 93.23 \\
\hline 16 & -4.66 & 3.28 & -0.74 & -1.11 & -0.78 & -0.94 & -0.39 & 1.34 & 0.55 & 88.41 & 89.88 & 84.57 & 89.57 & 91.92 & 85.80 \\
\hline 17 & 2.27 & -2.97 & -0.29 & -0.88 & -1.76 & -1.32 & -0.13 & -1.15 & -0.57 & 97.32 & 94.88 & 95.68 & 96.97 & 96.54 & 95.64 \\
\hline 18 & -1.11 & 4.19 & 1.54 & -1.74 & -0.89 & -0.43 & -1.53 & -2.16 & -1.77 & 88.23 & 85.88 & 87.02 & 89.53 & 86.88 & 88.08 \\
\hline 19 & -3.69 & 0.69 & -1.55 & -0.48 & -1.17 & -0.88 & 1.87 & -1.64 & 0.11 & 87.04 & 89.23 & 88.02 & 99.82 & 90.86 & 94.26 \\
\hline 20 & -2.27 & -2.38 & -2.24 & 0.56 & -2.37 & -0.91 & 1.80 & 0.56 & 1.11 & 93.49 & 96.24 & 95.81 & 99.50 & 95.53 & 96.14 \\
\hline 21 & -3.35 & 1.44 & -1.06 & -6.57 & -2.85 & -4.71 & -2.37 & -1.39 & -1.88 & 96.78 & 94.08 & 94.31 & 96.99 & 95.37 & 95.60 \\
\hline
\end{tabular}


Tabela 8 - Valores das médias angulares das medidas dos ângulos do plano sagital (PC, LC, CT, LL) na análise interexaminador. Onde V (voluntário), PC (ângulo de protusão de cabeça), LC (ângulo da lordose cervical), CT (ângulo da cifose torácica), LL (ângulo da lordose lombar), E1 ( $1^{\circ}$ examinador), E2 ( ${ }^{\circ}$ examinador) e E3 ( $3^{\circ}$ examinador).

\begin{tabular}{|c|c|c|c|c|c|c|c|c|c|c|c|c|}
\hline \multirow[b]{2}{*}{ V } & \multicolumn{3}{|c|}{ PC } & \multicolumn{3}{|l|}{ LC } & \multicolumn{3}{|c|}{ CT } & \multicolumn{3}{|c|}{ LL } \\
\hline & E1 & E2 & E3 & E1 & E2 & E3 & E1 & E2 & E3 & $\mathrm{E} 1$ & E2 & E3 \\
\hline 1 & 53.85 & 55.41 & 54.63 & 82.10 & 82.60 & 82.35 & 122.88 & 122.03 & 122.46 & 85.39 & 84.61 & 85.00 \\
\hline 2 & 55.41 & 49.38 & 51.31 & 82.60 & 42.49 & 43.38 & 122.03 & 102.95 & 105.74 & 84.61 & 77.76 & 70.91 \\
\hline 3 & 47.55 & 47.41 & 47.48 & 30.89 & 52.10 & 36.50 & 104.34 & 106.05 & 105.20 & 61.51 & 64.52 & 63.02 \\
\hline 4 & 55.29 & 53.45 & 54.37 & 65.98 & 103.81 & 84.90 & 119.95 & 143.91 & 131.93 & 53.94 & 81.06 & 67.80 \\
\hline 5 & 56.32 & 52.75 & 54.54 & 60.23 & 31.23 & 45.73 & 107.99 & 81.03 & 94.51 & 59.21 & 57.58 & 58.40 \\
\hline 6 & 55.20 & 55.20 & 53.64 & 93.07 & 93.07 & 74.96 & 138.64 & 138.64 & 128.15 & 61.21 & 61.21 & 61.51 \\
\hline 7 & 56.00 & 56.97 & 56.49 & 35.50 & 51.52 & 43.51 & 96.53 & 102.28 & 99.40 & 63.08 & 64.11 & 63.59 \\
\hline 8 & 53.33 & 47.86 & 50.60 & 50.82 & 26.92 & 38.87 & 128.69 & 91.55 & 110.12 & 62.71 & 56.18 & 59.44 \\
\hline 9 & 47.74 & 43.89 & 45.81 & 38.65 & 30.75 & 34.70 & 122.22 & 101.80 & 112.01 & 79.45 & 60.46 & 1.078 .95 \\
\hline 10 & 54.47 & 46.96 & 50.72 & 51.98 & 39.86 & 45.92 & 127.62 & 100.76 & 114.19 & 89.86 & 66.51 & 78.19 \\
\hline 11 & 59.19 & 53.57 & 56.37 & 68.74 & 65.78 & 67.26 & 126.99 & 124.85 & 125.92 & 77.60 & 89.26 & 83.43 \\
\hline 12 & 49.17 & 49.14 & 49.16 & 45.83 & 69.14 & 57.49 & 101.57 & 113.77 & 107.67 & 73.23 & 90.48 & 81.85 \\
\hline 13 & 57.28 & 53.19 & 55.22 & 50.41 & 32.78 & 41.59 & 133.08 & 101.99 & 117.54 & 100.87 & 64.85 & 82.86 \\
\hline 14 & 52.50 & 45.97 & 49.24 & 48.53 & 44.93 & 46.73 & 121.50 & 106.06 & 113.78 & 76.78 & 65.46 & 71.12 \\
\hline 15 & 51.52 & 52.79 & 52.16 & 43.14 & 54.00 & 48.57 & 110.13 & 115.12 & 112.63 & 72.44 & 73.41 & 72.93 \\
\hline 16 & 60.57 & 59.41 & 59.99 & 46.98 & 54.23 & 46.10 & 90.17 & 94.47 & 92.32 & 53.51 & 57.84 & 55.67 \\
\hline 17 & 55.17 & 64.45 & 59.81 & 44.69 & 73.68 & 59.19 & 89.91 & 125.01 & 107.46 & 55.45 & 74.32 & 64.89 \\
\hline 18 & 52.66 & 47.81 & 50.23 & 59.42 & 42.83 & 51.13 & 122.79 & 113.67 & 118.23 & 93.52 & 88.21 & 90.87 \\
\hline 19 & 51.50 & 54.85 & 53.17 & 51.98 & 59.01 & 55.50 & 99.07 & 109.33 & 104.20 & 51.00 & 66.58 & 58.79 \\
\hline 20 & 53.20 & 53.56 & 53.38 & 66.65 & 67.47 & 67.06 & 129.37 & 129.72 & 129.55 & 100.81 & 101.85 & 101.33 \\
\hline 21 & 56.85 & 54.08 & 55.46 & 69.76 & 44.79 & 57.28 & 118.77 & 108.42 & 113.60 & 65.27 & 73.13 & 69.20 \\
\hline
\end{tabular}


Tabela 9 - Valores das médias angulares das medidas dos ângulos do plano sagital (BP, FJ, ATT) na análise interexaminador. Onde V (voluntário), BP (ângulo da báscula da pelve), FJ (ângulo do flexo de joelho), ATT (ângulo tibio társico), E1 ( $1^{\circ}$ examinador), E2 ( $2^{\circ}$ examinador) e E3 ( $3^{\circ}$ examinador).

\begin{tabular}{|c|c|c|c|c|c|c|c|c|c|}
\hline \multirow[b]{2}{*}{$\mathrm{V}$} & \multicolumn{3}{|c|}{ BP } & \multicolumn{3}{|c|}{ FJ } & \multicolumn{3}{|c|}{ ATT } \\
\hline & E1 & E2 & E3 & E1 & E2 & E3 & E1 & E2 & E3 \\
\hline 1 & 2.66 & 9.11 & 5.89 & 189.16 & 194.19 & 191.67 & 115.05 & 118.31 & 116.68 \\
\hline 2 & 9.11 & 2.35 & 1.13 & 194.19 & 177.73 & 177.70 & 118.31 & 108.19 & 107.86 \\
\hline 3 & -2.06 & 1.15 & -0.46 & 181.53 & 182.15 & 181.84 & 117.12 & 109.68 & 113.40 \\
\hline 4 & 8.07 & 2.84 & 5.46 & 184.65 & 185.54 & 185.00 & 114.62 & 107.03 & 110.82 \\
\hline 5 & 4.67 & 8.09 & 6.38 & 191.48 & 194.44 & 192.96 & 116.84 & 115.62 & 116.23 \\
\hline 6 & 2.59 & 2.59 & 5.75 & 183.00 & 183.00 & 183.97 & 109.85 & 109.85 & 111.08 \\
\hline 7 & 8.22 & 7.54 & 7.88 & 179.93 & 181.28 & 180.61 & 114.36 & 110.55 & 112.46 \\
\hline 8 & 3.45 & 5.52 & 4.49 & 181.54 & 184.18 & 182.86 & 110.46 & 114.94 & 112.70 \\
\hline 9 & 8.19 & 17.02 & 12.61 & 181.67 & 182.94 & 182.31 & 114.16 & 114.04 & 114.10 \\
\hline 10 & 4.33 & 7.82 & 6.08 & 175.97 & 178.35 & 177.16 & 111.85 & 109.98 & 110.92 \\
\hline 11 & 6.84 & 5.44 & 6.14 & 185.90 & 183.81 & 184.85 & 117.28 & 112.24 & 114.76 \\
\hline 12 & 4.05 & 8.70 & 6.38 & 185.84 & 189.44 & 187.64 & 116.28 & 116.01 & 116.15 \\
\hline 13 & 5.31 & 1.24 & 3.28 & 186.38 & 186.20 & 186.29 & 112.72 & 108.99 & 110.85 \\
\hline 14 & -3.02 & 1.03 & -0.99 & 188.37 & 184.65 & 186.51 & 115.54 & 114.73 & 115.14 \\
\hline 15 & 10.48 & 13.23 & 11.86 & 182.15 & 186.02 & 184.09 & 118.20 & 119.12 & 118.66 \\
\hline 16 & 9.93 & 7.84 & 8.89 & 178.65 & 182.01 & 180.33 & 109.44 & 109.03 & 109.23 \\
\hline 17 & 1.44 & 2.97 & 2.21 & 173.53 & 179.32 & 176.43 & 105.76 & 111.82 & 108.79 \\
\hline 18 & 6.46 & -0.22 & 3.12 & 184.74 & 184.73 & 184.73 & 11.75 & 107.81 & 109.78 \\
\hline 19 & -7.70 & -7.80 & -7.75 & 186.38 & 186.45 & 186.42 & 112.57 & 112.91 & 112.74 \\
\hline 20 & -7.10 & -4.24 & -5.67 & 180.95 & 182.01 & 181.48 & 112.65 & 115.32 & 113.98 \\
\hline 21 & 7.89 & 7.99 & 7.94 & 179.89 & 185.53 & 182.71 & 111.38 & 112.77 & 112.02 \\
\hline
\end{tabular}


Tabela 10 - Valores das médias angulares das medidas dos ângulos da face na análise intra-examinador. Onde OE (ângulo orbicular externo), CL (ângulo da comissura labial), AC (ângulo acrômio clavicular), EC (ângulo esternoclavicular), E1 ( $1^{\mathrm{a}}$ análise intra), E2 ( $2^{\mathrm{a}}$ análise intra).

\begin{tabular}{|c|c|c|c|c|c|c|c|c|}
\hline & \multicolumn{2}{|c|}{ OE } & \multicolumn{2}{|c|}{ CL } & \multicolumn{2}{|c|}{ AC } & \multicolumn{2}{|c|}{ EC } \\
\hline Voluntário & E1 & E2 & E1 & E2 & E1 & E2 & E1 & E2 \\
\hline 1 & -0.63 & -0.63 & -1.17 & -1.53 & 0.70 & 1.02 & -2.40 & 6.88 \\
\hline 2 & -0.83 & -3.81 & -1.14 & -2.18 & 0.86 & -1.53 & 6.69 & -1.81 \\
\hline 3 & 1.79 & 4.04 & -1.05 & 3.05 & -3.24 & -0.11 & -1.20 & -2.26 \\
\hline 4 & -1.61 & 2.04 & -1.09 & 1.45 & 1.05 & 1.73 & 0.96 & 5.37 \\
\hline 5 & -4.12 & -1.50 & -5.79 & -1.00 & -0.91 & 0.73 & -0.82 & 3.07 \\
\hline 6 & -2.47 & -5.78 & -0.82 & -5.31 & -1.19 & -0.59 & 1.24 & -2.50 \\
\hline 7 & -1.28 & -1.49 & -2.59 & -2.46 & -1.50 & -1.30 & -4.03 & -7.21 \\
\hline 8 & -2.14 & -3.43 & -3.26 & -4.02 & -4.46 & -4.37 & -4.98 & -3.28 \\
\hline 9 & -3.52 & -3.05 & -2.22 & -1.28 & -2.95 & -2.43 & -4.82 & -1.41 \\
\hline 10 & -3.33 & -2.94 & -2.33 & -2.11 & -4.21 & -3.68 & -6.99 & -3.44 \\
\hline 11 & -2.25 & -1.21 & -3.81 & -3.00 & -4.10 & -2.96 & -7.83 & -2.10 \\
\hline 12 & -3.34 & -2.22 & -3.52 & -3.09 & 0.49 & 1.88 & -1.45 & 1.40 \\
\hline 13 & -1.26 & $1 . .81$ & -1.67 & 1.55 & -3.46 & -3.11 & 3.00 & -3.85 \\
\hline 14 & 1.84 & -0.52 & 0.96 & -0.83 & 1.83 & 1.41 & -3.91 & -3.4 \\
\hline 15 & -6.17 & -6.27 & -4.81 & -4.40 & -2.38 & -2.13 & -3.28 & -10.64 \\
\hline 16 & -3.25 & -0.10 & -3.42 & -0.06 & -2.47 & -1.06 & -4.69 & -0.19 \\
\hline 17 & -1.43 & 1.42 & -2.54 & 0.47 & -1.46 & 2.18 & -8.26 & -0.27 \\
\hline 18 & -5.76 & -4.99 & -5.33 & -4.71 & -0.89 & -0.75 & -6.18 & -1.31 \\
\hline 19 & -2.63 & -1.82 & -1.60 & -1.57 & -2.80 & -3.67 & -1.09 & -3.81 \\
\hline 20 & -3.04 & -2.71 & -3.75 & -3.80 & 0.31 & -2.05 & -0.46 & -0.98 \\
\hline 21 & -0.87 & 3.22 & -3.24 & 1.34 & -3.23 & -0.77 & 2.23 & -1.64 \\
\hline
\end{tabular}


Tabela 11 - Valores das médias angulares das medidas dos ângulos do plano frontal anterior na análise intra-examinador. Onde AS (ângulo da EIAS), AJd (ângulo do joelho direito), AJe (ângulo do joelho esquerdo), $\Delta \mathrm{Td}$ (triângulo de Talles direito) e $\Delta \mathrm{Te}$ (triângulo de Talles esquerdo). E1 (1 ${ }^{\mathrm{a}}$ análise intra), E2 ( ${ }^{\mathrm{a}}$ análise intra).

\begin{tabular}{|c|c|c|c|c|c|c|c|c|c|c|}
\hline \multirow[b]{2}{*}{ Voluntário } & \multicolumn{2}{|c|}{ AS } & \multicolumn{2}{|c|}{ AJd } & \multicolumn{2}{|c|}{ AJe } & \multicolumn{2}{|c|}{$\Delta \mathrm{Td}$} & \multicolumn{2}{|c|}{$\Delta \mathrm{Te}$} \\
\hline & E1 & E2 & E1 & E2 & E1 & E2 & E1 & E2 & E1 & E2 \\
\hline 1 & 1.42 & -2.17 & 174.88 & 172.39 & 176.16 & 175.59 & 7.47 & 12.92 & 11.41 & 14.65 \\
\hline 2 & -3.17 & -3.99 & 172.33 & 175.67 & 175.66 & 179.82 & 13.25 & 14.74 & 14.33 & 15.33 \\
\hline 3 & -1.37 & -1.22 & 177.38 & 175.09 & 177.38 & 177.89 & 18.29 & 21.21 & 16.91 & 17.71 \\
\hline 4 & 0.56 & -0.77 & 175.95 & 176.32 & 176.53 & 175.98 & 12.22 & 13.84 & 9.61 & 12.27 \\
\hline 5 & 2.11 & 1.14 & 176.72 & 177.38 & 178.20 & 177.01 & 8.79 & 10.30 & 10.30 & 8.94 \\
\hline 6 & -2.21 & -1.20 & 174.52 & 176.01 & 175.52 & 175.74 & 15.75 & 14.84 & 16.90 & 20.52 \\
\hline 7 & -2.72 & -1.67 & 172.92 & 174.17 & 175.48 & 173.83 & 5.69 & 7.38 & 8.00 & 6.66 \\
\hline 8 & 2.74 & -1.28 & 176.50 & 178.83 & 175.67 & 177.30 & 24.75 & 26.08 & 20.32 & 23.70 \\
\hline 9 & -0.61 & 0.88 & 169.29 & 174.15 & 175.96 & 173.75 & 21.45 & 18.04 & 22.21 & 21.20 \\
\hline 10 & 0.26 & 2.36 & 172.65 & 175.64 & 177.31 & 175.82 & 13.34 & 13.29 & 16.08 & 14.71 \\
\hline 11 & -1.40 & -1.97 & 173.24 & 175.78 & 177.94 & 176.24 & 16.98 & 11.60 & 17.23 & 9.81 \\
\hline 12 & 3.46 & 1.07 & 175.83 & 175.29 & 175.65 & 177.44 & 17.29 & -17.14 & 17.83 & 15.54 \\
\hline 13 & 0.27 & 3.12 & 175.74 & 178.16 & 178.44 & 176.30 & 12.23 & 16.02 & 13.80 & 17.98 \\
\hline 14 & 3.33 & 2.97 & 174.41 & 114.33 & 175.44 & 174.49 & 16.84 & 19.45 & 12.50 & 13.90 \\
\hline 15 & -4.35 & -3.92 & 172.59 & 174.28 & 176.61 & 175.56 & 5.92 & 0.00 & 10.76 & 8.72 \\
\hline 16 & 1.00 & -1.48 & 187.58 & 176.09 & 177.67 & 178.29 & 14.70 & 16.34 & 11.27 & 12.66 \\
\hline 17 & -0.34 & 0.98 & 172.03 & 172.18 & 183.99 & 177.49 & 16.43 & 17.98 & 14.26 & 19.14 \\
\hline 18 & -2.63 & -1.17 & 174.68 & 177.08 & 177.14 & 176.21 & 21.09 & 23.06 & 31.09 & 30.91 \\
\hline 19 & 0.58 & -1.93 & 178.24 & 177.38 & 174.42 & 176.01 & 6.60 & 11.90 & 15.18 & 13.71 \\
\hline 20 & 3.00 & 1.29 & 177.53 & 115.10 & 176.34 & 175.92 & 12.05 & 12.15 & 9.75 & 9.49 \\
\hline 21 & 2.29 & 1.58 & 173.49 & 175.01 & 179.89 & 176.56 & 12.67 & 15.39 & 18.15 & 16.74 \\
\hline
\end{tabular}


Tabela 12 - Valores das médias angulares das medidas dos ângulos do plano frontal posterior na análise intra-examinador. Onde IE (ângulo inferior da escápula), PS (ângulo das EIPS), IPd (ângulo da inclinação do pé direito) e IPe (ângulo da inclinação do pé esquerdo), E1 (1 ${ }^{a}$ análise intra), E2 ( $2^{\mathrm{a}}$ análise intra).

\begin{tabular}{|c|c|c|c|c|c|c|c|c|c|c|}
\hline \multirow{3}{*}{$\begin{array}{c}\text { Voluntário } \\
1\end{array}$} & \multicolumn{2}{|c|}{ IE } & \multicolumn{2}{|c|}{ OS } & \multicolumn{2}{|c|}{ LP } & \multicolumn{2}{|c|}{ IPd } & \multicolumn{2}{|c|}{ IPE } \\
\hline & E1 & E2 & E1 & E2 & E1 & E2 & E1 & E2 & E1 & E2 \\
\hline & -2.62 & -2.40 & & & -0.08 & -0.87 & 97.52 & 95.41 & 98.06 & 97.32 \\
\hline 2 & -3.60 & -1.46 & & & -0.99 & -1.64 & 95.51 & 49.67 & 97.09 & 43.07 \\
\hline 3 & 0.96 & 3.72 & & & 0.70 & -0.45 & 88.29 & 91.67 & 95.18 & 93.19 \\
\hline 4 & -3.35 & -3.05 & & & 1.42 & 1.55 & 92.72 & 92.68 & 97.76 & 88.31 \\
\hline 5 & 3.17 & 2.31 & & & -1.55 & -0.57 & 87.77 & 86.37 & 86.56 & 86.85 \\
\hline 6 & 5.46 & 3.94 & & & -3.58 & -0.52 & 99.99 & 99.49 & 94.66 & 97.34 \\
\hline 7 & 2.30 & 4.22 & & & 1.55 & -0.12 & 98.13 & 103.05 & 99.10 & 95.02 \\
\hline 8 & 2.14 & 3.27 & & & 1.37 & 2.80 & 94.49 & 178.83 & 99.84 & 177.30 \\
\hline 9 & -6.35 & -0.56 & & & -2.87 & 0.76 & 88.26 & 88.71 & 84.18 & 83.83 \\
\hline 10 & -0.58 & 1.91 & & & -2.80 & -2.85 & 90.43 & 89.74 & 89.81 & 88.86 \\
\hline 11 & -2.17 & 0.52 & & & -1.02 & -1.56 & 97.79 & 98.03 & 99.56 & 96.57 \\
\hline 12 & 3.41 & 1.93 & & & -0.66 & -1.15 & 81.80 & 84.44 & 84.44 & 83.35 \\
\hline 13 & -5.57 & -2.06 & & & -0.49 & 0.26 & 85.93 & 83.97 & 93.76 & 92.13 \\
\hline 14 & 0.86 & 0.14 & & & 1.47 & 0.04 & 92.73 & 96.01 & 93.97 & 89.01 \\
\hline 15 & 1.90 & 2.93 & & & -0.58 & -0.16 & 88.67 & 87.58 & 95.33 & 93.19 \\
\hline 16 & -4.66 & 3.29 & & & -0.39 & 1.18 & 88.41 & 90.13 & 89.57 & 91.89 \\
\hline 17 & 2.27 & -2.94 & & & -0.13 & -1.10 & 97.32 & 95.09 & 96.97 & 96.15 \\
\hline 18 & -1.11 & 4.26 & & & -1.53 & -70.49 & 88.23 & 86.05 & 89.53 & 87.02 \\
\hline 19 & -3.69 & 0.73 & & & 1.87 & -1.58 & 87.04 & 89.82 & 99.82 & 91.83 \\
\hline 20 & -2.27 & -2.16 & & & 1.80 & 0.59 & 93.49 & 96.54 & 99.50 & 95.38 \\
\hline 21 & -3.35 & 1.36 & & & -2.37 & -1.30 & 96.78 & 94.37 & 96.99 & 95.29 \\
\hline
\end{tabular}


Tabela 13 - Valores das médias angulares das medidas dos ângulos do plano sagital (PC, LC, CT, LL) na análise intra-examinador. Onde PC (ângulo de protusão de cabeça), LC (ângulo da lordose cervical), CT (ângulo da cifose torácica), LL (ângulo da lordose lombar), BP (ângulo da báscula da pelve), FJ (ângulo do flexo de joelho), ATT (ângulo tibio társico), E1 ( $1^{\mathrm{a}}$ análise intra), E2 (2 ${ }^{\mathrm{a}}$ análise intra).

\begin{tabular}{|c|c|c|c|c|c|c|c|c|c|c|c|c|c|c|}
\hline & \multicolumn{2}{|c|}{ PC } & \multicolumn{2}{|c|}{ LC } & \multicolumn{2}{|c|}{ CT } & \multicolumn{2}{|c|}{ LL } & \multicolumn{2}{|c|}{ BP } & \multicolumn{2}{|c|}{ FJ } & \multicolumn{2}{|c|}{ ATT } \\
\hline Voluntário & E1 & E2 & E1 & E2 & E1 & E2 & E1 & E2 & E1 & E2 & E1 & E2 & E1 & E2 \\
\hline 1 & 53.85 & 55.32 & 82.10 & 82.39 & 122.88 & 121.97 & 85.39 & 84.62 & 2.66 & 9.30 & 189.16 & 194.43 & 115.05 & 117.97 \\
\hline 2 & 55.41 & 49.67 & 82.60 & 43.07 & 122.03 & 103.33 & 84.61 & 78.16 & 9.11 & 2.44 & 194.19 & 178.14 & 118.31 & 111.79 \\
\hline 3 & 47.55 & 52.51 & 30.89 & 42.43 & 104.34 & 105.75 & 61.51 & 64.72 & -2.06 & 1.42 & 181.53 & 182.18 & 117.12 & 109.51 \\
\hline 4 & 55.29 & 53.41 & 65.98 & 103.72 & 119.95 & 143.62 & 53.94 & 81.69 & 8.07 & 2.92 & 184.65 & 186.02 & 114.62 & 107.13 \\
\hline 5 & 56.32 & 52.46 & 60.23 & 31.22 & 107.99 & 81.11 & 59.21 & 5 & 4.67 & 8.06 & .48 & 194.73 & 116.84 & 115.06 \\
\hline 6 & 55.20 & 51.52 & 93.07 & 56.66 & 138.64 & 118.04 & 61.21 & 61.58 & 2.59 & 8.89 & 183.00 & 185.37 & 109.85 & 112.27 \\
\hline 7 & 56.00 & 56.84 & 35.50 & 51.56 & 96.53 & 102.11 & 63.08 & 63.86 & 8.22 & 7.60 & 179.93 & 181.52 & 114.36 & 110.16 \\
\hline 8 & 53.33 & 47.87 & 50.82 & 26.69 & 128.69 & 90.96 & 62.71 & 55.94 & 3.45 & 5.90 & 181.54 & 184.47 & 110.46 & 114.56 \\
\hline 9 & 47.74 & 43.79 & 38.65 & 30.66 & 122.22 & 102.06 & 70.44 & 60 & 8.19 & 17.41 & 181.67 & 183.12 & 114.16 & 113.93 \\
\hline 10 & .47 & 46.93 & 51.98 & 39.68 & 127.62 & 100.40 & 89.86 & 66 & 4.33 & 7.87 & 97 & 178.30 & 111.85 & 109.99 \\
\hline 11 & 59.19 & 53.11 & 68.74 & 66.03 & 126.99 & 125.05 & 77.60 & 88 & 6.84 & 5.51 & 90 & 183.73 & 117.28 & 112.03 \\
\hline 12 & 49.17 & 49.20 & 45.83 & 69.65 & 101.57 & 113.84 & 73.23 & 90.41 & 4.05 & 8.62 & 84 & 189.91 & 116.28 & 115.19 \\
\hline 13 & 57.28 & 52.93 & 50.41 & 32.92 & 133.08 & 102.67 & 100.87 & 64.69 & 5.31 & 1.22 & 186.38 & 186.22 & 112.72 & 108.55 \\
\hline 14 & 52.50 & 45.93 & 48.53 & 44.65 & 121.50 & 106.09 & 76.78 & 65.65 & -3.02 & 1.02 & 188.37 & 184.89 & 115.54 & 114.33 \\
\hline 15 & 51.52 & 52.42 & 43.14 & 53.98 & 110.13 & 116.27 & 72.44 & 73.71 & 10.48 & 13.85 & 182.15 & 186.44 & 118.20 & 119.04 \\
\hline 16 & 60.57 & 59.12 & 46.98 & 45.64 & 90.17 & 94.55 & 53.51 & 58.15 & 9.93 & 8.21 & 178.65 & 182.57 & 109.44 & 108.16 \\
\hline 17 & .17 & 3.80 & 4.69 & 73.75 & 89.91 & 125.19 & 55.45 & 73.98 & 1.44 & 3.17 & 17 & 179.43 & 105.76 & 111.62 \\
\hline 18 & 52.66 & 47.64 & 59.42 & 42.64 & 122.79 & 114.16 & 93.52 & & 6.46 & -0.63 & & 184.66 & 11.75 & 107.86 \\
\hline 19 & 51.50 & 54.66 & 51.98 & 59.16 & 99.07 & 109.01 & 51.00 & & -7.70 & -7.57 & 18 & 186.55 & 112.57 & 112.44 \\
\hline 20 & 53.20 & 53.51 & 66.65 & 67.61 & 129.37 & 130.02 & 100.81 & 101.78 & -7.10 & -4.14 & 180.95 & 182.23 & 112.65 & 115.10 \\
\hline 21 & 56.85 & 53.96 & 69.76 & 44.98 & 118.77 & 108.45 & 65.27 & 73.30 & 7.89 & 8.09 & 179.89 & 185.78 & 111.38 & 112.99 \\
\hline
\end{tabular}


Tabela 14: Valores das médias angulares (em graus) das medidas dos ângulos da face na análise de repetibilidade do método de avaliação. Onde OE (ângulo orbicular externo), CL (ângulo da comissura labial), AC (ângulo acrômio clavicular) e EC (ângulo esternoclavicular). A $2^{\mathrm{a}}$ série refere-se as fotografias realizadas 7 dias depois da $1^{\text {a }}$ série.

\begin{tabular}{|c|c|c|c|c|c|c|c|c|}
\hline & \multicolumn{2}{|c|}{ OE } & \multicolumn{2}{|c|}{ CL } & \multicolumn{2}{|c|}{ AC } & \multicolumn{2}{|c|}{ EC } \\
\hline $\begin{array}{c}\text { Voluntário } \\
1\end{array}$ & $\begin{array}{l}\mathbf{1}^{\text {a }} \text { série } \\
-1,22\end{array}$ & $\begin{array}{l}\mathbf{2}^{\mathrm{a}} \text { série } \\
-0,89\end{array}$ & $\begin{array}{l}\mathbf{1}^{\mathrm{a}} \text { série } \\
0,53\end{array}$ & $\begin{array}{l}\mathbf{2}^{\mathrm{a}} \text { série } \\
0,41\end{array}$ & $\begin{array}{l}\mathbf{1}^{\mathrm{a}} \text { série } \\
-0,28\end{array}$ & $\begin{array}{l}\mathbf{2}^{\mathrm{a}} \text { série } \\
-2,07\end{array}$ & $\begin{array}{l}\mathbf{1}^{\mathrm{a}} \text { série } \\
5,31\end{array}$ & $\begin{array}{l}2^{\mathrm{a}} \text { série } \\
-1,69\end{array}$ \\
\hline 2 & $-0,54$ & $-2,64$ & 0,66 & $-3,50$ & $-0,80$ & $-1,11$ & $-0,79$ & $-1,92$ \\
\hline 3 & $-2,02$ & 1,89 & $-2,24$ & 1,35 & $-4,64$ & $-1,40$ & $-2,83$ & 2,99 \\
\hline 4 & $-0,15$ & 1,21 & $-1,54$ & 0,35 & 2,62 & 2,53 & 1,79 & 2,26 \\
\hline 5 & $-2,91$ & $-4,11$ & $-2,68$ & $-4,82$ & $-0,60$ & $-0,64$ & $-2,97$ & 2,60 \\
\hline 6 & $-0,44$ & 1,72 & $-1,17$ & 0,76 & $-1,28$ & 1,08 & $-4,10$ & $-0,86$ \\
\hline 7 & 8,07 & 9,68 & 6,07 & 7,10 & 0,82 & 4,58 & 0,42 & 3,47 \\
\hline 8 & $-2,10$ & 0,50 & $-2,82$ & $-0,03$ & 0,08 & 3,86 & 0,50 & 5,52 \\
\hline 9 & $-4,71$ & $-4,12$ & $-6,63$ & $-5,18$ & $-2,27$ & $-1,09$ & 2,49 & $-4,19$ \\
\hline 10 & 1,95 & 2,10 & 1,55 & 1,58 & $-0,58$ & $-0,47$ & $-3,32$ & $-6,72$ \\
\hline 11 & $-2,28$ & $-2,58$ & $-3,10$ & $-1,61$ & $-2,46$ & $-1,97$ & $-0,55$ & $-0,80$ \\
\hline 12 & $-1,22$ & $-3,04$ & $-2,42$ & $-3,57$ & $-0,40$ & $-3,91$ & 3,86 & $-2,94$ \\
\hline 13 & $-1,47$ & $-2,02$ & $-2,55$ & $-2,19$ & $-1,63$ & $-3,55$ & 0,26 & $-8,58$ \\
\hline 14 & $-2,24$ & $-0,40$ & $-1,97$ & 0,46 & 0,31 & $-0,66$ & $-0,68$ & 2,43 \\
\hline 15 & $-0,65$ & 0,45 & $-2,24$ & $-0,84$ & $-2,66$ & $-2,96$ & $-4,34$ & $-1,01$ \\
\hline 16 & $-1,44$ & $-4,91$ & 0,54 & $-2,51$ & $-4,10$ & $-4,05$ & $-3,43$ & $-6,11$ \\
\hline 17 & 1,38 & 2,55 & 0,19 & 1,10 & $-1,63$ & $-3,13$ & $-3,12$ & $-6,61$ \\
\hline 18 & 0,22 & $-1,90$ & 0,61 & $-1,48$ & $-0,07$ & $-3,25$ & 5,14 & 4,72 \\
\hline 19 & $-2,95$ & 0,68 & $-1,29$ & 1,41 & $-2,51$ & $-0,76$ & $-6,43$ & $-7,09$ \\
\hline 20 & $-4,47$ & $-5,04$ & $-4,28$ & $-4,40$ & $-3,90$ & $-3,91$ & $-5,18$ & $-1,81$ \\
\hline 21 & $-0,93$ & $-0,83$ & $-1,17$ & $-1,44$ & 0,70 & 0,86 & $-2,40$ & $-6,69$ \\
\hline
\end{tabular}


Tabela 15: Valores das médias angulares (graus) das medidas dos ângulos do plano frontal anterior na análise de repetibilidade do método de avaliação Onde AS (ângulo da EIAS), AJd (ângulo do joelho direito), AJe (ângulo do joelho esquerdo), $\Delta T d$ (triângulo de Talles direito) e $\Delta T e$ (triângulo de Talles esquerdo). $\mathrm{A} 2^{\mathrm{a}}$ série refere-se as fotografias realizadas 7 dias depois da $1^{\mathrm{a}}$ série.

\begin{tabular}{ccccccccccc}
\hline & \multicolumn{3}{c}{$\mathbf{A S}$} & \multicolumn{2}{c}{ AJd } & \multicolumn{2}{c}{ AJe } & \multicolumn{2}{c}{$\Delta$ Td } & \multicolumn{2}{c}{$\Delta$ Te } \\
\hline Voluntário & $\mathbf{1}^{\text {a }}$ série & $\mathbf{2}^{\text {a }}$ série & $\mathbf{1}^{\text {a }}$ série & $\mathbf{2}^{\text {a }}$ série & $\mathbf{1}^{\text {a }}$ série & $\mathbf{2}^{\text {a }}$ série & $\mathbf{1}^{\text {a }}$ série & $\mathbf{2}^{\text {a }}$ série & $\mathbf{1}^{\text {a }}$ série & $\mathbf{2}^{\text {a }}$ série \\
1 & 4,20 & 5,19 & 176,21 & 176,59 & 172,21 & 173,42 & 12,65 & 14,56 & 11,74 & 12,97 \\
2 & 0,65 & 1,59 & 178,73 & 176,36 & 178,35 & 176,98 & 13,16 & 17,18 & 15,94 & 16,19 \\
3 & 0,46 & $-5,66$ & 176,96 & 175,49 & 173,28 & 174,64 & 12,90 & 13,52 & 14,33 & 16,99 \\
4 & $-0,74$ & $-0,51$ & 177,40 & 176,12 & 179,39 & 179,13 & 28,28 & 30,07 & 28,39 & 29,72 \\
5 & $-1,30$ & $-2,06$ & 174,49 & 175,00 & 177,17 & 176,20 & 14,03 & 12,94 & 11,13 & 10,49 \\
6 & $-0,84$ & 1,13 & 174,46 & 175,55 & 176,77 & 175,12 & 11,07 & 10,97 & 10,99 & 13,40 \\
7 & $-5,36$ & $-4,92$ & 177,68 & 177,06 & 176,61 & 176,35 & 13,88 & 17,40 & 11,45 & 12,54 \\
8 & 1,01 & 1,31 & 173,10 & 173,28 & 175,78 & 176,43 & 15,93 & 15,76 & 13,13 & 12,61 \\
9 & $-4,07$ & $-3,80$ & 173,53 & 174,11 & 176,59 & 175,94 & 14,64 & 14,46 & 21,02 & 24,37 \\
10 & 1,48 & 2,09 & 176,33 & 175,95 & 174,20 & 175,85 & 12,58 & 13,66 & 10,75 & 12,51 \\
11 & $-0,47$ & 1,38 & 176,00 & 176,07 & 172,96 & 171,74 & 11,05 & 13,80 & 9,05 & 12,30 \\
12 & $-3,50$ & 3,25 & 175,69 & 175,50 & 176,19 & 177,21 & 17,28 & 22,24 & 24,60 & 26,16 \\
13 & $-2,21$ & $-1,53$ & 175,43 & 176,99 & 176,37 & 175,01 & 13,38 & 12,93 & 16,94 & 15,86 \\
14 & 1,53 & 1,53 & 174,96 & 174,81 & 177,70 & 177,08 & 18,13 & 16,47 & 16,71 & 17,62 \\
15 & $-1,57$ & 0,46 & 177,21 & 175,91 & 177,04 & 177,60 & 11,41 & 12,18 & 18,34 & 17,81 \\
16 & $-0,60$ & 1,49 & 174,25 & 174,34 & 172,38 & 171,67 & 12,11 & 9,06 & 10,09 & 10,15 \\
17 & 87,44 & 1,03 & 176,39 & 177,33 & 175,63 & 174,61 & 10,15 & 13,29 & 10,55 & 11,31 \\
18 & 1,55 & 2,22 & 176,70 & 178,21 & 178,27 & 175,73 & 26,68 & 28,38 & 23,54 & 23,72 \\
19 & 2,92 & 0,84 & 176,50 & 175,42 & 175,47 & 175,42 & 10,76 & 11,96 & 13,01 & 11,83 \\
20 & 0,56 & 0,47 & 173,91 & 175,62 & 173,48 & 172,84 & 16,55 & 13,10 & 16,31 & 14,59 \\
21 & 1,42 & 2,17 & 174,88 & 172,33 & 176,16 & 175,66 & 7,47 & 9,25 & 11,41 & 14,33 \\
\hline
\end{tabular}


Tabela 16: Valores das médias angulares (graus) das medidas dos ângulos do plano frontal posterior na análise de repetibilidade do método de avaliação Onde IE (ângulo inferior da escápula), PS (ângulo das EIPS), IPd (ângulo da inclinação do pé direito) e IPe (ângulo da inclinação do pé esquerdo). A $2^{a}$ série refere-se as fotografias realizadas 7 dias depois da $1^{\text {a }}$ série.

\begin{tabular}{|c|c|c|c|c|c|c|c|c|c|c|}
\hline & \multicolumn{2}{|c|}{ IE } & \multicolumn{2}{|c|}{ PS } & \multicolumn{2}{|c|}{ LP } & \multicolumn{2}{|c|}{ IPd } & \multicolumn{2}{|c|}{ IPe } \\
\hline Voluntário & $1^{a}$ série & $2^{a}$ série & $1^{a}$ série & $2^{\mathrm{a}}$ série & $1^{\mathrm{a}}$ série & $2^{a}$ série & $1^{a}$ série & $2^{\mathrm{a}}$ série & $1^{a}$ série & $2^{a}$ série \\
\hline 1 & 4,12 & 4,03 & $-3,55$ & $-3,67$ & $-4,34$ & $-1,19$ & 93,62 & 92,62 & 91,55 & 92,08 \\
\hline 2 & $-0,29$ & 1,70 & $-3,14$ & $-3,66$ & 0,38 & 0,84 & 86,05 & 87,16 & 88,82 & 86,94 \\
\hline 3 & 4,07 & 2,73 & 1,90 & 0,95 & 0,00 & 0,71 & 84,60 & 84,31 & 87,98 & 83,68 \\
\hline 4 & 0,73 & $-0,05$ & $-4,07$ & $-3,14$ & $-1,14$ & $-0,86$ & 83,46 & 84,12 & 87,68 & 88,84 \\
\hline 5 & $-4,20$ & 3,28 & $-3,76$ & $-1,07$ & $-2,51$ & $-1,69$ & 98,74 & 95,60 & 90,26 & 91,28 \\
\hline 6 & 6,06 & 8,72 & $-4,88$ & $-2,68$ & $-1,19$ & $-1,75$ & 94,95 & 92,34 & 90,35 & 88,73 \\
\hline 7 & $-1,56$ & 0,90 & 1,91 & 1,98 & 2,23 & 3,35 & 95,74 & 93,72 & 85,20 & 88,85 \\
\hline 8 & 1,38 & 5,68 & $-6,88$ & $-6,21$ & 1,25 & $-1,82$ & 95,40 & 91,41 & 88,31 & 92,58 \\
\hline 9 & $-2,31$ & 1,10 & $-1,02$ & 2,07 & 0,00 & 3,11 & 93,48 & 92,71 & 90,50 & 91,16 \\
\hline 10 & 0,76 & $-2,09$ & $-2,96$ & 1,90 & 1,62 & 0,63 & 90,50 & 94,28 & 89,34 & 88,32 \\
\hline 11 & $-2,94$ & 1,14 & 3,72 & $-4,71$ & 2,13 & $-0,68$ & 89,62 & 87,19 & 93,40 & 92,25 \\
\hline 12 & $-0,05$ & $-0,04$ & $-1,93$ & $-1,27$ & 1,38 & $-0,40$ & 87,05 & 86,14 & 87,57 & 87,62 \\
\hline 13 & $-4,60$ & 7,90 & $-0,65$ & 0,94 & 0,20 & 1,37 & 86,72 & 86,58 & 89,93 & 90,07 \\
\hline 14 & 2,54 & 2,90 & 0,17 & 3,04 & $-2,92$ & $-1,02$ & 100,19 & 98,32 & 94,25 & 96,25 \\
\hline 15 & $-0,74$ & 2,76 & $-1,97$ & $-2,69$ & 2,20 & $-0,52$ & 88,63 & 89,98 & 92,41 & 92,10 \\
\hline 16 & 7,32 & 2,64 & $-0,65$ & 0,85 & 0,52 & 2,66 & 95,02 & 92,81 & 93,53 & 92,91 \\
\hline 17 & 1,27 & 7,42 & 2,68 & 0,62 & $-1,05$ & $-1,17$ & 88,97 & 88,63 & 87,44 & 87,92 \\
\hline 18 & $-5,95$ & $-1,90$ & 2,35 & $-1,70$ & 1,81 & 1,19 & 88,03 & 84,26 & 86,92 & 91,14 \\
\hline 19 & 2,50 & $-2,46$ & $-3,45$ & $-3,47$ & $-2,08$ & $-3,34$ & 95,97 & 96,26 & 96,97 & 97,00 \\
\hline 20 & 2,45 & 2,58 & $-0,23$ & $-0,56$ & 0,90 & 1,91 & 90,45 & 90,07 & 90,15 & 91,31 \\
\hline
\end{tabular}


Tabela 17 - Valores das médias angulares das medidas dos ângulos do plano sagital na análise de repetibilidade do método de avaliação. Onde PC

(ângulo de protusão de cabeça), LC (ângulo da lordose cervical), CT (ângulo da cifose torácica), LL (ângulo da lordose lombar). A $2^{a}$ série refere-se as fotografias realizadas 7 dias depois da $1^{\mathrm{a}}$ série.

\begin{tabular}{|c|c|c|c|c|c|c|c|c|}
\hline & \multicolumn{2}{|c|}{ PC } & \multicolumn{2}{|c|}{ LC } & \multicolumn{2}{|c|}{ CT } & \multicolumn{2}{|c|}{ LL } \\
\hline Voluntári & $1^{a}$ série & $2^{a}$ série & $1^{a}$ série & $2^{a}$ série & $1^{a}$ série & $2^{a}$ série & $1^{a}$ série & $2^{a}$ série \\
\hline 0 & & & & & & & & \\
\hline 1 & 51,42 & 51,78 & 40,98 & 31,39 & 103,27 & 80,96 & 68,20 & 55,53 \\
\hline 2 & 51,13 & 52,33 & 23,78 & 34,67 & 68,18 & 82,16 & 47,38 & 48,71 \\
\hline 3 & 56,61 & 55,62 & 38,07 & 46,07 & 83,20 & 92,64 & 52,53 & 68,46 \\
\hline 4 & 49,88 & 51,00 & 26,66 & 25,41 & 72,10 & 80,41 & 55,53 & 54,56 \\
\hline 5 & 58,45 & 52,71 & 53,36 & 39,33 & 89,07 & 84,32 & 60,98 & 61,89 \\
\hline 6 & 55,15 & 53,55 & 55,27 & 42,43 & 105,29 & 94,51 & 77,24 & 70,43 \\
\hline 7 & 51,76 & 50,43 & 35,91 & 29,10 & 78,96 & 73,20 & 51,88 & 43,62 \\
\hline 8 & 56,93 & 56,84 & 48,98 & 34,78 & 90,74 & 89,98 & 64,04 & 65,12 \\
\hline 9 & 53,19 & 48,39 & 48,67 & 38,38 & 93,40 & 81,43 & 60,07 & 53,98 \\
\hline 10 & 51,66 & 52,31 & 29,03 & 28,73 & 70,78 & 69,68 & 38,64 & 37,93 \\
\hline 11 & 52,11 & 51,22 & 34,23 & 35,31 & 81,95 & 80,34 & 57,48 & 46,95 \\
\hline 12 & 44,73 & 45,11 & 28,77 & 23,94 & 84,46 & 69,62 & 59,08 & 50,00 \\
\hline 13 & 47,82 & 43,05 & 23,55 & 26,12 & 68,10 & 84,71 & 51,19 & 62,71 \\
\hline 14 & 44,86 & 49,04 & 45,07 & 29,01 & 93,52 & 84,22 & 66,48 & 57,12 \\
\hline 15 & 55,30 & 53,83 & 41,93 & 34,65 & 99,22 & 77,58 & 72,09 & 60,26 \\
\hline 16 & 47,39 & 46,63 & 40,95 & 25,64 & 79,37 & 69,34 & 52,88 & 48,29 \\
\hline 17 & 56,28 & 54,68 & 35,41 & 30,34 & 84,43 & 88,45 & 61,24 & 55,97 \\
\hline 18 & 55,46 & 54,35 & 28,06 & 20,95 & 77,43 & 61,56 & 45,27 & 40,04 \\
\hline 19 & 55,57 & 56,88 & 42,84 & 38,61 & 87,78 & 91,46 & 53,32 & 60,51 \\
\hline 20 & 53,62 & 51,80 & 32,35 & 34,81 & 87,17 & 96,69 & 46,41 & 67,95 \\
\hline 21 & 53,85 & 55,41 & 52,10 & 52,60 & 108,54 & 108,19 & 64,05 & 77,76 \\
\hline
\end{tabular}


Tabela 18 - Valores das médias angulares das medidas dos ângulos do plano sagital na análise de repetibilidade do método de avaliação. Onde BP (ângulo da báscula da pelve), FJ (ângulo do flexo de joelho), ATT (ângulo tibio társico). A $2^{\mathrm{a}}$ série refere-se as fotografias realizadas 7 dias depois da $1^{\mathrm{a}}$ série.

\begin{tabular}{|c|c|c|c|c|c|c|}
\hline & \multicolumn{2}{|c|}{ BP } & \multicolumn{2}{|c|}{ FJ } & \multicolumn{2}{|c|}{ ATT } \\
\hline Voluntário & $1^{\mathrm{a}}$ série & $2^{\mathrm{a}}$ série & $1^{\mathrm{a}}$ série & $2^{a}$ série & $1^{a}$ série & $2^{\mathrm{a}}$ série \\
\hline 1 & 3,61 & 6,30 & 183,72 & 186,72 & 112,30 & 118,76 \\
\hline 2 & 4,12 & $-3,32$ & 186,35 & 191,29 & 111,31 & 113,73 \\
\hline 3 & 9,86 & 7,24 & 192,22 & 192,30 & 113,92 & 115,51 \\
\hline 4 & 0,65 & $-1,31$ & 176,60 & 177,79 & 99,87 & 101,96 \\
\hline 5 & 2,45 & 4,68 & 178,80 & 173,72 & 110,26 & 101,12 \\
\hline 6 & 6,83 & 4,47 & 182,04 & 182,12 & 106,99 & 104,96 \\
\hline 7 & 2,57 & 4,01 & 174,83 & 173,69 & 106,34 & 103,94 \\
\hline 8 & $-3,79$ & $-0,15$ & 189,11 & 193,44 & 115,93 & 111,65 \\
\hline 9 & 9,48 & 9,90 & 171,35 & 177,05 & 105,26 & 104,19 \\
\hline 10 & 5,82 & 3,20 & 186,64 & 187,92 & 112,00 & 108,49 \\
\hline 11 & 4,23 & 1,26 & 189,09 & 186,13 & 108,70 & 107,86 \\
\hline 12 & $-2,75$ & $-0,76$ & 179,78 & 177,97 & 105,60 & 105,57 \\
\hline 13 & $-4,43$ & 0,49 & 180,83 & 190,91 & 108,21 & 113,31 \\
\hline 14 & 8,37 & 1,42 & 181,38 & 182,54 & 109,93 & 115,05 \\
\hline 15 & 0,60 & $-2,68$ & 185,19 & 189,93 & 114,97 & 111,84 \\
\hline 16 & 1,13 & 4,53 & 197,00 & 190,02 & 119,06 & 116,44 \\
\hline 17 & $-2,26$ & 3,20 & 182,29 & 182,02 & 107,71 & 106,34 \\
\hline 18 & $-3,33$ & $-0,38$ & 187,59 & 186,52 & 109,61 & 107,18 \\
\hline 19 & 14,24 & 4,76 & 191,82 & 190,45 & 115,84 & 111,91 \\
\hline 20 & 2,63 & 6,61 & 183,02 & 187,11 & 111,59 & 111,24 \\
\hline 21 & 2,66 & 9,11 & 189,16 & 194,19 & 115,05 & 118,19 \\
\hline
\end{tabular}


ANEXOS 


\title{
ANEXO A - Termo de Consentimento Formal concordando em participar da pesquisa
}

\author{
TERMO DE CONCORDÂNCIA
}

$\mathrm{Eu}$,

abaixo assinado (a), tendo sido informado do assunto e do fim da pesquisa "ANÁLISE DA CONFIABILIDADE INTER E INTRA-EXAMINADOR NA AVALIAÇÃO POSTURAL PELA FOTOGRAMETRIA COMPUTADORIZADA" a ser feita no Curso de Fisioterapia, da Universidade José do Rosário Vellano - Unifenas, e devidamente informado previamente, do modo como essa pesquisa deverá ser feita, declaro que estou livre e inteiramente de acordo em participar dela, sabedor (a) de que será guardada em segredo qualquer informação que eu fornecer sobre minha pessoa e sobre minha vida particular; que receberei todo o tratamento necessário se a minha saúde for de algum modo prejudicada; que serei compensado (a) de qualquer prejuízo material que tiver por participar dessa pesquisa, podendo deixar de participar dela quando bem quiser, sem perder o direito a tratamento.

Estou ciente que terei que ser fotografado em trajes de banho para que possa ser analisada minha postura.

Portanto, concordo em participar desta pesquisa, com direito a manter em meu poder uma cópia deste formulário, renunciando neste ato, a qualquer indenização por danos morais.

Alfenas, de de

(assinatura do participante ou de seu responsável) 


\section{ANEXO B- Aprovação do Comitê de Ética e Pesquisa}

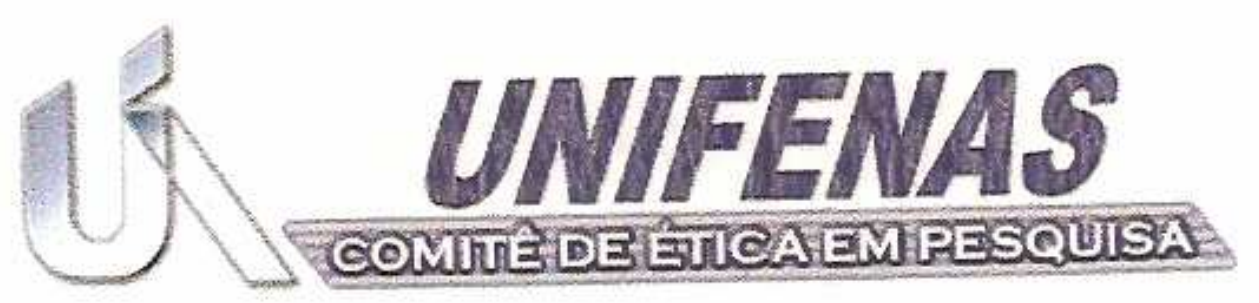

\section{DECLARACÃo}

O COMITÊ DE ÉTICA EM PESQUISA - CEP, da UNIFENAS, constituido de conformidade com a Portaria $\mathrm{n}^{\circ} 32$, de 19 de abril de 2001, da Reitoria, e nos termos da Resolução $n^{\circ}$ 196/96 do Conselho Nacional de Saúde, declara que a Prof. Denise Hollanda Iunes apresentou o relatório final referente ao projeto de pesquisa intitulado ANÁLISE DA FOTOGRAMETRIA COMPUTADORIZADA NA AVALIAÇÃO POSTURAL, cujo protocolo, $n^{\circ} 75 / 2003$, fora aprovado por este Comitê na data de 28/08/03.

Alfenas, 08 de julho de 2004

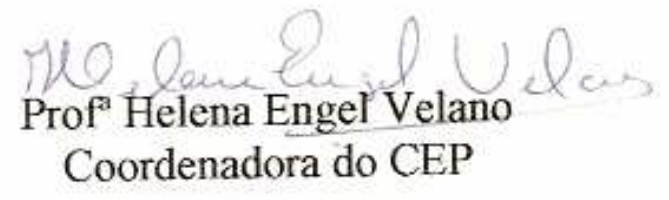

